University of Louisville

ThinkIR: The University of Louisville's Institutional Repository

$5-2019$

\title{
Remaking identities, reworking graduate study : stories from first- generation-to-college rhetoric and composition PhD students on navigating the doctorate.
}

\author{
Ashanka Kumari \\ University of Louisville
}

Follow this and additional works at: https://ir.library.louisville.edu/etd

Part of the Adult and Continuing Education Commons, Communication Commons, Community College Leadership Commons, Curriculum and Instruction Commons, Curriculum and Social Inquiry Commons, Development Studies Commons, Educational Administration and Supervision Commons, Educational Assessment, Evaluation, and Research Commons, Educational Leadership Commons, Fine Arts Commons, Language and Literacy Education Commons, Leadership Studies Commons, Modern Languages Commons, Other Arts and Humanities Commons, Other English Language and Literature Commons, Other Languages, Societies, and Cultures Commons, Other Social and Behavioral Sciences Commons, Rhetoric and Composition Commons, Scholarship of Teaching and Learning Commons, and the Teacher Education and Professional Development Commons

\section{Recommended Citation}

Kumari, Ashanka, "Remaking identities, reworking graduate study : stories from first-generation-to-college rhetoric and composition PhD students on navigating the doctorate." (2019). Electronic Theses and Dissertations. Paper 3206.

https://doi.org/10.18297/etd/3206

This Doctoral Dissertation is brought to you for free and open access by ThinkIR: The University of Louisville's Institutional Repository. It has been accepted for inclusion in Electronic Theses and Dissertations by an authorized administrator of ThinkIR: The University of Louisville's Institutional Repository. This title appears here courtesy of the author, who has retained all other copyrights. For more information, please contact thinkir@louisville.edu. 
REMAKING IDENTITIES, REWORKING GRADUATE STUDY: STORIES FROM FIRST-GENERATION-TO-COLLEGE RHETORIC AND COMPOSITION PHD STUDENTS ON NAVIGATING THE DOCTORATE

\author{
By \\ Ashanka Kumari \\ B.A., The University of Alabama, 2013 \\ B.A.C., The University of Alabama, 2013 \\ M.A., University of Nebraska-Lincoln, 2015 \\ A Dissertation \\ Submitted to the Faculty of the \\ College of Arts and Sciences of the University of Louisville \\ in Partial Fulfillment of the Requirements \\ for the Degree of \\ Doctor of Philosophy \\ in English/Rhetoric and Composition \\ Department of English \\ University of Louisville \\ Louisville, Kentucky
}

May 2019 
Copyright 2019 by Ashanka Kumari

All rights reserved 

REMAKING IDENTITIES, REWORKING GRADUATE STUDY:

STORIES FROM FIRST-GENERATION-TO-COLLEGE RHETORIC AND

COMPOSITION PHD STUDENTS ON NAVIGATING THE DOCTORATE

\section{By}

Ashanka Kumari

B.A., The University of Alabama, 2013

B.A.C., The University of Alabama, 2013

M.A., University of Nebraska-Lincoln, 2015

A Dissertation Approved On

April 15, 2019

by the following Dissertation Committee:

Andrea R. Olinger

Dissertation Co-Director

Bronwyn T. Williams

Dissertation Co-Director

Beth Boehm

LuMing Mao 


\section{DEDICATION}

This dissertation is dedicated to my parents,

Ashok Kumar and Asha Kumari,

हरचीज के लिए धन्यवाद।

Haracheej ke lie dhanyavaad.

Thank you for everything. 


\section{ACKNOWLEDGEMENTS}

Thank you, first, to Andrea Olinger for going above and beyond the call of codirecting my project. Thank you for the many times you gave me (often last-minute) space to share my feelings, offered your empathetic ear and advice, and for your focused and detailed attention and feedback on each word of my project, and for all of your advice and brilliance along the way. To Bronwyn T. Williams, thank you for your guidance, repeated reassurance that my ideas mattered despite my endless moments of imposter syndrome, and for your insight and expertise throughout my process. To Beth Boehm: thank you for your perspective and knowledge of higher education that this project would not be the same without — thank you for engaging in this project from the beginning threads and supporting my journey. To LuMing Mao, thank you for introducing me to constellations and cultural rhetorics, concepts that reaffirm the value of the stories in this project. And to all of the participants in my study, thank you for sharing and trusting me with your stories.

Thank you as well to Steve Parks for not only being an excellent collaborator and listener, but also a model mentor who checked in on me regularly and offered critical feedback on my ideas from the moment we met. To Mary P. Sheridan and Bruce Horner for helping me thrive as an emerging scholar and administrator by listening to and encouraging my ideas along the way. To Susan and Ryne helping me take care of my mental and emotional health through regular counseling and therapy sessions, for reminding me to breathe. To the University of Louisville Writing Center for offering a 
safe space to workshop my drafts in progress. To Latonia Craig and Michelle Rodems for showing me what successfully supporting graduate students from underrepresented populations entails and inspiring my own pursuits. To Patrick Berry, Dànielle Nicole DeVoss, and the Computers and Writing Graduate Research Network for their invaluable feedback on this project in process. To Hannah Rule, Temptaous Mckoy, Dawn Opel, and Karrieann Soto Vega for welcoming my voice and collaborating on ideas surrounding the mentoring of graduate students.

I am also immensely grateful to the teacher-mentors who have been with me long before my doctoral program without whose support this project could not have come to fruition. To Robert Brooke, Erin T. Chandler, Meredith Cummings, Donna Keeton, Katherine Pitts, Terry Ownby, Pat Stegall, Shari Stenberg, Stacey Waite, David Waters, Jon Whitaker, John Wingard, and Adrian S. Wisnicki, thank you for supporting my process and growth and showing me what exceptional teachers, scholars, and mentors can look like.

This project and the years of graduate work it reflects would not have been possible without many impeccable friendships in my graduate programs. Thank you to Caitlin E. Ray, Laura Tetreault, Sara P. Alvarez, Khirsten L. Scott, Michael Baumann for teaching me so much about navigating graduate study and academia as an underrepresented student, having my back, and helping me recognize my calling to continually fight for equitable, sustainable, and inclusive structures for all. To Charlotte Asmuth, Megen Boyett, Nicholas Caluda, Elizabeth Chamberlain, Erin Cheatham, Emily Cousins, Joan D’Antoni, Cooper Day, Michelle Day, Rob Detmering, Joe Franklin, Tasha and Justin Golden, Sarah Griswold, Annelise Gray, Rachel Gramer, Megan Faver Hartline, Jaclyn Hilberg, Claire Jackson, Jamila Kareem, Brittany Kelley, Courtney 
Lawton, Keri Epps Mathis, Jessie Newman, Amy McCleese Nichols, Bernice Olivas, Natalie O’Neal, Rebecca Pattillo, Rachel Rodriguez, Travis Rountree, Chris Scheidler, Brita M. Thielen, and Taleia Willis for your ongoing encouragement and support throughout my journey. To Adam and Tiffany Hubrig, Patrick and Kate Lafferty Danner, Jon Udelson and Hilary Sortor, Sara and Steven Alvarez, Khirsten and Spencer Scott, Anna and John Roberson, and Craig Haughton for opening your homes and feeding me both literally with food and metaphorically with conversation time and time again. To Erin Kathleen Bahl, Sweta Baniya, Sara Doan, Robin Garabedian, Les Hutchinson, Gavin P. Johnson, Lucy Johnson, Kyle Larson, Margaret Price, Zarah C. Moeggenberg, Allegra W. Smith - the PhD Crowd, NextGEN listserv, and the DBLAC Virtual Writing Groupthank you for your ongoing virtual support and regular reminders that I'm not alone in this process. I could not have survived these years without each and every one of you.

To my best friends Genna Bradley, Jordan Sparks, Jimmy Johnson, and Josh Gresham, thank you for being with me since my early teen years, for continuing to care about me and my life plans, and for checking in and staying in touch all these years.

I want to thank my family, but particularly my parents, Ashok Kumar and Asha Kumari and my brother Aman Khurana for their endless love and support, for more than I can put into words here. Thank you for giving me the opportunity to get an education, for attending all five of my graduation ceremonies along the way, for always believing in me. To Jamie, Sean, and Michael Landry, thank you for welcoming me as your daughter/sister-in-law and for your unconditional support. To my cat Trixie, thanks for being the best writing buddy. Finally, to my soup snake, my life partner, and my absolute best friend Joey Landry: thank you for always staying by my side on my high and low days, for reading drafts of my work, for your genuine respect and adoration. I love you. 


\begin{abstract}
REMAKING IDENTITIES, REWORKING GRADUATE STUDY: STORIES FROM FIRST-GENERATION-TO-COLLEGE RHETORIC AND COMPOSITION PHD STUDENTS ON NAVIGATING THE DOCTORATE
\end{abstract}

\author{
Ashanka Kumari
}

April 15, 2019

This dissertation responds to the decreasing number of first-generation-to-college doctorates in the humanities and the limited scholarship on graduate students in Rhetoric and Composition. Scholars in Rhetoric and Composition have long been invested in discussions of academic and/or disciplinary enculturation, yet these discussions primarily focus on undergraduate students, with few studies on graduate students and far fewer on the doctoral students training to become the next wave of a profession. In this dissertation, I argue that if we engage intersectional identities as assets in the design of doctoral programs, access to higher education and academic enculturation can become more manageable for students from historically underrepresented or marginalized populations.

Through an analysis of themes within semi-structured interviews with 21 Rhetoric and Composition $\mathrm{PhD}$ students and recent alumni from two doctoral programs, I investigate how, as the first in their families to attend college, my participants negotiate the professional expectations of graduate study with their personal lives and many other 
obligations. This project creates new knowledge about how we can increase support for and growth in more diverse student populations. To attain this goal, I use a cultural rhetorics methodology to foreground the underrepresented stories of first-generation-tocollege doctoral students, who are among the future leaders of the field. Ultimately, I show how Rhetoric and Composition can rethink how we gain, train, and mentor future teacher-scholars. 


\section{TABLE OF CONTENTS}

PAGE

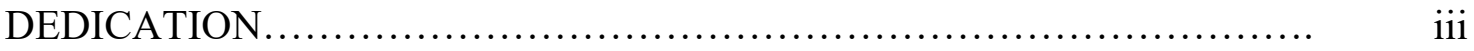

ACKNOWLEDGEMENTS ........................................... iv

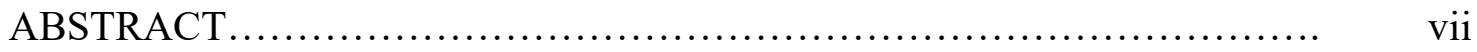

CHAPTER ONE: Introduction...........................................

CHAPTER TWO: Method/ologies....................................... 27

CHAPTER THREE: The "Sticker on Your Back": On Belonging, Fitting In,

and (Not) Identifying with the First-Generation Label...................... 62

CHAPTER FOUR: Empowering Empathetic Relationships: First-Generation

Student Experiences as an Asset for Professional Lives in Rhetoric and

Composition........................................................... 125

CHAPTER FIVE: Conclusion and Future Matters: So what do we do now?...... 165

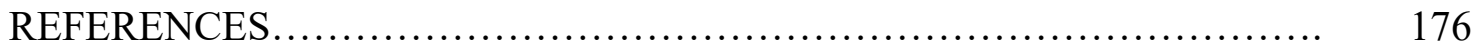

APPENDICES ......................................................... 191

CURRICULUM VITAE .............................................. 210 


\section{CHAPTER ONE}

\section{INTRODUCTION}

"All of these stories make me who I am. But to insist on only these negative stories is to flatten my experience and to overlook the many other stories that formed me. The single story creates stereotypes, and the problem with stereotypes is not that they are untrue, but that they are incomplete. They make one story become the only story." -Chimamanda Ngozi Adichie, The Danger of a Single Story, 2009

Let me tell you a story. ${ }^{1}$ When I was seventeen, I knew I was going to college. I didn't know anything else except that I loved learning and that's what college would offer: more learning opportunities. When my dad was seventeen, he knew he wanted better. For years, he watched as his four older siblings faced financial challenges while acquiring their education post-high school in India. My dad knew life in India wasn't getting better. When a group of his friends told him about opportunities to make money working abroad, my dad decided to take the risk, acquired travel papers to go to Europe, and began the immigration journey to what became his life in America. Instead of attending college, he chose to leave his lower-class family in India and travel to gain

\footnotetext{
${ }^{1}$ Portions of this introduction, and small pieces of Chapters 3 and 4 are forthcoming in "Desi Girl Gets a PhD: Brokering the American Education System with Cultural Expectations" (Kumari, 2019) in First-Gen Memoirs: U.S. Immigrant Scholars in Rhetoric, Composition, and Communication. Copyright 2019 by the National Council of Teachers of English. Reprinted with permission.
} 
financial independence. My dad made it to Greece where he worked various trades for five years and learned how to speak Greek fluently enough to get his travel papers to take an opportunity to work at a Greek restaurant in New York City, in America.

After a few years in America, my dad acquired a visa to return to India and began the process of getting married. He and my mother acquired an arranged marriage; shortly thereafter, my dad left India again, leaving my mother behind for two years while he worked to acquire travel papers for her and a place for them to begin their lives together. From what he's told me, he didn't envision a bright life for his future family in India and wanted more than he possessed growing up in India's lower class. My dad earned his American citizenship after this move; my mom, a U.S. Citizen today, chose the green card route at the time. I arrived in the world a few years later in Long Island City in Queens, New York; their first child. My dad knew he wanted me to have an education, so he started an education savings fund for me, one that helped me pay for college when my time came.

I think about my dad almost every time I walk into a higher education space.

Often, I enter and exit these spaces with his voice in my ear literally, as I call to see how he's doing. I describe myself as either at, going to, or going home from school when he asks where I am. In those moments, it's always about my relationship to my education, the one that makes my dad proud of his daughter. I chose to attend college because I didn't think anything seemed better than continuing my education, what my parents raised me to believe would set me up for the best life. For my dad, foregoing college in India to work in Greece offered a change towards something better.

Our journeys to our careers contain rich complexities, yet the paths of those of us who identify as first-generation-to-college students are often misinterpreted or narrowly 
understood. As Chimamanda Ngozi Adichie (2009) argues, single stories of a person or group of people belittle our intricate identities, because one story can't represent all stories and can become an oppressive fiction for an identity group. My dad's immigration narrative is complicated. It reflects perseverance and presents examples of non-linear literacies that influence my upbringing and education so much so that I decided to pursue this dissertation project focusing on first-generation doctoral students in Rhetoric and Composition. While my parents understood my getting an education as a way to obtain upward career and class mobility, I understood it as a responsibility to my parents, a way to create my own financial and job security, a way to carry our family name forward. Getting my education became a cultural value beyond my parents' expectations.

This dissertation is grounded in stories. Specifically, these stories offer perspectives about what it means to not only be the first person in your family to get a college degree, but also to pursue a career in academia, in Rhetoric and Composition. This dissertation intervenes in disciplinary and academic discourses surrounding doctoral education in English, specifically, Rhetoric and Composition. For Rhetoric and Composition administrators, future graduate students, and graduate program designers, understanding, appreciating, and integrating the perspectives of first-generation students at any level (e.g., coursework, $\mathrm{ABD}$, alumni) can help us build stronger, more inclusive graduate programs. The stories of doctoral students and recent alumni within this project illuminate the present-day culture of doctoral study in English, further contributing to conversations about academic literacy and identity development in higher education. In order to increase support for and growth in more diverse student populations, I argue that we must reconsider how we gain, train, and mentor future scholars in Rhetoric and Composition. 
Since 1987, when representatives from $80 \mathrm{PhD}$-granting English departments came together to consider the future of doctoral studies in English (Lunsford, Moglen, \& Slevin, 1989), scholars in Rhetoric and Composition have been invested in "the nature of the profession for which we train and into which we socialize our graduate students" (Lunsford, Moglen, \& Slevin, 1989, p. v). Questions of how graduate programs can better reach and train students from historically underrepresented populations are among these concerns. As several scholars on graduate study attest (Semenza, 2005; Baliff, Davis, \& Mountford, 2008; Casanave \& Li, 2008; Semenza \& Sullivan, 2015; Skinnell, Holiday, \& Vassett, 2015), not all graduate students come to or through graduate study through the same physical, emotional, financial, or personal means, positions, or experiences. Scholars and administrators continue to be invested in graduate education, yet 30 years later, these physical, emotional, financial, and personal concerns have intensified with changing material conditions. Particularly, in the last decade, the number of doctoral degrees granted to students who, among historically underrepresented populations, identify as first-generation has decreased. According to the 2014 National Science Foundation's annual Survey of Earned Doctorates:

The number of first-generation college students who later received a doctorate peaked at 19,060 in 1973. Doctorates awarded to this group declined at an average rate of nearly 2\% per year from 1973 to 1987; despite short periods of growth and decline there has been no discernible trend since 1987. [...] the proportion of doctorate recipients who were first-generation college students has fallen from more than two-thirds in 1963 to less than one-third in 2014. (p. 10) First-generation students, as used in this project and in scholarship cited here, refers to "individuals who are the first in their family to graduate from college" (Holley \& 
Gardner, 2012, p. 112). The decrease in first-generation PhD recipients may partly be attributed to an increase in the number of graduates in the parent population; however, if graduate programs increasingly seek "diverse student bodies," we must address the challenges of access to higher education for first-generation student populations (Kniffin, 2007, pp. 50,60). If we want to increase access to higher education and "work to provide equal and fair opportunities to [individuals] whose parents did not earn bachelor's degrees," it is imperative that we study the larger systems behind this "trend's causes and consequences" (Kniffin, 2007, p. 70).

This dissertation project offers perspectives from individuals from first-generation backgrounds pursuing work in Rhetoric and Composition that can inform the development of program structures that better meet the needs of students from this and other historically underrepresented populations. Although only $8 \%$ of doctoral recipients were from humanities-based disciplines, humanities fields awarded the least number of doctorates to first-generation students in 2014 , only surpassing the category of "other non-science and engineering fields" by $2 \%$ (National Science Foundation, 2015, p. 11). This project centers specifically on Rhetoric and Composition doctoral programs, responding to the need for scholarship that examines how "disciplinary context influences student experiences" (Gardner \& Holley, 2011, p. 89). It is crucial that we consider how doctoral students from first-generation backgrounds move through doctoral training. While some programs are in place, such as the McNair Scholars Program, to aid first-generation students in learning more about the academy and work towards graduate education, not all students are aware or a part of these systems. Additionally, most existing narratives or guidebooks on graduate study tend to focus to audiences already within academia. 
Scholars in Rhetoric and Composition have long been invested in discussions of academic and/or disciplinary enculturation (Berkenkotter, Huckin, \& Ackerman, 1988; Casanave, 2002; Chiseri-Strater, 1991; Ivanič, 1998; North, 2000; Penrose, 2002; Prior, 1998; Simpson \& Matsuda, 2008; Sternglass, 1997). These discussions primarily focus on undergraduate students, with fewer studies on graduate students and even fewer on the doctoral students training to become the next wave of the profession. While scholars across composition, rhetoric, and literacy studies have pointed to students' identity negotiations as they grow as writers (Berkenkotter, Huckin, \& Ackerman, 1988; LeCourt, 2004; Williams, 2006), such discourse primarily focuses on undergraduate students and their academic trajectories, not the graduate students who teach and research generally in the discipline. Further, discussions of graduate study in the humanities, while interdisciplinary across rhetoric and composition, literacy studies, applied linguistics, literature, and psychology, among others (Anderson \& Romano, 2006; Ballif, Davis, \& Mountford, 2008; Casanave \& Li, 2008; Semenza \& Sullivan, 2015), focus on graduatelevel writing genres (e.g., seminar papers, exams, and dissertations), but feature few actual narratives from graduate students about their academic identities.

This project began as a response to the absence in narratives from graduate students. After a pilot study of three Rhetoric and Composition doctoral students, it became clearer that I wanted to focus on one particular population that appears less in scholarship —-first-generation-to-college students who choose to continue their education and ultimately earn PhDs. To better understand the experiences of the first-generation doctoral students and alumni participants in this study, I approached this study with the following questions: 
- How do/did first-generation doctoral students and alumni understand and navigate the connections between their identities/positionalities (e.g., class, race, ethnicity, gender, sexuality, religion, dis/ability) and the goals of graduate study in Rhetoric and Composition?

- How do/did these goals and their emerging identities as academics in Rhetoric and Composition fit with their other personal, academic, and professional goals?

These questions ground the methods and methodological approach I take to this study with semi-structured interviews and writing responses (see Chapter 2: Method/ologies).

\section{Theoretical Framework and Literature Review}

In this section, I present my rationalization for why I chose to focus on firstgeneration doctoral students. I also present some of the published literature that has informed my thinking. First, I describe some of the stakes and challenges for firstgeneration students as apparent in published scholarship in Rhetoric and Composition and Higher Education. Then, I offer an overview of scholarship that has been published about graduate students broadly in the humanities and then more specifically in Composition and Rhetoric. Next, I recap scholarship on identity development and academic enculturation, focusing on work on first-generation doctoral students that I have found most pertinent for this project.

\section{Challenges for First-Generation Students}

In order to study first-generation doctoral students, we must consider some of the barriers these individuals face regarding a college education such as class status, imposter phenomenon, and cultural capital. Researchers in higher education and rhetoric and 
composition regularly find class status to be one of the key sociocultural differences between first-generation and continuing-generation individuals (Linkon, 1999; Kniffin, 2007; Peckham, 2010). In my study, I follow these scholars and theorize that firstgeneration students often fall in the working-class, though this term, along with class distinctions in general, have complex definitions and uptake. For instance, Paul Fussell (1983) reasons that definitions of class are complicated by our own positions:

At the bottom, people tend to believe that class is defined by the amount of money you have. In the middle, people grant that money has something to do with it, but think education and the kind of work you do almost equally important. Nearer the top, people perceive the taste, values, ideas, style, and behavior are indispensable criteria of class, regardless of money or occupation or education. (p. 3)

Class designations remain immensely complicated by numerous factors such as those that Fussell describes. The understanding of working-class becomes more elaborate in Pierre Bourdieu's (1984) survey of French people focusing on the links between cultural and educational capital and its relation to social class origins. Bourdieu argues that those with high cultural capital are the ones who can determine what counts as "taste" within a society. These taste distinctions are determined by our choices and influences throughout our life.

First-generation students often come from working-class backgrounds, which, when entering middle-class academic spaces, means navigating class-based challenges such as feelings of belonging and understanding the space. Researchers often describe first-generation college students as feeling "separated from their families and communities when they returned home" as their language changed (p. 85). Michelle M. Tokarczyk and Elizabeth A. Fay (1993) build on Bourdieu's ideas on taste and class 
status shifts in their introduction to their edited collection of essays about and by working-class women in the academy. They note that women, particularly from workingclass backgrounds, may feel that after earning tenured positions, "they have severed all connection with their working-class backgrounds, and they have the titles and salaries to prove it. These women often display a middle-, even upper-middle class aesthetic" (p. 6). Tokarczyk and Fay challenge ideas that one can wholly change classes because of the values and tastes instilled in students from working-class upbringings and backgrounds; however, they wonder to what degree the "process of the doctorate dissatisf[ies] us with our backgrounds, instilling in us a desire for elite values and prejudices" (p. 6). The issues presented in Tokarczyk and Fay's collection, while focusing on working-class women academics, highlight some of the challenges of working-class status in academia.

Entering academia is often cited as one way those that self-identify as workingclass individuals escape the working-class (Borkowski, 2004; Peckham, 2010). However, the class we come from cannot necessarily be escaped. As several scholars writing about class mobility and negotiating our backgrounds in academia describe, many of us learn to fit in and survive by mimicking or adopting social cues from those we perceive as acclimated to the space; however, no matter how hard we try to hide our backgrounds or feel we are fitting in, moments of imposter phenomenon always creep back to remind us where we came from (Mack, 2017; Peckham 2010; Richardson, 2013). Imposter phenomenon, also often described as imposter syndrome, refers to the many "conflicts related to feeling like an imposter" many working-class students historically experience (Mack, 2017, p. 145). Imposter phenomenon can result in many "contradictory behaviors based on a fear" of failure, as Mack further describes: 
Fearing exposure from failure can manifest in perfectionism, workaholic tendencies, saying yes to all opportunities, and being overly charming. Fearing exposure through success might lead to self-doubt, procrastination, avoiding risk, and not applying for rewards or advancement. (p. 145)

In other words, these feelings lead to a lot of emotional labor exerted by those feeling it, what Mack describes as the way "emotions are managed in order to display those that align with corporate and organizational goals" (p. 146). First-generation students typically come from working-class families, which often means negotiating financial challenges that contribute to "feelings of otherness" because they are working to "reconcil[e] the poverty that many had come from" while trying to "belong to the academic world" (Gardner, 2013, p. 49). In her literacy memoir, Sharon Jean Hamilton describes imposter syndrome as "the feeling that one's ability is not sufficient to warrant one's position-[as] common, particularly among women" (pp. 2-3). Hamilton, like many first-generation students, felt she "was alone in [her] feelings of "fooling" others and even [her]self (when [she] occasionally felt [she] actually belonged among the professoriate)" (pp. 2-3). Numerous scholars have cited imposter syndrome as common for graduate students, particularly women of color (Boehm \& Lueck, 2016; Gardner \& Holley, 2011; Kniffin, 2007; Okawa, 2002). Beverly J. Moss (1998) draws us to Paul Laurence Dunbar's 1972 poem "We Wear the Mask" as a way to consider the implications of class status on these feelings of "otherness":

As a way of fitting in, many of us find ourselves "wearing masks" [...,] and trying to erase any racial, ethnic, gender, or class markers that point to our differences. Many of us try to fit into two worlds, wearing a mask in the office, in the 
classroom, at conferences, and in publications, and taking it off in the privacy of our homes or when we're with our "friends from home." (p. 161)

The feeling of shifting identities or "masks" across spaces is, of course, not limited to those from first-generation backgrounds in academia.

In regard to class discourses, these continue to be ingrained in a person during their upbringing and can be difficult to escape. Moreover, some have acknowledged the presence of a "class ceiling" like that of the "glass ceiling" for women in the workforce. As Mary Kosut (2006) describes it, "a class ceiling exists within the upper levels of the academy impeding less privileged colleagues from achieving the same levels of success as their privileged colleagues. The class ceiling is supported by everyday practices" (p. 247) such as moments when individuals are humiliated for pronouncing a theorist's name wrong. Considerations of class are a key part of my focus on the ongoing challenges students navigate.

Along with issues of class, first-generation students may struggle to understand graduate education as a system. Unlike continuing-generation students, first-generation doctoral students typically do not have family members with working knowledge of navigating graduate study, much less doctoral education. "Without models from home, from popular culture, or from their undergraduate education," writes higher education researcher Susan Gardner (2013), "many of these first-generation doctoral students struggle to understand the 'rules' of graduate education, or what Lovitts (2001) referred to as the 'cognitive map' of graduate school" (p. 47). In her study of first-generation student perceptions of their academic literacy skills and college performance, Ann M. Penrose (2002) focuses on the differences between first-generation and continuinggeneration students and the ways they move through a college education. Citing Mike 
Rose's personal account on academia (Lives on the Boundary), Penrose notes that Rose's descriptions of "the socio-economic factors that often distinguish them from their peers, the self-doubt and isolation that may result, the range of coping strategies or resistance behaviors this outsider role inspires" are common concerns among first-generation students (p. 438). However, parental and familial support help many first-generation students continue to thrive, as I explore further in Chapter 3. Penrose characterizes that student "narratives demonstrate that supporting the goal of a college diploma may be quite different from understanding and supporting the daily activities college attendance entails, particularly the additional pressures and the need to spend time away from family" (p. 442). However, familial support remains significant for many first-generation students in persevering through their education. Though her study focuses on undergraduate students, Penrose's work builds on Rhetoric and Composition's ongoing research on the ways students navigate "newcomer roles" (p. 438).

Cecilia Milanés Rodriguez (1998) additionally builds on the impact of coming to academia from a non-academic background:

coming to work in the academy as a working-class individual means not knowing how to negotiate up front all you need to, so you don't get stuck with the crappy teaching load, unventilated office, lower starting salary, no explanation of the ground rules, or game strategies for surviving your first year. (p. 146)

Rodriguez articulates what is presented as a common issue across scholarship looking at students and scholars from first-generation backgrounds - not knowing how to navigate institutional structures. These challenges present questions of the degree to which doctoral training in Rhetoric and Composition prepares students for workplace discourses prior to the beginning days of the first job out of a PhD program. Further, they build on 
implications of Bourdieu's (1984) notion of habitus, which refers to the embodiment of cultural capital or key knowledges about a space. In this case, for first-generation students, habitus normally does not include knowledge of institutional structures that then need to be learned over time differently from continuing-generation students.

Much of the scholarship citing imposter syndrome presents mentoring relationships as one potential solution for navigating these feelings. For instance, Amy Lueck (Boehm \& Lueck, 2016) describes the impact of peer mentoring as a "psychosocial support mechanism" for traversing the culture of a graduate program and fighting imposter syndrome:

Because of the clear power differential between graduate students and faculty, I am more likely to experience "imposter syndrome" in my relations with faculty, afraid to ask questions that may reveal my own ignorance. With peers, I have a greater sense of trust, confident in the expectation that they may have quite recently asked the same questions and faced the same uncertainties. (p. 193) Peer mentorship fosters enculturation through sharing experiences and best practices with individuals going through similar circumstances in a supportive space.

Lueck's point about power differentials also aligns with Michel Foucault's scholarship on the impact of power on institutional spaces and vice versa. Specifically, Lueck's argument for peer mentorship can be read as a way of helping individuals conform to academic norms. In his oft-cited text Discipline and Punish (1977), Foucault argues that disciplinary spaces control their participants by their structural designs and tendency to make individuals conform to particular norms. For Foucault, the main purpose of disciplinary power is to train; thus, systems punishing and rewarding individuals such as ranking systems in departments operate as a way of maintaining 
normative structures. For Foucault, a perfect disciplinary institution is one where those in power can observe everything, such as Jeremy Bentham's famous Panopticon structure. However, this imagined surveillance structure creates discomfort for those who do not historically fit into particular normative structures. The stories in this dissertation further illuminate structural and disciplinary challenges that highlight the impact of power and who is afforded power in academia through the stories of how the first-generation participants in this study navigate academia with their lives.

Along with considering power dynamics, mentoring programs and those that mentor graduate students can do more to address socioeconomic concerns that continually impact all graduate students, but particularly those from working-class and/or first-generation backgrounds. In their study of graduate students in humanities and social science programs, Rebecca K. Grady and colleagues (2014) describe graduate students as at risk for psychological health problems, citing several previous studies that find correlations between how well students balanced graduate study with other demands in their lives. Notably, institutional structures add to these concerns: "key to graduate students' marginality is that while they contribute to institutional goals, they are relegated to low-status, low-pay positions and thus are not highly supported" (p. 7). Graduate students in this study described poor faculty mentorship, feelings of isolation, and inadequate or unstable funding as key reasons for stress and strain. Susan K. Gardner's article on "The Challenges of First-Generation Doctoral Students" lists similar key concerns and recommends building stronger mentoring programs as one way to support first-generation students in particular.

Gardner and Holley (2011) and Gardner (2013) are among the few studies of firstgeneration doctoral students. In their concluding thoughts, Gardner and Holley suggest 
that "given the underrepresented nature of first-generation doctoral students in particular fields, additional research might provide insight into how the disciplinary context influences student experiences" (p. 89). My dissertation project is a step to fill this gap in existing scholarship with a focus on the field of Rhetoric and Composition. As Gardner and Holley relate, "higher education administrators [among administrators across other areas] need to receive guidance and professional development in relation to firstgeneration students' needs" (p. 88). My dissertation project illuminates some of the challenges specific to our field and offers valuable ideas for those leading graduate programs and training future teacher-scholars.

\section{Advice and Narratives on Graduate Study in the Humanities}

Several handbooks and edited collections exist regarding the "best practices" for graduate study in the humanities (Ballif, Davis, \& Mountford, 2008; Casanave \& Li, 2008; Semenza, 2005; Semenza \& Sullivan, 2015; Skinnell, Holiday, \& Vassett, 2015). These handbooks often direct graduate students to consider how they can build academic careers in humanities-based fields and broadly target both the audiences of new graduate students as well as the faculty and administrators training them. These works focus primarily on more generalized practices and approaches to graduate study and training, including how to build a career in humanities-based disciplines and produce written genres for various purposes (e.g. seminar papers, articles, conference papers). As many of these handbooks state, the challenges graduate students face in their courses of study are unique to each student and influenced by a number of social, economical, and political factors; however, few of the handbooks attend to these factors and move toward offering perspectives on how graduate students negotiate their institutions' set(s) of expectations 
with the increasing demands of their own lives. For instance, doctoral students are expected to complete coursework, pass comprehensive examinations, and write a dissertation to earn a $\mathrm{PhD}$, but not all of them work toward these ends through the same physical, emotional, financial, and personal means, positions, or experiences-some students are additionally navigating motherhood or fatherhood, new marriages, and even jobs, to name a few additional roles, outside of the Ivory Tower.

One book that begins to offer some counter-narratives that take in more intersectional identity considerations is Gregory Semenza and Garrett A. Sullivan, Jr.'s (2015) edited collection of "meditations on the academic work-life balance," which covers topics of motherhood, race, disability, and gender, among others. These ideas are among the concerns graduate students face today but are often not visible in scholarship or the literature surrounding graduate study. When these topics are not covered in the literature or illuminated in other ways, they can become invisible and contribute to feelings of isolation or imposter syndrome. James T. Zebroski, who focuses on social class issues in particular, advocates for "witness narratives" in scholarship as a way to break down potentially invisible discourses and "open up a space for student experience, that acknowledges their legitimate contributions" (p. 28, original emphasis).

However, a few pieces of scholarship on graduate study do include the voices of graduate students and begin to touch on personal narratives of experience, notably Casanave and Li's (2008) and Skinnell et al. (2015) collections. In their edited collection, Christine Pearson Casanave and Xiaoming Li consider graduate study as a set of literacy practices. Presenting stories from multiple perspectives including scholars across composition, rhetoric, applied linguistics, and literacy studies; both native and non-native speakers of English; and both current and former graduate students, this collection 
comprises reflections on what these narrators wish they had known when they began their graduate programs including how to work with administration, put together committees, and balance teaching while working on their degrees. This collection builds on theories of identity construction and situated learning (Lave \& Wenger, 1991) to argue that graduate study requires multiple forms of strategic participation and time spent developing one's professional identity. This collection presents a look into how graduate students balance work and life commitments like that in Semenza and Sullivan's collection; however, Casanave and Li's collection focuses more explicitly on narratives of this balance as a graduate student rather than the advice-focus for academics at large in Semenza and Sullivan.

Meanwhile, Skinnell et al.'s (2015) collection features more than a dozen chapters and over two dozen responses all written by graduate students furthering the same questions authors in Casanave and Li's collection take up: what do graduate students wish they knew when they began graduate study? What advice can they offer future graduate students based on their experiences? Narratives in this collection are directed toward future graduate students, presenting insight for negotiating the challenges of graduate study and building a professional identity.

Considered together, this literature suggests a deep investment in aiding and guiding new graduate students through their programs by working to make dialogues surrounding the standard challenges all graduate students face (getting through coursework, exams, and writing a thesis or dissertation) visible. While these collections feature extensive advice and narratives, my project will examine doctoral students' experiences empirically rather than anecdotally. 


\section{Identity Studies and Academic Enculturation}

Doctoral education in English Studies has been around since the late $19^{\text {th }}$ century, with specializations in Rhetoric and Composition beginning to appear in the 1970s (North, 2000). Much discussion around what a PhD in English Studies and, subsequently, Rhetoric and Composition should entail exists in scholarly journals and books, including Covino, Johnson, and Feehan (1980); Lunsford, Moglen, and Slevin (1989); Pemberton (1993); Lauer (1994); North (2000); Horner (2000); Young (2000); Crisco et. al (2003); Anderson and Romano (2006); Kopelson (2008); Yancey (2009); Horner and Lu (2010); Goodburn, et. al (2013); Bousquet (2015); and Horner (2016). Despite this focus, discussions about "what actually happens during the seventy or more credit hours programs have long since required" are often absent from published dialogues (North, p. 3, original emphasis); this dearth in scholarship continued long after North's book was published.

Scholarship on doctoral education in Rhetoric and Composition is primarily theoretical in nature, offering ideas for redesigning or reevaluating the design and goals of doctoral programs. However, a few qualitative studies have come out regarding doctoral education. Most contemporary studies on graduate students focus on concerns surrounding graduate teacher or graduate writing program administrator identity (Byrnes, 2001; Elder, Schoen, \& Skinnell, 2014; Hauman, Kastner, \& Witte, 2015) and navigating the job market (Sano-Franchini, 2016). Much work remains to be done on the ways doctoral students, particularly from underrepresented backgrounds such as those who identify as first-generation and working-class, maneuver graduate education.

Several scholars have also theorized about the identities of the academic writers (or students more generally) studying within programs, such as Berkenkotter, Huckin, \& 
Ackerman (1998); Chiseri-Strater (1991); Lave and Wenger (1991); Sternglass (1997); Ivanič (1998); Prior (1998); Herrington and Curtis (2000); Casanave (2002); LeCourt (2004); Hall and Burns (2009); Norton (2013); and Roozen and Erickson (2017). Most of these studies center on undergraduate writers across disciplines with little focus on graduate students, but some of the arguments made about undergraduates may also apply to graduate students. In an example of a study focusing on basic writers, Marilyn S. Sternglass (1997) argues that we must give students "the opportunity to bring their world knowledge and experience to the fields they are studying" rather than asking them to assimilate into academic communities" (p. 113). How might the world knowledges and personal experiences the first-generation doctoral students, such as those in this dissertation, bring with them to academia impact how they navigate the work of a $\mathrm{PhD}$ program? Additionally, what challenges might these identities present?

These studies also further considerations of disciplinary enculturation, a term reflecting the "richness and complexity of what it means to learn how to participate in the specialized activities of people who live and work in academic settings and who hold (or behave as though they hold) certain values and beliefs about what knowledge is and does" (Casanave, 2002, p. 26). Prior (1998) also notes that "disciplinary enculturation... refers not to novices being initiated, but the continual process whereby an ambiguous cast of relative newcomers and relative old-timers (re)produce themselves, their practices, and their communities" (p. xii). In the setting of a PhD program, Prior's definition can be useful for thinking about incoming cohorts each year. Members of new cohorts are relative newcomers and old-timers, that is, they understand the general practices of the academy from their experiences in undergraduate and master's programs but are new to the discourses of this higher degree. However, Prior's definition also has 
applications beyond new cohorts. Old-timers, in Prior's notion, also includes faculty members. This expanded definition aims at the "continual process" whereby doctoral students and faculty continually "(re)produce themselves, their practices, and their communities" (p. xii).

Prior's idea of (re)producing practices also begins to get at the impact of doctoral education on one's identity - the practices of working through a doctoral program require participants to repeatedly inhabit the practices and spaces of academia (e.g. go to conferences, publish, teach). Adapting cultural anthropologist Sherry Ortner's metaphor, Casanave (2002) argues that academia is filled with games that students have to strategize and negotiate with and against to participate or enculturate successfully. Through these negotiations, students begin to identify with academic communities: identities [are] continually in the process of being constructed as the members of the academic communities learn to engage in different sets of practices and envision themselves on different possible trajectories. [...] Learning the game rules and constructing identities as participants in the game seems to involve the uncomfortable process of actual trial and error practice and of gradually garnering awareness of patterns across conflicting behaviors and practices from more expert participants. [...] In all cases of identity construction in academic settings, identity is shaped in general by power relations among game players and more specifically by the discoursal constructions of self in the writing that people do. (p. 23-24).

Casanave, along with other scholars studying academic enculturation, accedes that this type of academic enculturation takes time, and writing is a primary way of showcasing growth, practicing, and demonstrating knowledge of and in a discipline. It's crucial also 
to note the "expert game" is not as stable as we think, as Casanave's and Prior's descriptions allude.

Case studies are a common methodology by which scholars write about doctoral students. For example, Berkenkotter, Huckin, and Ackerman's (1988) oft-cited study of rhetoric PhD student "Nate" reiterates that the literacies of doctoral study do develop over time; researchers must take time to ascertain an understanding of what the student brings with them prior to doctoral education when drawing conclusions about their literacy practices. Using samples of writing "Nate" produced prior to coming to his $\mathrm{PhD}$ program, Berkenkotter, Huckin, and Ackerman trace a history of his writing background and find that he made "substantial progress in developing a command over the conventions of the academic writing that was required of him in the rhetoric program" over his first year (p. 36). Berkenkotter, Huckin, and Ackerman's study offers implications for why we must consider doctoral students' backgrounds when designing programs and mentoring students. Hall and Burns (2009) build on the idea of strategic mentorship and argue that for faculty mentors to be effective, they must consider how graduate students identify as professional researchers and writers and socialize into graduate programs. Each program of study differs based on the values of the institution and faculty within it. Hall and Burns note that these differences can determine success within a program: "students that have or attempt to acquire these norms will be deemed successful. Students who fail to acquire or openly resist the norms will likely risk being marginalized" (p. 53). While their study focuses on students as researchers specifically, it does lend itself to ideas of what identities are valued in a doctoral program. Speaking to matters of being included in institutional life, Sara Ahmed (2012) uses the visual of the 
way crowds operate as one way of thinking about marginalization at the institutional level:

Institutions are crowded. In noticing the crowds, we also notice the orientation devices that direct the flow of human traffic in particular ways. We all know the experience of 'going the wrong way' in a crowd. Everyone seems to be going the opposite way than the way you are going. No one person has to push or shove for you to feel the collective momentum of the crowd as pushing and shoving. To keep going, you have to push harder than any of those individuals who are going the right way. The body who is 'going the wrong way' is the one experienced as 'in the way' of a will that is acquired as momentum. For some, mere persistence, 'to continue steadfastly,' requires great effort, an effort that might appear to others as stubbornness, willfulness, or obstinacy. (p. 186)

For students such as the first-generation students at the center of this dissertation, it is crucial to consider how they work in and/or work against disciplinary and institutional discourses and structures. In Composition and Rhetoric programs, publishing research is arguably the primary way to build one's professional identity in the field, but teaching and service commitments can slow down progress for graduate students or cause them to deprioritize research to negotiate the pressures of other academic values such as teaching. These choices are further complicated by the need to balance the challenges that can come with one's own personal life such as financial strains and understanding department culture that many first-generation and working-class students must navigate.

Regarding mentorship, Hall and Burns find that students "benefit most when mentors provide regular opportunities for them to meet and reflect on their experiences" (p. 62). To this end, scholars argue that learning and identity development, like writing, 
are a process of negotiations. Lave and Wenger (1991) present one way to theorize these negotiations of identity and participation called legitimate peripheral participation, which offers a "way to speak about the relations between newcomers and old-timers, and about activities, identities, artifacts, and communities of knowledge and practice" (p. 29). To Lave and Wenger, "learning is not merely situated in practice - as if it were some independently reifiable process that just happened to be located somewhere; learning is an integral part of generative social practices in the lived-in world" (p. 35). Legitimate peripheral participation is thus a conceptualization to describe engagement that happens during learning. For doctoral students, this concept might be best exemplified through the practices of doctoral study such as conducting research, designing and teaching classes, and writing a dissertation. Practices such as these are how doctoral students get to know and become enculturated in a discipline: "knowing is inherent in the growth and transformation of identities and it is located in relations among practitioners, their practice, the artifacts of their practice, and the social organization and political economy of communities of practice" (p. 122).

These recursive practices tie well to Paul Prior's (1998) theorizations of identities as laminated, which, in this case, refers to the way in which the multiple activities doctoral students repeatedly participate in become ingrained as part of who they are. Graduate students are asked to "represent tasks and produce texts" in ways that consider how "those texts are received and used by professors, peers, and authors" (p. 32). These moments offer ways for graduate students to practice and internalize new identity traits such as "publisher," "presenter," "scholar" that then become part of who they are as a professional in the field. Prior argues that writing is a key element of activity in the field and reflects "locally situated, extensively mediated, deeply laminated, and highly 
heterogeneous" engagements within (p. 275). In one chapter of his book, Prior studies two graduate students and finds three primary modes of participation in graduate study: passing, procedural display, and deep participation (p. 100). Students are considered passing when they merely meet the requirements of a program and check off the boxes, so to speak. Procedural display refers to moments of display or "doing a lesson" and "highlights practices of alignment and coordination that [Prior] argue[s] are central to communication, learning, and activity" (p. 101). In this dissertation, while I do not focus on the level to which participants engage in various aspects of their programs, I do explore their perceptions of their involvement in terms of both personal and professional roles they feel they identify with based on their various involvements. Overall, various levels of involvement within their lives, work, and careers contribute to distinct experiences and understandings of their ever-evolving identities.

\section{Chapter Overview}

This dissertation is organized as follows. Chapter Two, "Method/ologies," details my methods and methodological framework. Here I describe my qualitative approach to this study, including a mix of interviews, observations, and intertextual analysis. Further, this chapter describes the cultural rhetorics methodology through which I orient this project. Specifically, I highlight that this methodological approach means recognizing and acknowledging my participants' embodied lives, practices, and orientations together in a constellating relationship, building on work by Andrea M. Riley Mukavetz (2014), Shawn Wilson (2008), and Malea Powell (2012), among other cultural rhetoricians. Additionally, this chapter features brief background information on the 21 participants in this project. 
Chapter Three, “The 'Sticker on Your Back': On Belonging, Fitting In, and (Not) Identifying with the First-Generation Label," ${ }^{2}$ presents participants stories about what it means to identify as a first-generation student working to or holding a $\mathrm{PhD}$ in Rhetoric and Composition. I argue the term "first-generation student" offers an imprecise heuristic for thinking about a student's institutional position. In this chapter, I break down myths and pressures common in scholarship and present in data along the following themes: 1) financial status and performing class, 2) navigating academia with our families, and 3) our relationship to the broader institution of the academy.

Chapter Four, "Empowering Empathetic Relationships: First-Generation Student Experiences as an Asset for Professional Lives in Rhetoric and Composition," explores how the first-generation-to-college doctoral student and recent alumni participants in this project understand their place in the academy. I offer an analysis of portions of interview conversations discussing responses to a writing prompt asking study participants to list professional and personal roles they see themselves filling. I analyze both the lists of roles and our conversations about the lists together alongside other contextual or relevant pieces of our conversations. After offering more context on my approach to engaging participants with these writing prompts as well as some brief discussion about relevant trends, I analyze responses to two types of roles participants regularly associated with their professional selves: TEACHER roles and MENTOR roles. After discussing the trends and how they align or are in tension with other aspects of participant stories and experiences, I analyze one final role typically in tension for most participants: WRITER,

\footnotetext{
${ }^{2}$ The "sticker on your back" refers to a part of an interview with participant Kelly who described feeling that the first-generation status felt like a "sticker on [her] back" that she carried rather than a more embodied identity or role that might feel more natural.
} 
a role often left out of lists or one many participants felt conflicted with despite working in a discipline that studies writing.

Finally, Chapter Five, "Conclusion and Future Matters: What do we do now?" the concluding chapter, I discuss possible strategies for rethinking and building stronger mentoring relationships in Rhetoric and Composition graduate programs, reflecting on my work co-writing the forthcoming Conference on College Composition and Communication's "Statement of Professional Guidance for Mentoring Graduate Students" alongside the findings presented from the data at the center of this dissertation. I offer a framework for engaging mentoring relationships with emphasis on firstgeneration students as well as other historically underrepresented populations. 


\section{CHAPTER TWO \\ METHOD/OLOGIES}

Early on in my graduate career, I learned that conducting research on a group of people requires researchers to complete Institutional Review Board (IRB) and articulate a protocol for approaching this work. I also learned that people-based research can occur in numerous ways and it is up to researchers to explain why they chose to conduct research one way over another; in other words, we have to explain our research methods. Further, these methods must be informed by some kind of theoretical foundation, of which there are endless possibilities. To that end, this chapter details my methods and methodological approach to studying a population of first-generation-to-college doctoral students.

To begin, I discern the terms method and methodology in my approach to this research and analysis. Drawing on Gesa E. Kirsch and Patricia A. Sullivan's (1992) introduction to Methods and Methodology in Composition Research, I characterize "method as a technique or way of proceeding in gathering evidence, and methodology as the underlying theory and analysis of how research does or should proceed" (p. 2, original emphasis). Specifically, I approach this study qualitatively with hope to "achieve 
an understanding of how people make sense of their lives to delineate the process (rather than the outcome or product) of meaning-making, and note how people interpret what they experience" (Merriam, 2016, p. 14, original emphasis). Likewise, I engaged in 56 interview sessions across 21 participants during the course of which I also asked participants to respond to two writing prompts. ${ }^{3}$ Additionally, I solicited professional writing samples of their choosing from all 21 participants. Together, this data illuminates each participant's unique set of processes navigating their identities as first-generation students within graduate study in rhetoric and composition, academia, and their lives.

Along with pursuing qualitative methods, I orient this project through a cultural rhetorics methodology where story functions as theory (Powell, 2012). Cultural rhetorics refers to "an orientation to a set of constellating theoretical and methodological frameworks" (Powell, et. al, 2012, p. 2). Andrea M. Riley Mukavetz (2014) writes that enacting a cultural rhetorics approach means engaging both respectfully and responsibly "to form and sustain relationships with cultural communities and their shared beliefs and practices including texts, materials, and ideas" (p. 109). Particularly, researchers should engage "with texts, bodies, materials, ideas, or space knowing that these subjects are interconnected to the universe and belong to a cultural community with its own intellectual tradition and history" (p. 109).

Like Riley Mukavetz and other researchers employing a cultural rhetorics approach, I incorporate moments of self-reflective storytelling as well as sharing participant stories as ways to interpret the lived experiences of the first-generation-to-

\footnotetext{
${ }^{3}$ The idea of engaging participants with writing prompts like these came from my colleague Megen Boyett who similarly engaged her own participants in a pilot study during our graduate seminar on research methods.
} 
college participants in this project. Further, I recognize and acknowledge my participants' embodied lives, practices, and orientations and see all of these factors working together in a constellating relationship. Malea Powell conceptualizes the idea of constellation as one that allows for all of the meaning-making practices and their relationships to matter such that "multiply-situated subjects [can] connect to multiple discourses at the same time, [and] those relationships (among subjects, among discourses, among kinds of connections) [can] shift and change without holding a subject captive" (Powell, et. al, 2014, n.p.).

Constellative practice, as Phil Bratta and Malea Powell (2016) further describe, "emphasizes the degree to which knowledge is never built by individuals but is, instead, accumulated through collective practices within specific communities. These collective practices, then are what create the community; they hold the community together over time even when many of them are no longer practices but day-to-day events.” (n.p.)

Shawn Wilson describes this epistemology as relationality in his book Research is Ceremony (2008), which focuses on Indigenous research methods. Specifically, relationality is a cultural rhetorics practice where researchers seek to understand our relation to everything around us. It's about living in relation to all: the universe, world, all living and non-living others. Wilson stresses the significance of relationships, or "the relationality of an Indigenous ontology and epistemology" as crucial to his engagement with scholars at an Indigenous Scholars Conference (p. 80). Particularly, he notes that existing relationships can be used to establish a context upon which new relationships can form. It is the forming of healthy and strong relationships that leads to us being healthy and strong researchers. ... The reverse may also be true, in that the research process may also build or strengthen a sense of community. 
Through maintaining accountability to the relationships that have been built, an increased sense of sharing common interests can be established. (p. 86) Though the relationships Wilson refers to describe those across Indigenous families, relatives, and Elders, this concept of relationality can function in how one might consider research populations within academia such as those in this study. If we consider academia as one larger community with a community of Rhetoric and Composition students, scholars, and teachers within, the concept of relationality offers a useful way to consider networking relationships and snowball sampling. In this study, I build on my established relationships in Rhetoric and Composition to build a pool of participants who are uniquely connected through their institutional affiliation and as members of the Rhetoric and Composition scholarly community. All of my participants belong not only to a community of Rhetoric and Composition students, scholars, and teachers, but also a community of first-generation-to-college students more largely in academia. The theories grounding this project also emerge from the communities being studied rather than imposed from the outside. I then use existing narratives and scholarship about and by first-generation higher education and rhetoric and composition scholars to interpret the conversations and stories I collected as part of this study.

\section{Ethical Considerations and Implications}

When I chose to pursue a dissertation project looking at first-generation-tocollege doctoral students in Rhetoric and Composition, I recognized the necessity to position myself within this project. I, too, am a first-generation student. My features and body reveal my Indian-American identity whenever I enter a space, and many times in this case, a Skype video call. In determining my participant pool for this semi-structured 
interview- and document-based project, I chose to include myself and act as both a researcher and interview participant. In other words, as I interviewed the other 20 participants in this study, I asked a colleague to interview me and went through the same questions and writing prompts in the "interviewee role" like other participants. Of course, I must account for the insider knowledge of knowing the interview questions ahead of time, for instance, but I tried to approach this position as objectively as I feasibly could as the designer of the study. This critical self-reflection allows my story to additionally inform the conclusions and narratives of first-generation Rhetoric and Composition doctoral students I collect, analyze, and present.

I am cognizant of several ethical considerations as I conduct my dissertation research study. First, I acknowledge my position as a current graduate student in one of the two programs I am studying. Several of my participants are undoubtedly people I consider close friends in my department. Gesa E. Kirsch (2005) remarks that researchers must be careful to consider and "delineat[e] clear boundaries" as researchers "so that neither party unwittingly compromises expectations of friendship, confidentiality, and trust" (p. 2166). Kirsch cites Pamela Cotterill (1992) who "reminds us that "close friends do not usually arrive with a tape recorder, listen carefully and sympathetically to what you have to say and then disappear'” (p. 559, qtd on p. 2166). With all of my participants, and especially with colleague-friends, I strove to remain clear about the goals of the interview and my research study. Further, I did my best not to discuss interviews in conversations outside the interview space or in the context of my dissertation project unless I was clarifying or following-up with participants regarding interviews, my project, and vice versa. However, as with most research, most of these choices are easier said than done. For instance, while transcribing an interview with a friend-colleague, it 
became tempting to send a text about a particular comment the interviewee had made. In this moment, I found myself drafting a text briefly before pausing and deleting. Each part of the research process required continued critical, conscious attention to my relationships with myself, my participants, friends, and colleagues.

As I completed transcripts and wrote up my data, I included my participants during various stages of the process to offer them moments to "qualify and challenge [my] reading" and understanding of our conversations and represent their comments accurately (Newkirk, 1996, p. 12). I shared transcripts with my participants and gave them an opportunity to clarify or omit anything before analyzing my data. Once I completed the analysis, I shared chapters with participants to give them a chance to see how their words are being used and interpreted and offer participants time to respond to my interpretations. As Thomas Newkirk (1996) reminds, it is the ethical "responsibility [of researchers] to include participant interpretations even if they conflict with the judgment the researcher is making" to make fair claims (pp. 13-14). Finally, all participants were assigned pseudonyms to protect their identities; however, I recognize that a name change might not be enough to protect someone's identity, so I also masked any other key identity-revealing details such as their past education, jobs, or names of advisors.

\section{Research Sites and Participant Recruitment}

For this study of first-generation-to-college doctoral students and alumni in Rhetoric and Composition, I focused on current and former doctoral students from two different Rhetoric and Composition Programs: one at a southeastern metropolitan institution, and, the other, a midwestern public ivy. Both institutions are public research 
universities located within hours of one another. While I could have recruited participants nationally, I chose to narrow the parameters of this study to two programs so I could form a manageable data set for this project. I wanted to spend more time with fewer participants and get a stronger sense of how each participant's experiences interact with, respond to, and shape the culture of these two programs as well as how they are shaped by their experiences in these doctoral programs and their shared identity categorization as first-generation-to-college students. Focusing on two institutions allowed me to control one variable impacting these participants' experiences as first-generation-to-college students: their doctoral program. These participants functioned under one of two sets of institutional parameters and programs. Though their experiences within these programs are different, the structures are as similar as they can be in a qualitative study like this.

Because I intended to conduct in-person interviews as much as possible, I elected to study two programs to which I could travel to and from relatively cheaply and frequently enough to leave research time for data transcription, analysis, and writing. At the time of data collection, I lived at a location almost in the center of the locations of these two institutions, so I planned to travel as needed to both locations. However, the majority of my interviews occurred over Skype, where distance became less of a variable, because half of my participants were alumni of these two doctoral programs and no longer within a drivable distance. Distance continued to matter less when many participants within a driving distance opted to participate via Skype to better accommodate both of our schedules during the semester. Otherwise, I conducted inperson interviews at on-campus spaces such as libraries and offices or by phone at the choice of the participant. 
I chose to focus on rhetoric and composition doctoral programs because I feel $\mathrm{PhD}$ student and alumni participants can speak to a larger trajectory of graduate studies in the field that seem to mirror discussions in the handbooks and scholarship grounding my research questions (see Chapter 1: Introduction). Further, master's students do not spend as many years in their programs as doctoral students or always work to the same types of academic goals, making fair points of comparison across interviews between master's and doctoral students more limited or perhaps impossible.

Further, I wanted participants in this study to reflect three different progress levels in doctoral programs, which I referred to as "early stage," "mid-end stage," and "alumni stage." Early stage participants refer to those who are in their first or second year of their program of study and pre-exams, categorized as "PhD Student" here. Mid-end stage participants were in exam or later phases in their program. Finally, alumni participants must have received their $\mathrm{PhD}$ in Rhetoric and Composition from either university within the last decade. Because programs continually evolve with administration, faculty, and curriculum changes, I specified that alumni must have earned their PhD during this time frame to retain a focus on the current trends of these institutions and the field. Early and mid-end stage participants of this study were current doctoral students at one of the two institutions under focus as of fall 2017. I planned to recruit at least three participants from each stage at each institution; however, as Table 1 below indicates, my participants primarily fell in the "mid-end stage" and "alumni stage." 


\begin{tabular}{|l|l|l|l|}
\hline IPseudo]Name & PhD Status at time of Study & Sex & Race \\
\hline Ashanka & PhD Candidate & F & Asian \\
\hline Ashley & PhD Candidate & F & White \\
\hline Carter & Alumnus & M & White \\
\hline Charlie & PhD Student & M & White \\
\hline Diane & PhD Candidate & F & White \\
\hline Elliott & Alumnus & M & White \\
\hline Gina & Alumna & F & White \\
\hline Hannah & Alumna & F & White \\
\hline Jack & Alumnus & M & White \\
\hline Jaidev & Alumnus & M & Asian \\
\hline Jeff & PhD Student & M & White \\
\hline Kelly & PhD Candidate & F & White \\
\hline Nora & Alumna & F & White \\
\hline Pera & Alumnus & M & Asian \\
\hline Peter & PhD Student & M & White \\
\hline Robert & PhD Student & M & White \\
\hline Samantha & PhD Candidate & F & White \\
\hline Sharon & Alumna & F & White \\
\hline Tina & Alumna & F & White \\
\hline Trinity & PhD Candidate & F & Black \\
\hline Zeke & PhD Candidate & M & White \\
\hline Tabe & Dem &
\end{tabular}

Table 1: Demographic information about 21 participants in this study.

To participate in this study, participants had to self-identify as first-generation-to-college students. As Susan K. Gardner (2013) notes in her study of first-generation doctoral students, "there are many definitions of first-generation status," which I elaborate further on in chapter three (p. 43). Like Gardner, I refer to Pascarella et al.'s (2004) definition that first-generation-to-college students are those "from families where neither parent has completed a college degree or beyond" (Gardner, 2013, p. 44).

To recruit participants, I asked graduate directors of both programs to send a recruitment email (see Appendix 1) on my behalf through their respective graduate program listservs. These emails yielded few participants, so I sought alternative forms of recruitment including word-of-mouth, snowball sampling, and a recruitment post on one 
program's graduate program alumni Facebook group. Additionally, I sent targeted emails to program alumni and current students of the public ivy using lists on this program's website, because I personally had less of a connection to members of this department. Because I did not know which students or alumni identified as first-generation-to-college students, I opted to send emails to every current doctoral student listed and several alumni from the last decade.

To better inform myself of the state of the departments in which these students are earning or have earned their $\mathrm{PhD}$ in Rhetoric and Composition, I spoke with six of the relevant administrators (e.g., Directors of Graduate Studies, Department Chairs) who are and were active during the time graduate students and $\mathrm{PhD}$ alumni were members of the programs and studied program websites. These conversations and websites offered some of the historical context of the programs that better informed my interpretations of data.

I received 40 responses to my recruitment messages, of which 24 came from people who were eligible and interested in participating in my study. The others were primarily messages from people who expressed interest in the project but were not firstgeneration-to-college students. Five messages came from people who were uncertain if they were eligible based on more complex histories of family members' participation in college. I attempted to schedule interviews with the 24 eligible people who responded to my recruitment messages. Three potential participants never responded to emails about scheduling interviews. Ultimately, I scheduled and successfully interviewed 21 participants, the descriptions of whom I describe later in this chapter.

\section{Data Gathering Methods}


Semi-structured interviews took place throughout the spring 2018 semester (see Appendix 1 for interview questions). Prior to each initial interview, participants completed informed consent forms and were asked to send me any professional documents such as job letters, personal statements, or CVs that they wanted to contribute to our conversations. The first interview resembled an oral history interview in which our conversations focused on questions intended to get a sense of the background and current experiences of each participant. Here, I focused on getting a sense of my participants' upbringing, schooling, and what led them to pursuing college and ultimately a $\mathrm{PhD}$ in Rhetoric and Composition. For the vast majority of participants, it took 2-3 sessions to complete the initial interview, meaning we scheduled follow-up times within days or weeks of the first conversation. Later interviews concentrated on the professional documents I asked participants to share with me. At this point, we discussed how participants felt these documents represented them at the time of their composition and today. These documents reflect participants' identities at different points of their professional careers, so I was interested in learning about any changes from initial graduate program entrance documents such as personal statements to texts further along like job letters or teaching philosophies. Further, these documents offered space for discussing differences between official and unofficial narratives of graduate study and academia. Finally, during the last part of the interviews, I asked participants to complete two writing prompts: one asked them to list professional and personal roles they felt they occupy, and the second asked them to describe themselves through metaphors. Following time for writing, I asked participants to explain their choices in the lists.

The initial and follow-up interviews ranged from 1 to 3 hours in length. In the end, with my 21 participants, I conducted 56 conversations, totaling about 50 hours in 
audio. All interviews were audio recorded and transcribed either personally using transcribe.wreally.com as a transcription tool or paying professional transcriptionists on rev.com with some research funding. I proofread all transcripts with the audio to ensure they were as accurate as possible. The dataset also includes 42 responses to writing prompts (two from each participant). Additionally, I received 60 solicited professional writing samples from participants, though not all participants chose to contribute writing samples.

\section{Challenges and Limitations}

While the 21 participants in this study offer many perspectives of navigating doctoral study in Rhetoric and Composition and academia from a first-generation-tocollege background, they only reflect a small percentage of this population focused at two research institutions in a similar region. Ideally, this study would look at numerous institutions and types of institutions across the nation that offer doctoral programs in Rhetoric and Composition. In future research, I hope to engage more institutions and participants. Further, participant demographics would ideally be more diverse. The majority of participants in doctoral programs in Rhetoric and Composition are white. While I reached out to as many doctoral students and alumni as I could, my participant pool remains mostly white. Studying programs across more geographical locations could benefit this pool in future studies.

Additionally, my definition of first-generation-to-college students presents an ongoing challenge and possible limitation to my participant pool for this study, as I describe further in chapter 3. Definitions of "first-generation student" vary across spaces 
and organizations; thus, potential participants might not respond to a recruitment message based on differing understandings of the term "first-generation student."

Interview environments and technology created additional challenges. While I originally intended to video record all participants, due to technological issues and access, I could not always meet this goal. Many times, I could not set up a camera in a way that appropriately captured a participant or had issues where a camera stopped working halfway through the interview. Ultimately, all conversations were audio recorded, but only a small handful were video recorded.

An additional limitation comes from my own positionality as a researcher. I am also a colleague in the field for all of my participants. Further, I attend one of the two institutions in this study. While this relationality often operated as an asset, it also presented challenges in the way participants and I came to the conversation. Because of my status as a colleague and/or friend of my participants, I often came to interviews knowing something about the interviewee. Likewise, they often knew something about me beyond my status as a researcher in this project. Sometimes this meant participants could describe ideas without too much context; other times, this meant that I would learn something about other members of the institutions that shifted my own understanding of these spaces and people. While I maintain interview details in confidence, it was challenging to keep them separate from my own comprehension of and interactions with these institutions and people after new information about them in interviews.

Many of the challenges and limitations of this interview mirror those that Jonathan Potter and Alexa Hepburn (2012) describe in their chapter about "Eight Challenges for Interview Researchers." Specifically, they note that researchers can do better to contextualize interviews in writing about our research wherein the role of the 
interviewer and questions are present in writing. To this end, I include the setup questions and parts of interactions when quoting my participants in this project. Further, Potter and Hepburn note that researchers should attend to the larger research agenda of a project and the varying stake of interviewers and interviewees, which I try to acknowledge in my writing in this chapter (556).

\section{Demographics of Study Participants}

At the time of this study (spring 2018), all participants were either current $\mathrm{PhD}$ students in or alumni of doctoral programs in Rhetoric and Composition at either the southeastern metropolitan institution or the midwestern public ivy of focus in this study. All participants also self-identified as first-generation-to-college students by opting into this study, though their specific feelings about this label varied as I further describe in chapter 3 . Of the 21 participants, 10 participants were program alumni and 11 were current students. Of the 11 current students, 2 occupy dual roles as staff members at other institutions while in PhD candidacy; in other words, these participants are still enrolled in these PhD programs but also working in full-time jobs elsewhere while working on their dissertations part-time. Additionally, one current student is enrolled as a part-time $\mathrm{PhD}$ student while working in a permanent teaching position at the same institution.

Otherwise, the remaining current students are all full-time members of their programs. Six of the 10 program alumni attended the southeastern metropolitan institution; the other 4 completed their degrees at the midwestern public ivy. Demographically speaking, 17 participants in this study are white, 3 are Asian, and 1 is Black. Eleven participants are women; 10 are men. Three participants are international students; two are non-native English speakers. 


\section{Brief Participant Bios}

In what follows, I offer brief background information about 20 of the 21

participants in this study. I chose to exclude myself here, the $21^{\text {st }}$ participant, because, my narrative appears throughout this project. I recognize that identities are malleable and want to note that these brief descriptions reflect how participants described themselves during our interviews in the context of this study. It is crucial to note that these identifiers are not permanent descriptors, but rather, who these participants are in this context and moment of their lives as graduate students, professors, teachers, scholars, and people. Throughout these descriptors, I include pieces of responses to questions asking participants to "tell me about yourself" that began each conversation along with other relevant moments where participants discuss their identity influences and choices throughout our conversation. All names used in this study are pseudonyms.

\section{Ashley (PhD Candidate)}

Ashley was weeks away from graduating with her $\mathrm{PhD}$ and had recently accepted a job as an assistant professor at a Western university. Originally from the Midwest, Ashley, a white woman, says that although she went to college right after completing high school, she dropped out early and chose to work instead. "So, I came to grad school kind of a little bit later, you know. I didn't go straight through and that's something that's a little bit different than some of the other students at [PhD institution]." Reflecting back, Ashley feels her choice to drop out of college early came as a response to not feeling prepared: "I just did not have the life skills I think that you need to be successful in school cause you know, I just didn't have a lot of support from parents or financial 
support or anything like that." Prior to graduate school, Ashley says her life was "very chaotic and unstable financially particularly." She says that because her parents were divorced earlier in her life, she moved around a lot as a child. In her last year of her $\mathrm{PhD}$ program, Ashley felt like a "ghost" partly because she was on fellowship and rarely physically present in her department but also because she says she did not feel comfortable there: "I don't particularly enjoy spending time on campus. I don't really like being around the faculty there." However, Ashley describes herself as an invested teacher and advocate. She is married with three pets and a big fan of movies.

\section{Carter (Alumnus)}

An assistant professor and coordinator for developmental writing at a southeastern institution, Carter, a white man, describes himself professionally as an administrator, teacher, mentor, and researcher and personally as a hiker, gamer, and son. "It's kind of like in grad school. Instead of being a student, now I'm a teacher is what a lot it comes down to. But I mean, I do, since really the main thing that I'm doing here is usually job related, I hike. I have dogs. I have a gaming group. So, we do some tabletop gaming, Dungeons and Dragons, stuff like that." Raised in the south, Carter says he always enjoyed school: "There were just a lot of classes that I was interested in while I was in school and it was something that I was good at. I was encouraged by my parents and family members and by teachers." Despite working in Rhetoric and Composition today, Carter notes that English was not his favorite subject growing up; he primarily enjoyed reading and originally considered attending college for international studies programs. However, he switched over to English and history programs early in his college career. After being hired as an assistant writing program administrator after his master's, he 
became invested in Composition and Rhetoric and eventually went to earn his $\mathrm{PhD}$ in the area a few years later. Carter indicates the cost of his education as a primary challenge, one that he feels he could have avoided with guidance from family members who attended college.

\section{Charlie (PhD Student)}

A PhD student and white man, Charlie first described himself as someone who didn't think he would be in school, having had a troubled history with the education system: "I graduated high school with a 2.01 and got expelled." Charlie has ADHD and was placed in "slow learning disorder classes" early in his life. His parents put him in a Christian private school from which he got expelled. After this and also getting expelled from high school later, he tried to join the military, but they did not accept him. After some time, Charlie completed his high school degree at a new high school. Charlie says he first decided to go to community college after a "hilariously tragic" moment in his life during a time when he was losing lots of sleep, working two jobs, and playing in a band. While in community college, Charlie continued to work numerous jobs. During his time in a literature class in community college, Charlie's professor told him to apply to a public liberal arts college in the south. This southern university advocates a pass/fail, no GPA college system, which worked well for Charlie. Ultimately, Charlie's work in writing centers throughout his community college and undergraduate experiences led to his interest in writing studies and earning his master's and $\mathrm{PhD}$ in Rhetoric and Composition. Charlie continues to be frustrated by the educational system but finds these feelings as primary motivators for his social justice and activist work both in and outside the field. 


\section{Diane (PhD Candidate)}

When we spoke, Diane was a PhD Candidate writing her dissertation and participating in the academic job market. She describes herself as a "white and queeridentified woman" raised in New England areas of America. Diane is among a handful of participants who went straight through high school, undergrad, master's, and her $\mathrm{PhD}$. Because of this, Diane says that "in a lot of ways, academia is all I've ever known." An only child, Diane describes her experiences as "heavily mediated and also softened by a lot of economic privilege, and a lot of white privilege, too." Despite these privileged schooling experiences, Diane says she still did not feel ready for the reality of higher education. She describes moments of tension between her and her family regarding money and geographical shifts for her education. Additionally, she notes many of these tensions furthered by the underlying class expectations of the academy wherein she feels she learned "financial irresponsibility." Diane also notes no separation for her between her work and personal life:

I'm very extroverted, and I like to be around people. So, I do a lot of personal things in the sense that I go out all the time. [...] But I guess the lack of separation is like, I might be doing that but still talking about work and thinking about working with the same people I saw all day at work.

\section{Elliott (Alumnus)}

Newly a lecturer at a university in the West and father of two, Elliott, a white man, describes himself as a "really nerdy guy" who likes to play video games and watch Rick and Morty. 
really nerdy guy. That's one of the crucial aspects of my identity. That's what I present to my class too, on the first day, as I'm going through my interests. I like playing video games. I watch Rick and Morty. I talk about all that stuff on the first day of class. I'm a very nerdy guy.

Additionally, Elliott identifies heavily with politics, referring to himself as a "liberal squish" who is always reading about politics and political events. Elliott grew up in the Midwest and says attending college was always an expectation for him growing up. Elliott identifies as first-generation but emphasizes that his parents did both attend some college though they did not graduate. His relationship with the term "first-generation student" developed later in his education:

It was maybe early in my $\mathrm{PhD}$ program where I started to figure out "well, wait a second, here's why I might be a little confused about this stuff." And part of it, and I want to make this clear, is that I have a number of advantages that go way beyond being a working-class person, because I'm a white dude.

After reading scholarship by and about working-class academics, Elliott says he began to realize the impact of his upbringing and background on his educational experiences.

\section{Gina (Alumna)}

Gina, a white woman, works as an associate professor at a southern university who feels she is her job:

I feel like people say, “Oh, you're not your job,” but I feel like you are your job when you're a professor. It's kind of on the back burner all the time if it's not right in front of you, but you're thinking about your students, you're thinking about what you're researching, you're thinking about how to present yourself 
professionally when you're attending conferences or meetings with other faculty from different departments.

Gina says her undergraduate experiences in the Midwest were a "big awakening" for her in terms of her education. She began to see graduate study as a possibility. Prior to this, her lived experiences being raised in a single-parent home and living in government subsidized housing originally meant she could not attend college; however, she says that Something changed. The landscape changed. Previously, I had thought of pursuing the issue with the federal government because I wanted to say, "you can't do this to poor students. You can't tell us that we can't move away from home to go to college." As I noted before, the legal rules flipped and I was finally allowed to go away to college without jeopardizing my mother's government subsidized housing arrangement. I was allowed to apply to distant or even out of state schools. So I applied to [undergraduate institution], got in, and left.

Gina says she was always encouraged by people throughout her education despite many moments when she was less confident about her abilities and work.

\section{Hannah (Alumna)}

Hannah works as an assistant professor at a northeastern university. Hannah, a white woman, enjoys engaging in outdoor activities with her partner and dog. Initially after earning her PhD, Hannah did not have the tenure-track position she has today and says she was "unhappy" at her non-tenure track position because it kept her from parts of her personal life:

I got a full-time position, full-time faculty but non-tenure track and it was a 5-5 load at [university name]. I could've stayed there as long as I wanted. I was very 
unhappy there. It was a long-distance relationship. I couldn't bring my dog, things like that. Now we're all together again and so, I'm a much happier person personally.

Hannah began studying Rhetoric and Composition after being unhappy with her undergraduate program in creative writing and literature:

I was pretty unhappy with that degree program, because I would always ask questions that my professors didn't like. I'd ask questions about literature and now that I got into Rhetoric and Composition, I realized the only thing that interested me about literature was a rhetorical perspective on literature and that's not really what people wanted to talk about. I was seeking this other thing and didn't know about composition and rhetoric.

She feels strongly about her work and role as a professor who teaches writing while maintaining a distinct relationship between her personal and professional roles.

\section{Jack (Alumnus)}

Jack, a white man, works as an assistant professor at a northeastern university. $\mathrm{He}$ describes himself as a father of two and a partner first and regularly brought up his family in our conversation. Additionally, Jack remains committed to community literacy work, volunteering regularly at a local learning center. Jack says he did not originally intend to pursue a career in Rhetoric and Composition after undergrad. Instead, he attended seminary, had a "terrible experience," but learned he truly wanted to teach theology rather than preach it. After his wife's program was cancelled, she decided to pursue a master's degree in another discipline. Jack followed his wife to graduate school: 
I did an English degree there just because we were there. I did a master's in literature. [...] We had one Rhet Comp professor there who was the Writing Center Director. I took one class that was basically like Writing Center Theory and Practice, so that I could consult in the Writing Center there. I taught, which was a big part of the reason for going into Rhetoric and Composition, teaching first-year courses for the first time. After that, I got a lot of positive feedback in the graduate program, in the master's program. [...] There was more mentoring. There was more supportive and definitely more active shaping of an academic trajectory.

It was this mentorship that ultimately led Jack to pursue a PhD and now a career in Rhetoric and Composition.

\section{Jaidev (Alumnus)}

An assistant professor awaiting a tenure decision from his northeastern institution, Jaidev, a Southeast-Asian man, grew up in Southeastern Asia where he attended private schools throughout his upbringing. After high school, continual praise of his Englishlanguage skills led to him changing his academic pursuits from science to English; however, this path came with financial challenges. Jaidev continued to pursue graduate degrees in Southeast Asia, but says he grew tired of teaching and learning English literature, because the society did not know how to make it especially meaningful. In a sense, we were just teaching, but I didn't know how that, beyond us just being the English people, how that makes any sense in a society of professional academics. And that did sort of become a bubble of its own, which I didn't like. 
Jaidev applied for his $\mathrm{PhD}$ in Rhetoric and Composition in America thereafter and the rest is history. Along with his work as a "multilingual, multicultural, transnational, and secular" individual, Jaidev describes himself as

a person shaped by the particularities of [his] family, the complex social relationships and dynamics of friends and colleagues in many different contexts around the world, and [his] own values and beliefs, which put [him] in connections and tensions as to what education and educating means and does.

\section{Jeff (PhD Student)}

Jeff, a white man, part-time PhD student, and full-time writing instructor in a business school who says he has always identified as a teacher rather than an academic. Though he has more recently learned about his position as a first-generation-to-college student, Jeff describes moments of "not knowing" throughout his education that are typically described in scholarship about first-generation students:

I was always comfortable with not knowing. [...] There are few instances where I feel like I didn't know how to navigate the system, and it got me into problems. Jeff chose to pursue a $\mathrm{PhD}$ in Rhetoric and Composition after working as a visiting instructor for several years at the same institution. A colleague and mentor guided him to apply to the $\mathrm{PhD}$ program with a tuition waiver through his existing position, which he felt would help increase his job security and prospects in the future. In fact, Jeff was still a visiting instructor when we first began our conversations. By the final conversation, Jeff had been hired in a permanent position. 
It's a huge relief. [...] I think I see my $\mathrm{PhD}$ and my place at $[\mathrm{PhD}$ institution] in a whole new light now because I know that I'1l, as long as I keep doing a good job and want to be here, I can be here.

In addition to his teaching and doctoral work, Jeff is a partner, father, and music lover.

\section{Kelly (PhD Candidate)}

Born in a small rural area in the southeast in a working-class family, Kelly, a white woman, describes herself as invested in the intersections between "real life and academic life." Kelly chose to return to school for her graduate degree years after earning her bachelor's degree when she became interested in career as a writing center director. "I applied for my dream job and realized that in fact, I really needed a PhD," Kelly described. Today, Kelly says she has earned this dream job working in a writing center at a first-generation-student-focused institution despite not having completed her $\mathrm{PhD}$ yet. Kelly, like Samantha, occupies a career space between $\mathrm{PhD}$ and professional in the discipline. When her dream job came open during her second year in her PhD program, Kelly said that despite still in the stages of completing coursework and entering PhD candidacy, she needed to apply to the position because "when you're dream job comes open, you just apply for it." However, working in this writing center staff position and on her dissertation are not the only key negotiations in her life. Kelly is also a mother, a role she first took on during her first year as a PhD student. Kelly chose to give up her graduate student stipend to pursue this job, which shifts her time-to-degree past the proposed or expected time of her PhD-granting institution; however, the positive shifts to her lifestyle in her new position outweigh these concerns. 


\section{Lance (PhD Student)}

Lance, a white man, was finishing up his first year as a PhD student when we spoke. He is the first person in his extended family to go to college. He has worked since he was old enough to work beginning his first job on his $16^{\text {th }}$ birthday. Lance says he chose to go to college after years of success in school:

Since the beginning of my schooling, I've always done really well at school, so I was the person in my family that everyone just assumed would go to college, right? There's really not that assumption for anyone else. [...] None of my siblings ever applied anywhere, and I have [six siblings ...]. It was just something that wasn't really a part of our family conversations, ever.

Lance serendipitously pursued a master's degree when he was encouraged to apply for an open spot in the program. After this degree and teaching as an adjunct professor, Lance decided to get a PhD for more job opportunities:

So, you're teaching courses, you're getting the low pay, and you're getting nothing more than that; no benefits, you know? So, I thought, if I want to teach, a $\mathrm{PhD}$ is the way to go. I have to get a tenure-track, or at least a full-time faculty position at some point. [...] I was also really interested in doing some more substantive research. I really like the idea of a doing a dissertation, producing something that's a new contribution to the field at the end of my time.

Along with this quest, Lance identifies as a father, spouse, brother, son, neighbor, and citizen.

\section{Nora (Alumna)}


Nora wears many hats as she serves as chair of her English department and an associate professor at a southern institution. Nora, a white woman, says she values having activities outside of her work such as exercise and outdoor sports. She also rescues animals, a fact made clearer by a moment during one of our Skype conversations when Nora briefly went off screen to let her rescued dogs outside.

I'm an animal rescuer. I've played ultimate Frisbee pretty religiously for the last 20 years of my life. [...] I pretty consistently have rescued animals at my house. I work out a lot. It's like medication for me. Right now, I belong to two gyms. Another big part of her identity is her Canadian background and upbringing. She began working part-time jobs at age 14 describing brown polyester uniforms. Nora says she waitressed all the way through college. After marrying a Southern American, she moved to America and taught. Ultimately, she chose to pursue a master's degree after someone offered to pay her to get her master's.

That's when I really got invested in thinking about writing. Like everyone's story, I took the one Rhet Comp class, because there was one writing center director here who taught it, and though, "This is what I'm supposed to be doing." Nora aligns herself as a community mentor, scholar, and teacher across numerous spaces.

\section{Pera (Alumnus)}

Pera works as an assistant professor at a Mideastern institution. Raised in Southeast Asia, Pera immigrated to America in the early 90s and identifies equally with his Southeastern and American identities.

I'm truly bilingual, so I'm able to do translations and read texts in [native language] without any issue. And I'm able-bodied, male. [...] I see myself as not 
completely American, and also not completely [Southeast Asian]. I think it's not uncommon when you look at Asian American experience in this country. And I think this bicultural, bilingual status of mine puts me in an interesting situation because I can try to oscillate between different points of view, but also because I never feel quite at home in one place or another.

Pera says he did not have work-life balance as a graduate student: "It was work, work, work all the way." This work-focused attitude meant that Pera's professional goals became his personal goals. Since his PhD, Pera says he still has not achieved a work-life balance, but is taking steps toward the life he desires:

People say you could just do it [the tenure-track process] and then get through tenure and then do whatever you want. But then I see my colleagues here and the culture of this department. It's like the minute you get tenure, where's full professorship? [...] And I thought, well, since I don't want that life, I might as well start living. So, I'm like, okay, I'll do work. I don't want to do work today. Take some days off. And it's hard. I'm not saying it's easy to do. [...] And I talked to one of my advisors and she said something really compelling: "If you want to live, you take an R2 job. And then you write at your own pace." So that's what I did this fall.

\section{Peter (PhD Student)}

Peter, a white man, transitioned to his $\mathrm{PhD}$ program after spending time working in Europe. He describes himself as a traveler raised in a "high stress" and "not happy" home environment on the west coast. Peter says he and his siblings "coped mostly by playing sports or we played a lot of soccer." Peter got used to moving around numerous 
times growing up. This trend continues into his adulthood when he says he still has never "lived somewhere for more than two years since I was like 11 years old." He first moved out on his own as a senior in high school, completing both high school and some college classes successfully. Unfortunately, family ties made it challenging to complete his college degree the first time because he was considered a dependent of his mother's, which meant he had to pay out-of-state tuition. Peter has worked numerous jobs throughout his life, ultimately completing his undergraduate while working to fund the cost. After, he taught in Asia for a few years before returning back to work in America: It was, for me, a pretty big deal to get a funded acceptance to the master's degree because without it, I mean, when I accepted to the master's program, I was the part-time janitor at [a nonprofit], and it was a very different kind of intellectual environment.

Peter describes always enjoying school environments even from an early age. When I asked him what some of his favorite classes were growing up, he said "None," but instead described attending school as his favorite thing “cause I wasn't at home. [...] Being in class was fun." Today, Peter continues to enjoy traveling, conducting much of his research abroad and aspiring to return overseas after his $\mathrm{PhD}$.

\section{Samantha (PhD Candidate)}

Samantha, a white woman, works as a writing center director at a southwestern university. Like Kelly, she occupies a space between her PhD and a job in the field, because she chose to pursue a job while still in candidacy. Due to what she describes as issues with mentorship and support, she has not yet completed her dissertation and $\mathrm{PhD}$. 
....it was difficult. I think about it a lot, and it's not a happy time for me. There were some happy things about it, but a lot of it, I think, there's a lot of trauma within that $[\mathrm{PhD}]$ program that I experienced.

Samantha grew up in a working-class family in a small southwestern town. Samantha says this upbringing continues to influence her values though she notices shifts from her choice to pursue her education:

I still have a lot of my working-class values, although I have, over the course of probably the last 20 years, it took a long time, moved from a very conservative outlook on life to a very, very liberal outlook. And because of my experiences with education and working with students and other faculty and staff that have been much more diverse than [the area she grew up], in terms of thoughts and ways of doing things and fiscal responsibility. So, education has changed the way I think about a lot of things in a lot of different ways.

\section{Sharon (Alumna)}

An assistant professor at a southern university, Sharon is a married white woman with two pets. Because she and her husband both work most of the time, Sharon says it's hard for her to "think about [her] life outside of work right now. It's sad." Raised in the South, Sharon worked many jobs before graduate school that kept her busy. She says she chose to pursue graduate study in Rhetoric and Composition after she discovered the discipline near the end of her undergraduate career:

I felt I had finally found the thing that I had been wanting to do, my undergrad is in literature. So, I didn't really have a plan for what to do next and I realized that I had this really exciting new discipline I wanted to know more about and I did my 
BA and my MA at the same institution, so it was kind of a whim honestly that I applied to do my master's degree and luckily it worked out for me because I didn't have much of a plan. I didn't have much of a plan after college, it was, I guess, I'm going to work at [retail store] for the rest of my life, which I did not want to do.

Sharon says that she doesn't think she fits a working-class identity today, though she was raised in this background. Likewise, Sharon feels more comfortable claiming her firstgeneration and working-class identities:

Had you emailed me a couple of years ago, I might not have wanted to claim this identity. It's taken me a while to even be comfortable saying that, and I don't know why. I'm not embarrassed as my mom and my sister keep insisting that I am, but it's been interesting to have these conversations with other working-class people that I know in the field and we all feel the same way.

\section{Tina (Alumna)}

Tina is an assistant professor and writing program director at a northeastern university who identifies as a queer, white-coded woman from a working-class background. Prior to graduate study, Tina worked in the industry as a creative director, graphic designer, and writer. When asked what drew her to pursuing a college degree especially as the first in her family, Tina reflected on finding a book that perhaps forecasted her present

This is a question I've often wondered myself. I remember when I was moving 20 years ago and doing the move purge, I found some old books from when I was a kid. I was a voracious reader. My aunt was a librarian, I think was part of that 
answer. She gave me tons of books to read. My parents were always very supportive of reading, and were largely self-educated in a way, especially my dad. I found a couple of books from when I was a kid, and I had printed in my awkward kid handwriting on the inside cover "[Tina's real name], PhD." And I don't even know how I knew what that meant, and maybe I didn't really know what it meant, but I thought it was so fascinating. And even when I found those books, I was still in industry, I wasn't an academic. And so, I think some part of me was always drawn to the life of the mind, as they say, and to education, and to getting paid to think and read and teach, and I think that was largely due to my aunt and my teachers. But I didn't have a role model of what a professional academic or professor looked like.

Tina says she was drawn to Rhetoric and Composition as a "practical outlet for [her] love for literacy and education and English.”

\section{Trinity (PhD Candidate)}

Trinity self-identifies as a black woman raised in the South in a single-parent home. When we spoke, she was finishing up her $\mathrm{PhD}$ in Rhetoric and Composition and had recently accepted a job as an assistant professor. Like most participants in this study, she grew up attending public schools. She chose to attend an HBCU (historically black colleges and universities) as an undergraduate student where she participated in numerous study abroad and study away programs and engaged as a student leader. Additionally, Trinity is one of two participants in this study who previously participated in the McNair Scholars or a similar program as an undergraduate student. She also participated in an Andrew Mellon funded program through which she researched abroad. 
She cites these experiences as solidifying her desire to pursue a graduate degree. Trinity points to many moments of mentoring, especially from other black women, as crucial for both her decision to pursue her $\mathrm{PhD}$ and also in helping her succeed in her pursuits along the way:

One of my professors who was my advisor [in undergrad] and now a definite lifelong mentor told me that I was going to go to graduate school. She was the first person I met with a PhD ever, first black woman. So, I don't know, it was things like that, that were really directive and really, I think an extension of the black community that if a professor tells someone that, that was not to a black woman, that it could be read a certain way like she was trying to control my life or something. I was just like "OK, grad school, maybe." It just really started to take form. She saw something that I couldn't see. [...] Really meaningful, really personal types of interactions.

\section{Zeke (PhD Candidate)}

Self-described as a "queer cat dad" who "teach[es] graduate students how to teach underclassmen," Zeke, a white man, was a newly minted PhD Candidate when we spoke, having recently completed his doctoral exams. Throughout his life, Zeke has worked numerous jobs. Zeke grew up in the southeast, was homeless 12 times, but did not let his life circumstances keep him from his educational pursuits:

I stayed in the same high school, gratefully, and that was part of the reason I think that I continued with education because it was so important. That was my ticket out, so to speak. 
Zeke describes school as "one of the most stable areas in [his] life." He says teachers positively impacted him because he saw and engaged with them regularly despite his unstable living or life situation in a given moment. However, Zeke sees his experiences living in "the real world" contributing a critical lens to his feelings about working in academia that he feels many others do not have:

I wasn't coddled. I know how the 40-hour week job... I know how pervasive that is outside of the academy. I understand that my students aren't going to follow the same path that I've been on, as far as getting a PhD. But, otherwise, I've lived outside the academy. I know what it's like to struggle. I know what it's like to clock in and out. [...] As far as being first-generation, fuck, I don't complain as much as most academics whenever we've got to do the work that we do. I'm not trying to say it hardened me, but maybe it has, I don't know.

\section{Data Analysis}

To manage this large qualitative dataset comprised of about 50 hours of transcribed interviews, 42 writing prompt responses, and 60 professional writing samples, I use a mixture of NVivo, a Computer-Assisted Qualitative Data Analysis (CAQDAS) software, Google Sheets and Excel, and word processing software including Microsoft Word and Google Docs, along with printed documents to analyze different parts of this data. I engaged in coding, or "the process of identifying units of analysis and classifying each unit according to the categories in a coding system — either a preexisting system or one developed for the data in question" (Grant-Davie, 1992, p. 272). First, I engaged in open coding or assembling data into categories that I invented based on my questions 
(Saldaña, 2009). I did keyword searches and looked at charts created by the NVivo software to help see patterns that emerged from my data.

From this open coding, I developed theme passages that "presen[t] evidence for the central phenomenon in the study" by pulling together numerous codes into themes to reflect my findings (Creswell, 2016, p. 174-175). Specifically, these theme passages allow me to "present the complexity of a theme on the basis of evidence collected during [this] study" (p. 175). Once I gained a sense of the common themes appearing within each participant's interview script, I moved to thinking about the most reoccurring themes and their appearances across all 21 participant scripts. From here, I began to build the central topics in this dissertation. In the next two chapters, I delve deeper into the most prevalent themes that appeared throughout my coding. Chapter Three, "The 'Sticker on Your Back': On Belonging, Fitting In, and (Not) Identifying with the First-Generation Label," presents participants stories about what it means to identify as a first-generation student working to or holding a $\mathrm{PhD}$ in Rhetoric and Composition. In this chapter, I break down myths and pressures common in scholarship and present in data along the following themes: 1) financial status and performing class, 2) navigating academia with our families, and 3) our relationship to the broader institution of the academy. In Chapter Four, "Empowering Empathetic Relationships: First-Generation Student Experiences as an Asset for Professional Lives in Rhetoric and Composition," I explore how the firstgeneration-to-college doctoral student and recent alumni participants in this project understand their place in the academy. I offer an analysis of portions of interview conversations discussing responses to a writing prompt asking study participants to list professional and personal roles they see themselves filling. I analyze both the lists of roles and our conversations about the lists together alongside other contextual or relevant 
pieces of our conversations. After offering more context on my approach to engaging participants with these writing prompts as well as some brief discussion about relevant trends, I analyze responses to two types of roles participants regularly associated with their professional selves: TEACHER roles and MENTOR roles. 
CHAPTER THREE

THE “STICKER ON YOUR BACK”:

ON BELONGING, FITTING IN, AND (NOT) IDENTIFYING WITH THE FIRST-

GENERATION LABEL

I didn't grow up identifying as a first-generation student. I first learned this term as an undergraduate student amidst applying for master's programs. I remember writing a short narrative about my immigrant parents and their influences on my education for a significant portion of my initial draft of a personal statement. After reading this draft, a professor mentoring me through the process told me I should use the term "firstgeneration student" to describe myself because my story fit this designation. Not truly understanding what this meant, I assumed the term referred to my racial background as an Indian-American woman and my status as a child of immigrants, to which my previous statement draft vividly alluded. I trusted this professor's advice and included the term "first-generation student" in all of my applications. I was accepted to 10 out of 12 of the programs I applied for; though, I, a well-rounded undergraduate student, did not attribute this success solely to my outing myself as a first-generation student and child of immigrants, I can't help but wonder today how much it impacted how graduate committees read my materials. During my master's program, I learned more about the concept of "generations." This process began after my confusion at a professor's 
comment referring to me as a " 1.5 generation immigrant." After some research, I recognized the inaccuracy of this term and worried I had previously misidentified myself. The term " 1.5 generation" refers to people who emigrate to the United States as children after being born in another country and spending their early years elsewhere. While my parents did immigrate to America, this move happened prior to my being born in New York City. I identified that I actually fit the term "second-generation immigrant." So why did my undergraduate mentor tell me otherwise?

I didn't think too much about this term again until I began applying for doctoral programs in the next year. Upon reviewing my master's statements as a starting point to drafting my doctoral ones, I reminded myself of this "first-generation student" designation. I discussed my confusion with a colleague whose work focuses on McNair Scholars, a federal program intended for first-generation students with an emphasis on those with financial need. She noted that I was correct on both accounts: I am a firstgeneration student and a second-generation immigrant. The first-generation status depended upon my parents having not completed college degrees. So, I incorporated "first-generation student" into all of my doctoral application materials.

Being first-generation is a lived experience, and like most lived experiences, it's complicated. Taking on terms to identify ourselves also requires us to contextualize their purposes and use. For instance, I never call myself a "first-generation student" when talking to family members although they directly influence why I operationalize this identity; this term is strictly reserved for my academic vocabulary utilized in academic spaces. What if I had never shared my story with a professor who recognized that it fit the "first-generation student" designation? If this identity is primarily mobilized in academic spaces within particular contexts, how does one come to identify as a first-generation 
student? Additionally, what happens if one doesn't recognize they belong in this group? What is lost?

In this chapter, I present a brief review of scholarly conversations surrounding first-generation students to illuminate the complexity of the term. I present participant stories highlighting attitudes about what it means to identify as a first-generation student working to or holding a $\mathrm{PhD}$ in Rhetoric and Composition. I argue the term "firstgeneration student" offers an imprecise heuristic for thinking about a student's relationship to the academy. In other words, for institutions, the term "first-generation student" operates as a shorthand for recognizing which students might need specific attention in terms of mentorship and resources for navigating academic spaces. However, it is crucial to recognize that not all first-generation students are the same or require the same kinds of attention; a one-size-fits-all model of a first-generation student experience does not exist. In this chapter, I break down myths and pressures common in scholarship and present in data along the following themes: 1) financial status and performing class, 2) navigating academia with our families, and 3) our relationship to the broader institution of the academy.

In order to engage in the question of what it means to be a first-generation-tocollege doctoral student in Rhetoric and Composition, I must first contextualize the term “first-generation." As Ostrove, Stewart, and Curtin (2011) remind, "our understanding of how social identities matter is greatly enhanced by paying attention to the contexts in which these identities develop" (p. 748). Likewise, I argue that first-generation as an identity intersection operates in the critical context of the academy. Identifying as firstgeneration is complex in many ways, but the nature of research complicates it further. By agreeing to participate in my study, each of my 21 participants revealed themselves as 
first-generation-to-college students in Rhetoric and Composition at one of two universities. In the call for participants, I specified that I was seeking "current Rhetoric and Composition doctoral students at [one of the two $\mathrm{PhD}$ institutions I focused on for this study] who identify as first-generation college students (first in their family to get a college degree) to participate in my dissertation study" (emphasis added). I chose this definition after reflecting on my own experiences under this identity categorization alongside scholarship on first-generation students in higher education and rhetoric and composition.

Largely, scholars and national education organizations cite one of two key definitions surrounding the concept of "first-generation student": 1) students whose parents did not complete a college degree, and 2) students whose parents did not attend college. Occasionally, some scholars cite definitions that distinguish the term to periods of time such as "students whose parents attended college, but for less than one year" (Hertel, 2002). Or this definition is complicated by the type of schooling - attending but not completing a degree at a four-year institution, for instance (Osborn, 2015). However, the two key definitions I offer here guide most inquiries. The complexity of the term can impede connection to resources designed for first-generation students, as several of my participants' stories illuminate. If a student cannot connect with these proposed definitions or is offered one interpretation of "first-generation student" over another, they might not recognize they belong to the population. During interviews, for instance, I asked each of my 21 participants if they participated in the McNair Scholars or a similar program as undergraduate students. Only two acknowledged participating in such programs — both citing McNair as the specific program — while the majority of 
participants said they either did not participate, did not have access to it, or had never heard of it.

By recognizing they are part of this demographic of first-generation students, however, connections to resources, focused mentoring relationships, and feelings of camaraderie may increase while imposter syndrome may lessen. However, as many of the participants in this study indicate, first-generation status is often not readily apparent or discussed in academic settings, and when it is, the definitions regarding who counts are not always clear or consistent. Notably, only three participants (Trinity, Samantha, and Ashanka) included that they identified as a "first-generation student" in response to an initial interview question asking them to tell me about themselves. Many only brought up the term if I prompted, such as when I asked, "How do you feel like being a firstgeneration student impacted your educational or personal experiences, or did it?” Perhaps not naming their first-generation position outright reflected the nature of the study-by participating, each person already acknowledged they fit this designation. However, this choice might reveal hesitation or disconnectedness with "first-generation" as a part of these participants' primary identities.

Further, since first-generation student status depends on whether a family member from a previous generation went to college rather than an embodied identity trait, students can likely "pass" in academic spaces despite challenges along the way. Patricia A. Sullivan (1998) similarly describes "passing" as middle class as a professor despite coming from different upbringings. Many teacher-scholars "pass" as part of the dominant class based on other identity factors such as race, ability, or gender, and as my participants describe later in this chapter, dress. 
What does appear consistent about these definitions is the connection to parental college completion status; though your older siblings might have also attended college, you are still considered a first-generation student if your parents did not complete a college degree. Unlike embodied identity characteristics such as our skin color and sex, which are determined by our biology, first-generation student status depends on both our parents' educational choices and our own. Additionally, this term typically requires us to disclose aspects of our background in academic spaces prior to its designation. Like most identity markers, first-generation student status operates in conjunction with other aspects of our identities. All 21 of the participants in my study spoke about their understanding of themselves as first-generation students alongside other intersectionalities and positionalities such as identifying as a parent, a teacher, queer, black, white, cisgendered, and disabled, among other identities. However, not all of my participants fully embrace or identify with the first-generation label as I show later in this chapter.

That said, the definition I offered in my call for participants left room for interpretation in regard to what constituted one's "family," as participants sometimes acknowledged in responses to my call or in our later recorded conversations. Despite offering a more open definition, I still found myself having to determine who could participate in the study. Several doctoral students or alumni emailed or approached me in person asking whether their particular upbringing or background fit the parameters of my study. For instance, are you considered "first-generation" if you know your grandparent received a college degree decades prior to you, but you have no connection to that grandparent? Do you count if your aunt (a family member), who you saw regularly throughout your upbringing though she did not raise you, has a college degree? I could not evade questions like these and ultimately made difficult choices to turn away some 
potential participants with a note that I might reach out in the future for a larger project. Ultimately, the nature of the relationship between participants and family members remains most significant for the purposes of this study; in other words, my interest fell in understanding the folkways and ideologies of systems of education that participants gained from family members as opposed to learning them in school. I felt it was not my place to determine whether or not they qualified as "first-generation students." I chose to exclude certain participants with more complicated understandings of themselves as firstgeneration students to make responses to my interview questions easier to compare across.

Like identity markers, first-generation student status is often complicated by numerous factors such as guardianship and upbringing. The term "first-generation student" often comes with problematic deficit implications, alluding that this population might be "less than" continuing-generation or other student populations who come to college with a clearer sense of the literacies entailed to navigate the space from their parents' experiences. However, "first-generation student" continues to operate as a term to acknowledge the implicit knowledge and cultural capital necessary to navigate the university that this population needs support to navigate. While "first-generation student" remains a problematic shorthand, it offers one way to signal issues of enculturation and implicit knowledge common among a subset of a student population. In what follows, I share three common misconceptions regarding first-generation status, which participant stories debunk or further complicate. Following each "myth,” I discuss an associated pressure shared among the majority of participants in this study and first-generation students at large. These concepts and stories connote that a one-size-fits-all conceptualization of a first-generation student cannot exist; educators and those that 
create resources for this population among others must attend to the diverse needs of this population and strive to empower students toward successfully attaining their degree and career goals.

\section{On Financial Status and Performing Class}

\section{Myth 1: First-generation students, students of color, and working-class students are} the same students

Despite definitions of "first-generation students" focusing on whether or not parents have attended or completed a college education, the term is often synonymous with people of color and/or working-class backgrounds. In other words, when one is identified as a first-generation student, this not only signals that this student most likely has a lack of knowledge of an educational system based on their family, but also that they might come from a particular class or racial background despite the term's definition having no mention of class status or racial background. According to the 2017 National Center for Educational Statistics' report First-Generation and Continuing-Generation College Students: A Comparison of High School and Postsecondary Experiences, in 2012, the highest percentage of first-generation college students was white, followed by Hispanic, Black, students of other races, and Asian (p. 6). This report does not use class signifiers, but instead focuses on income. Knowing that class status definitions are quite complicated (see chapter 1) extending beyond basic income, I offer these reported statistics as one representation of the demographic of first-generation students as reported in 2017 using household income data from 2002:

Compared to their continuing-generation peers, a larger percentage of firstgeneration college students came from lower earning households: that is, 
households that made $\$ 20,000$ or less ( 27 vs. 6 percent) and $\$ 20,001$ to $\$ 50,000$ (50 vs. 23 percent). Conversely, a lower percentage of first-generation college students came from households in the three highest income categories (over $\$ 75,001) .($ p. 6$)$

This trend shows that first-generation students come from lower-income families; however, these families may not necessarily be working-class families. The terms "working-class student" and "first-generation student" are often used synonymously in scholarship, though they do not mean the same thing —one can be first-generation and not working-class and vice versa. However, it is crucial to note that the majority of participants in this study identified as having working-class or low-income backgrounds that they continue to wrestle with while engaging in the field, academia as a middle-class enterprise, and largely, their lives (see Chapter 1).

Despite what class backgrounds or financial challenges we have come from, pursuing a degree and career in higher education often involves re-adaptations and reconsiderations of our class values especially as most graduate students work with small stipends and budgets. For me, as an undergraduate student who went away to college like many of the participants in my study, this shift in my financial expectations came in the form of purchasing textbooks priced higher than any of my clothes, on-campus housing in smaller spaces that cost as much as if not more than renting my family's apartment and mortgage payments on their home, and parking passes to allow me an opportunity to occupy a space not guaranteed. These become the luxuries and necessities of pursuing an academic degree away from home that then carried to graduate school and beyond. And, in recent years, as financial aid slips and tuition continues to rise, financial issues have become more broadly dispersed among student populations. I would be remiss not to 
acknowledge that though financial anxieties are oft-cited as a shared challenge across first-generation students, these realities are no longer solely distinctive or aligned with just first-generation and/or working-class students.

While we negotiate our own class backgrounds and values, we also ask our families to do so when we make the choice to go to college, and, arguably more so, when we choose to continue to graduate studies and beyond. In graduate school, the values of the academic middle class continue to complicate my own, and my participants', understandings of what we should value. For instance, I opened a credit card account to help pay for the cost of participating in conferences, joining scholarly organizations, and paying for those moments when I needed to exercise my position as an upper-level graduate student and reciprocate the unspoken expectation of purchasing a drink or meal for a visiting potential graduate student or colleague at a conference. I perform the middle-class values of academia by continuing to enact frugality and skills I learned from my working-class, immigrant parents such as teaching myself how to cook well with cheaper ingredients or buying blazers secondhand to cut costs. As I noted in Chapter 1, Michelle M. Tokarczyk and Elizabeth A. Fay (1993) note that women, particularly from working-class backgrounds, may feel that after earning tenured positions, "they have severed all connection with their working-class backgrounds, and they have the titles and salaries to prove it. These women often display a middle-, even upper-middle class aesthetic" (6). Tokarczyk and Fay challenge ideas that one can wholly change classes because of the values and tastes instilled in us from working-class upbringings and backgrounds; however, they wonder to what degree the "process of the doctorate dissatisf[ies] us with our backgrounds, instilling in us a desire for elite values and prejudices" (6). Fitting into many class discourses while moving through the American 
education system requires deep reflection of our positions as working-class, firstgeneration teacher-scholars but also offers moments for us to enact our diverse class and cultural literacies to productively engage in these spaces. In what follows, I present stories from participants working through their understandings of the values of educational systems as they strive to fit in. The nature of graduate study and low stipends means that most graduate students maneuver through financial, among other, challenges.

Not all first-generation-to-college students come from working-class backgrounds or have experience working in jobs outside of academia. Diane, a participant who selfidentifies as a "white and queer-identified woman" raised in the New England area of America, describes her experiences before and during graduate study as heavily mediated and also softened by a lot of economic privilege, and a lot of white privilege, too. I went to very expensive schools my whole life. From first grade through $12^{\text {th }}$ grade, I went to private schools [...] My parents basically didn't want me to go to the public schools in our town, because they were known as being overcrowded, and not super great. They sent me to private schools, and yeah. That's how I was educated, was in a really sort of intense academic environments $[\ldots]$ Yeah, just a private school environment.

Because she went straight through her primary and secondary education, Diane notes that "in a lot of ways, academia is all I've ever known." Diane says she still did not feel ready for the reality of higher education despite her privileged schooling experiences. She describes moments of tension between her and her family regarding money and geographical shifts for her education. Additionally, she notes many of these tensions furthered by the underlying class expectations of the academy wherein she feels she learned "financial irresponsibility": 
Ashanka: You started to, but tell me now about how being a first generation, now a college student, right, impacted your educational experiences growing up. You said it was kind of softened by the blow of privilege.

Diane: Yeah.

Ashanka: Tell me more.

Diane: Absolutely. I think that in terms of academically, academic challenges, it has not affected me very much at all, because I had the privilege of a private school education, and sort of a family that super, super valued education, and had the money to provide as good an education as possible. [...] Even though my parents always knew that I would go to college, and maybe an advanced degree, when I decided to go into academia, it was very, very strange and distressing for them. The idea that you have to move anywhere for a grad degree, and then that you have to move anywhere for a job, because historically, a lot of my family has stayed closer to home.

Diane's experience relating her higher education plans with her family mirror that of many participants who continue to work through this tension with their families, as indicated by stories later in this chapter surrounding negotiating academic goals with family life. What Diane's story here relates further is that the financial support she grew up with did not necessitate an understanding of how to create this support for herself, as she describes in the next portion of her response to my question:

[...] I think some ways of thinking about money have been different, and were things that changed for me in college, and especially in grad school, because I feel like all the lessons that my parents tried to teach me about saving and fiscal responsibility kind of went out the window when I went to grad school, because 
although I do come from a family with money, but it's definitely money that they've worked really hard for, and especially when I was born when my parents were older, they had a chance to save a ton of money, and all that, and had also gotten some family inheritance and things like that. They always tried to teach me, "Only spend what you have. Don't go into debt." But especially when I went to my master's program, I was around a lot of people who I think came from even more money, and learned financial irresponsibility, and the expectation that you sort of, even on a grad student salary, sort of live more like a young professional, especially because I was in [Northeastern city], which is very expensive, and always everybody's going out and everything. I'm definitely in a financial hole right now that I am sort of not dealing with before I get a job, and I can no longer talk to my parents about money, because they don't want to know how many loans I have, because I think it's not a disappointment to them, because they're proud of my degrees and stuff, but a mismatch of expectations, if that makes sense. This "mismatch of expectations" Diane describes sums up many of my participants' feelings about communicating their academic plans with their families. For Diane, coming from a middle-class financial background did not prepare her for the financial challenges of graduate study. However, she felt that she still needed to perform a middleclass aesthetic in her graduate program in response to what she observed others doing. She explains her perception of this middle-class aesthetic when describing academic norms, she learned over time:

Ashanka: Can you give me an example of a norm in academia that you felt like you didn't know? 
Diane: [...] I feel like in spite of the fact that there's not a lot of money in academia, a lot of people in academia have adopted a sort of cavalier, almost fatalistic attitude about money, where everyone's like, "Okay, we're in the humanities. We don't make any money. People spend forever in grad school and rack up a ton of debt, and then are probably in that debt forever, so whatever. Let's just drink," is I feel like sort of the attitude, and that is very different from how I grew up, which was, even though there was always enough money, there was also a little bit of a frugal attitude, or if you have extra, you should save it. Diane's perception of a "fatalistic attitude about money" among academics describes one characteristic many first-generation students and working-class students alike navigate for the first time when entering graduate study. Like Diane, several participants including myself noted shifts in how they/we understood money as a graduate student versus our understandings growing up. Later in this chapter, I present stories on fitting in to the academic class as an ongoing pressure for first-generation students to endure that further highlight shifts we make over time. Diane notes that she can no longer speak with her family about finances. Parents and family members become part of support systems for Diane and many other participants who described good relationships with their families, but these relationships are much more personal and not as focused on their professional plans or needs.

Diane describes herself today as "very specifically aspirational middle-class," because missing an opportunity, for her, does not equate financial failure or poverty. Diane explained this concept while we discussed class in her writing responses. Here, she describes what she meant when she wrote "trapeze swinger grabbing for the next thing to 
hold onto" as a metaphor in response to a writing prompt I gave her asking her to describe herself in metaphors:

Ashanka: Where do you see, or do you see, class intersecting with any of these roles [or metaphors], and how?

Diane: [...] I see it intersecting in a lot of ways ... One is, I think ... At that feeling of, if I don't grab the trapeze, if I lose this... then there's nothing. It feels very class inflicted, and very ... At least to me, very specifically aspirational middle-class. Because, if I missed it, I didn't get the opportunity, I have enough privilege that I wouldn't be poor. I wouldn't be hungry, I would still have a house and everything because I would have my family to fall back on. And, my family having money to fall back on. So, it wouldn't be a life-threatening thing.

Ashanka: So, sounds like there's a safety net under the trapeze.

Diane: There's a safety net, but it's not the safety net I want, and it would be so overwhelming of a ... I don't know. If not a physical threat, like a psychological and personal failure, that would be destructive. Because, I think my whole identity is tied into being an academic, and doing this thing, and having the idea of not being able to fill those roles anymore is just devastating to me to think about. Especially ... It's definitely related to class in terms of fear of almost not wanting to slip back into being a different class. Because, my whole childhood and teenager-hood was basically like, "I don't want to do what my family does. I don't want to do shift work [...]" [I didn't want a job where y]ou don't have control of your time, you're ruled by the time clock, and [...] You don't have much autonomy because you have a boss and stuff like that. My whole life is desperation to not slip back into that. 
Diane's experiences, among others, reflects the class shifts that occur when navigating academia. Though she has a financial backup when it comes to her family ties, she does not desire to pursue that avenue out of a "fear of almost not wanting to slip back into being a different class." Diane notes her strong dislike of the kinds of "Blue Collar, slight/somewhat White-Collar jobs" that in turn motivated her to pursue work in academia. In her responses, Diane made it clear that she did not think her parents any less for pursuing blue collar jobs, but rather, recognized them as not a path for her own interests. Donna Dunbar-Odom (2007) theorizes about how to “describe one's move from the working class to the middle class without demonizing or denigrating the working class" (p. 95). I highlight this sentiment here to note that coming from a working-class background or working a working-class job is not bad; however, as Dunbar-Odom citing Alfred Lubrano (2004) describes, the desire for upward class mobility comes from an interest in "a more comfortable life of less backbreaking work and greater reward than our parents knew" (Lubrano, 2004, p. 82, qtd on Dunbar-Odom, 2007, p. 93). Along the way, however, we are not trying to "reject who we are an where we came from to become educated," but rather pursue an alternate life path that our parents' experiences have now opened as a possibility for us (Lubrano, 2004, p. 82, qtd on Dunbar-Odom, 2007, p. 93). Growing up watching her parents working "clock-in, clock-out" types of jobs gave Diane a perspective of what that career could look like, which drove her interest in a career with more time-flexibility. This interest became one of the most important factors for Diane in her choice to pursue a $\mathrm{PhD}$ in Rhetoric and Composition and career as a professor at a university.

Diane's descriptions of re-negotiating her class understandings as a graduate student and now professional in the discipline mirror those of several participants as they 
discussed their backgrounds during our conversations. Jack, a participant who is a white man, father of two, and partner who works as an assistant professor at a northeastern university, describes moving between classes as an ongoing insecurity while explaining his choice to include "grad student +" as a metaphor to the writing prompt asking him to describe himself in metaphors. As he describes his writing responses, Jack works through many conceptions of himself and his class status, ultimately settling on understanding his background as coming from the precariat class and moving into the academic middle class with his current professional position and status. Though the many working-classidentifying participants in this study noted feeling their class status as based on their income marks them as middle-class, many felt they still identified with working-class values. These sentiments echo bell hooks (2000) who concludes that while the amount of money she makes "identifies me as upper class, I do not identify with this class positionality even though I often enjoy the class power it affords me," identifying further with democratic socialist views that challenge class hierarchies (p. 156). As his response indicates, Jack continues to come to terms with where he sees himself in regard to class status, reinforcing the complexities of class status labels in general:

Ashanka: How do you see or in what ways do you see class permeating within these roles? Class status I mean, not like ... Yeah.

Jack: $[\ldots]$ I think some of the insecurity for sure for me is sort of moving into the middle class and sort of ... Well, like our enterprise being about the reproduction of the middle class. [...] I think those [feelings of insecurity in identifying as a writer] are very much tied to my own uncertainty or ambivalence about climbing. [...] Some of that comfort comes from identifying on a level of class that is largely invisible in my appearance and I imagine my embodied practice now. [...] 
Certainly, my research it's $100 \%$ motivated [by my class status]. Well, not $100 \%$ but it's very much shaped by my own class experience, my own experience as... I think working class is something from my colleagues I sort of think about working-class literacies. But I don't really think that is so much, I don't know if working class is still a good term for like what ... My parents were always service industry and were hourly workers. [...] So yeah, I think the white hetero maleness, I think my class background is largely invisible in that sense. So, I don't think ... I think I can use it as capital in some sense. [...] Maybe it's negative to say it's capital. Those are some sort of moments where that identification along class lines does help me connect to students and to other colleagues who are much differently embodied than I am. But I think it also largely remains invisible. [...] a long-time assumption is I came from upper middle class, I'm good with tech. I must only be here because I do some sort of computers and writing work. So, I think that's like sort of sometimes is largely invisible there. But it probably does definitely shape sort of my identification with composition and literacy studies. In his description, Jack also notes the complexity of his own appearance as well as others' perceptions of him as markers of his class status such as how being "good with tech" indicates a particular kind of prowess for rhetoric, composition, and literacy researchers. He points to the potential of his position and appearance as offering a kind of "capital," or as hooks describes "power," in how he can navigate and operate in academia.

Jack and Diane's ongoing contemplations and new understandings of their positions in academia continue to complicate their ideas of their class statuses. Their stories debunk the myth at the front of this section—neither Jack (a white man) nor Diane 
(a white woman) are people of color. Diane, additionally, does not come from a workingclass upbringing and learned financial irresponsibility over her graduate school years. However, what Jack and Diane do share with many other first-generation students both in this study and largely in scholarship are their understandings of what it means to be or "look like" an academic. For Jack, this meant tweaking aspects of his appearance to further blend into the dominant academic class (a concept I delve into further in the next section. For Diane, these understandings contributed to spending money she had not earned such that she could socialize with other graduate students. In the next section, I focus on the classed dress practices of academic work and how dress choices reflect one aspect of the pressure to fit in for several participants in this study.

\section{Pressure 1: On Class and Clothing: "I'm not sure that anybody would have assumed that I was a first-generation student." \\ Dressing the Part}

Though I grew up working-class, some of my values now often reflect those of middle-class academia. These shifting outlooks create tensions and conflicting understandings between my parents and me. For instance, when my parents wanted to celebrate my getting into college with a gift, I asked for a The North Face brand jacket.

“A jacket? We can get you a jacket. What color?" my dad asked, assuming I just wanted new clothes.

"No. Not just any jacket—a The North Face jacket. You have to go to a special store for those, like not Walmart. They are more expensive, but they will last forever," I emphasized. 
Several times, my parents tried to coax me to buy another jacket back then, but I wouldn't budge. I desired this jacket because all of the popular students in my high school wore it - it was a status symbol. I never carried the label of "popular student" or wore the fanciest clothes, and I wanted to feel what that felt like. My working-class parents don't share these material values. For them, the jacket appeared as a hefty price tag. But they eventually gave in and bought the jacket for a little more than $\$ 100$ - the most they ever spent on a single article of clothing for me. I still wear this jacket on cold days, and I thank my parents for this valuable expense.

Along with serving as a status symbol, The North Face jacket operated as a way to fit into my educational environment. The tension that came from this jacket-purchase conversation perhaps comes as a response to a conflation of my identity as a student with that of my parents' daughter. I never articulated to my parents why certain clothing mattered in school. I struggled to explain the significance of this particular jacket and continued to make logos-based arguments to get my parents to see this jacket as an investment in my future such as the college acceptance that prompted its purchase. Conversations about expenses have always been complicated in my household. We talk about money, but we talk about how to save it first rather than spend it. To this day, if my mom learns the price I pay for a professional piece of clothing, better-quality lipstick, or haircut, she makes a comment that I "must think I'm coming from Clinton's House and live a rich life," a reference to former President Bill Clinton and the White House, symbols of a higher class and life status.

I share this story to offer a small glimpse into the complexities of class and culture in pursuing our education and navigating academia. In the next section, I share perspectives from a few of my 21 participants on dress as it relates to class status and 
belonging in academia. I show the impact of implicit and explicit dress codes on imposter syndrome.

First, let's return to participant Jack who, in the previous section, worked through his own perceptions of his class status. Our conversations took place over several Skype meetings. Along with being a father of two, partner, and assistant professor, Jack notes that he remains committed to community literacy work, volunteering regularly at a local learning center. Jack says he did not originally intend to pursue a career in Rhetoric and Composition after undergrad. Instead, he attended seminary, had a "terrible experience," but learned he truly wanted to teach theology rather than preach it. After his wife's program was cancelled, she decided to pursue a master's degree in another discipline. Jack followed his wife to graduate school. After a mentor told him about rhetoric and composition as a possible path for his future, Jack ultimately went on to get his $\mathrm{PhD}$ and a job in the field. During our conversation, dress came up when I asked Jack the question about whether he had participated in McNair Scholars or a similar program as an undergraduate student. Here's what Jack said:

Ashanka: Did you participate in any TRIO or McNair scholars, or any of the programs geared toward first generation or just educating folks about graduate study? [Jack shakes head no] No?

Jack: No, no, I didn't. I didn't even know the term first generation until I got to my PhD, until I got to [PhD-granting Institution], I'd never heard that term. I didn't know even that it could possibly be like a subjectivity. I think part of it is, like I said earlier, being a white man and being one that ... Even as a kid, I would spend all of my money or ask for all of my gifts to be clothing, even as a young kid. Instead of toys, I would ask for my parents to get me a nice shirt. I think, 
even at this age, I was thinking how to appear not poor. That went through every stage of school. I would invest any money that I would make, that didn't go to helping support household things, into my own appearance, which sounds super vain. But, it really, I think, was about trying to class myself differently. When I went to college, I don't think anybody, I don't even think my high school teachers would have assumed that I was a first-generation college student. My parents didn't know the term. I'm the first student on both sides of my extended family to go to college. Even my cousins, things like that, weren't people that my family was checking in with about opportunity.

Jack's response demonstrates again the nature of the term "first-generation student" as complicated to connect with when it is not an embodied identity characteristic such as one's skin color. Jack' describes sporting a particular style as one way he "passed" as not "first-generation" or "not poor."

The idea of passing as an academic as a first-generation student, especially from a working-class background, came up numerous times across participant interviews. Kelly, a working-class-identifying, white woman, brought up the idea of dress and "fitting in" in our conversation among many other sentiments. Our conversation took place during an academic conference. We both presented earlier in the day, so we were both dressed in blazers, dress pants or a skirt. During our conversation, I asked, as I did all my participants, how being a first-generation student impacted her professional and personal experiences. Here's part of Kelly's response and our conversation:

Kelly: I think sometimes when I think about class navigation, I think sometimes that's been a factor. I've almost developed a pathology around what I will wear, because I remember being like, "Okay, I'm clearly not dressed up enough for this. 
I don't belong here." Then it goes into a feedback loop of imposter syndrome, like I don't belong here. I don't have the right clothes. I think that's ... I actually don't like dressing up, but I like belonging. So, when I think about a conference, I micromanage what I will wear, because that just makes me very nervous. Ashanka: Sure, you look great.

Kelly: Thanks. This is [another grad student's skirt she swapped for in a clothing swap]. Grad school trade! Anyway, I think when I started to go to grad school, that's when I really started to notice dissonance. I don't think I really noticed as much in undergrad, or cared, because I was competent. I was a good student. I got through, I got my degree, I didn't care. And nothing mattered, like my clothes didn't matter. It didn't matter that I had ripped jeans. My mom would have been furious, because she actually ... My mom likes for everyone to look nice.

Ashanka: Same, actually. My mom's the same way.

Kelly: Yeah, so I was up in my ratty jeans, and she would have been like, "No, we have to go shopping."

Ashanka: Mom cares about more what I wear than what I care about. For sure, yeah, like a thing.

Kelly: That is a real thing. But grad school, I think, is when people were like, "Oh yes, these people haven't even read theory before." And I'm like, "I haven't read theory before, and also, why are they writing that way?" I read the Bible, I read ancient texts, but how they write makes sense for the time period. Somewhat, I think my grappling with theory or my insistence on theory practice together, I think some of that comes out of my background. But I don't know. Imposter syndrome was a big problem. It was, is. 
Here, Kelly describes the impact of her attire on her sense of belonging and "fitting in" in academic spaces. As a first-year master's student who had not worked closely with academic theory before, she said she personally found the writing styles of theory sometimes unnecessarily obfuscatory; that the other texts she had been familiar with through her religious upbringing or her undergraduate program were difficult to grapple with due to natural language change over time, whereas the work of some theorists occasionally seemed to take "practical concepts and distort [them] merely to seem “complex."” Her story reflects James Paul Gee's (1989) concept of "Discourse with a capital D" as it permeates academic writing and spaces. Kelly's reflection on deciphering theoretical texts corresponds with Gee's explanation of Discourse as the distinctive ways of speaking/listening and often, too, writing/reading coupled with distinctive ways of acting, interacting, valuing, feeling, dressing, thinking, believing, with other people and with various objects, tools, and technologies, so as to enact specific socially recognizable identities engaged in specific socially recognizable activities. [...] Discourses are all about how people 'get their acts together' to get recognized as a given kind of person at a specific time and place. (p. 6-7)

In this case, understanding and speaking about theoretical texts remains par for the course of academic culture. Kelly's movement from discussing her clothing choices to participating in academic spaces deemed "socially recognizable" like conferences and classrooms to navigating theoretical texts shows that she understands her clothing style and knowledge of theory as connected such that her clothing and overall performance in the classroom act as a synecdoche for herself. For working-class students like Kelly and myself, these practices often signal that we must perform particular social traits in order 
to belong and can further intensify feelings of imposter syndrome, or doubt that we belong in a space. Numerous scholars have cited imposter syndrome as common for graduate students, particularly women of color (Boehm \& Lueck, 2016; Gardner \& Holley, 2011; Kniffin, 2007; Okawa, 2002). Much of the scholarship citing imposter syndrome presents mentoring relationships as one potential solution for navigating these feelings. In chapter 5, “Conclusion and Future Matters: What do we do now?" I discuss possible strategies for rethinking and building strong mentorship within graduate programs.

Jack's, Kelly's, and my understandings of what constitutes appropriate dress in the academy reflect one way we each work to write ourselves into academic spaces. As Katie Manthey (2015) and William P. Banks (2003), among others, argue, writing is an embodied experience. I posit that we write our identities through several aspects of our being. For instance, when we enter our classrooms, we, through our appearance, dress, and movement, demonstrate our authority in the space. Of course, this idea of one's dress reflecting one's personality is not new, but the impact in the rhetorical situation remains key. Further, participant understandings of the function of our dress practices in academic spaces reflects practices to physically "fit in" middle-class academia and "pass" within these spaces by dressing more like the dominant middle-class.

\section{On Navigating Academia with Our Families}

\section{Myth 2: Parents aren't helpful at all because they don't understand the system.}

For the most part, participants in my study grew up in relatively stable two-parent households. Most participants' parents worked in traditional working-class jobs such as in factories, small stores, or public service positions. Because our parents did not 
complete their college education, it might be assumed that our parents are not helpful to our educational success. Not having family members who share our educational experiences contributes to a lack of familiarity with how college, graduate education, and academia writ large work and can create or exacerbate imposter syndrome as we navigate learning spaces without family member experiences to help guide us through the system. Specifically, Gardner (2013) describes this phenomenon as a tension for first-generation students seeking to belong in "'two worlds' $[\ldots]$ wherein the first-generation students sought to belong to the academic world while reconciling the poverty that many had come from" (p. 49). Negotiating their own goals with family goals for their education continues to be a running tension for many participants in Gardner's and my study especially when trying to belong among classmates who don't share their backgrounds, as Samantha's story later in this chapter alludes.

However, family members were often cited by participants as contributing to our goals and ambition to complete our education. In this section, I share stories from participants Carter, Samantha, and Kelly who reflect on their parents' impact on their education emphasizing different levels of support they received toward pursuing their academic goals and career choices.

\section{Carter}

Carter always enjoyed school and notes that he was regularly encouraged by his parents, other family members, and teachers to continue pursuing his studies.

Ashanka: What drew you to go in to college?

Carter: Well, I just kind of ... I enjoyed school. You know there was a lot, I liked reading. I was interested in history. And there were just a lot of classes that I was 
interested in while I was in school and it was something that I was good at. I was encouraged by my parents and family members and by teachers. So really, it was kind of the ... I think a lot of encouragement came from my teachers then to consider going into college. Actually, originally, when I was first thinking of college, my idea was, oh, I like computers. I'll go into computer science. But, a lot of my teachers, though, were saying, "Well, you were so good at these other things. You should consider other fields."

Support from family members alongside teachers to pursue careers in the humanities reaffirm our choices with encouragement to continue our education. Though this kind of support is helpful, for many participants, financial support remains absent and one of the largest challenges working with parents as Trinity's story in the next section also illuminates. Carter describes some financial assistance from his parents toward pursuing his college degree, though he still worked jobs to meet the full cost:

Ashanka: Did you ever have a job to get through school? Or while you were in school?

Carter: I had jobs, but I didn't need them. I had, in college, I had a full tuition waiver and my parents had set some money aside then, that they used to help with ... For covering room and board.

Ashanka: Sure.

Carter: So, I had a work-study four hours, six hours a week that I was eligible for and basically that was like just to sort of help with cost of living. It was the dining hall money. Right? Is what I was getting from that. To help with little incidentals and stuff like that. Because I didn't get any extra money. What my parents covered was ... They helped with again, with room and board, with the official 
check. But anything beyond that, I had to cover. So that's what the work-study helped for. And then later, I waited tables, only for about half a year, and mostly that was to get some extra money to help with study abroad. And then I had two summers where I had student assistantships in the English Department. So, I was doing some summer work for them, along with waiting tables.

While his parents did support some of his expenses, Carter says he still never quite understood how to thrive in his education without accruing debt. He indicates the cost of his education as a primary challenge, one that he feels he could have avoided with guidance from family members who attended college and had a better grasp of the financial aid structures.

Ashanka: Do you have any last thoughts that you want to add about your experiences as a first-generation identifying person, as a $\mathrm{PhD}$ student, as a person in the field, and/or do you have questions for me? I'm always open to hearing questions as well. Or even like, "Man, I wish you would ask that." I always like that too.

Carter: Yeah, I mean I guess a couple of things. The cost of education was just something that was never quite ... I mean I feel like I've ended up getting into a lot of debt that maybe if I'd had some more guidance on that it might have avoided doing, so just how the student loan system works has been something that I wasn't as aware of that as what I should have been. I think that that's something that someone who had family members who were in college before might have had a better grasp of.

This accumulation of debt and struggle with finances remains a common struggle among many participants both in this study and others focusing on underrepresented students in 
particular (Gardner \& Holley, 2011; Holley \& Gardner, 2012; Ostrove, Stewart, \& Curtin, 2011). Carter's experience as well as Diane's earlier in this chapter indicate that students should receive more education about navigating financial structures to complete their education without racking up a lot of debt.

\section{Samantha}

Like Carter, Samantha, a working-class white woman who works as a writing center director in a southwestern university, describes encouragement from her parents to pursue her education; however, Samantha interpreted her parents' support as hope for Samantha to establish a career that would help her move above the working-class:

Ashanka: In your opinion, how did being identified as a first-generation college student impact your educational experiences, both before graduate school but also in graduate school?

Samantha: Well, before graduate school, I didn't know what to expect. My parents always pushed me to go to college. It was very much like you would read in any kind of working-class studies, any kind of first-gen scholarship. Parents that they always push you to go to school. [...] But it was hard because they didn't really know what to tell me. They couldn't help me with my job applications, I mean my school applications. They didn't understand how to write scholarships, or what scholarship applications needed or looked for. They just said, "Go to the school counselor and have her help you, and I'm sure you'll be fine, you have the grades — well, I did, at some point— to do it."

We couldn't afford college. They definitely pushed me to do loans, and that's what I did, but they were very much like "You need to be very careful with your loans." 
I really wanted to go to [top-ranked East Coast schools] or something, and, of course, I couldn't do that because I didn't have the cultural capital to get up that far. I had the grades, and I got scholarships to all kinds of crazy schools—small scholarships, not full rides - but they were like no, you need to go to one of these two schools because the only two we'll let you go to. And it was [lists colleges]. So, we went and toured both of them [.... I attended a school that] was basically the one that my parents chose for me.

Samantha's parents helped support her emotionally to make it to college; however, as she describes, her parents could not give her the tools to maneuver specific genres (e.g. writing assignments, financial aid) that act as barriers to cross before one can obtain their college or graduate degrees. As Ann M. Penrose (2002) characterizes in her study of firstgeneration student perceptions of their academic literacy skills and college performance, student "narratives demonstrate that supporting the goal of a college diploma may be quite different from understanding and supporting the daily activities college attendance entails, particularly the additional pressures and the need to spend time away from family” (p. 442). Though Samantha's parents couldn't guide her as she wished through certain aspects of getting her education, the moral support allowed her to continue moving forward. Later in this chapter, I continue Samantha's story to show the impact of her parents' lack of understanding the system on her journey through college. Samantha's story features many moments where mentors failed her and did not support her through her process; however, she does not describe negative feelings toward her parents for simply not knowing the system.

\section{Kelly}


Unlike Samantha whose parents pushed her to be successful and continue her education, Kelly describes different expectations from her parents as she grew up: Ashanka: How did [being a first-generation student] impact your educational experiences? Growing up and even in college, undergrad, grad, now, and work life even?

Kelly: I think expectation levels from family during K-12 were probably different. My mom wasn't like, “No, you've really gotta get that ACT score up. That B, hmm, I don't know.” So, they didn't... I don't remember my parents shoving me into academics the way narratives I've heard from other friends and colleagues. They made the point, "You have to get good grades so you can go to college.” But good was like a range. And they were comfortable with me ... They didn't micromanage what I did in school, I guess. I definitely see it in college, because my mom's really good at systems and navigation. She figured out the financial aid system. She went to classes, took the initiative, was able to explain it all to me. So, in that way, I just have really brilliant parents. She was able to sit down with me and talk me through some of that stuff, and I realize that not everybody had that. There were other things that she just didn't know. I didn't realize that I was supposed to be networking with faculty, that I was supposed to be in office hours. I figured if I didn't understand, I just didn't get it. Sucks for me. I think later, I was watching peers and would figure out what they were doing. But comments on papers were very confusing at first. Just some of the... I just remember being confused sometimes those first couple of years, but it got better. And I'm pretty good at figuring stuff out. I think she brought me up to figure out how to navigate. 
Unlike most participants' parents, Kelly's mother had attended a year of college and also helped her work through educational systems by educating herself to support her daughter. Kelly's description and perspective of her mother's initiative to educate herself on the financial aid system reflect some of the life skills many first-generation-to-college students bring with them to the ivory tower; watching her mother approach resolving something her family knew less about showed Kelly one way to solve problems through learning. Kelly's experiences are reminiscent of David Bartholomae's (1986) "Inventing the University" in which he argues that a key part of the work of the composition classroom is to enable our students to engage in the discourses of the academy. His work leads us to consider both what constitutes academic discourse and how to enable our students to take authority. In the context of the project of this chapter, Bartholomae's text leaves questions about what happens when these same undergraduate students who have presumably "invent[ed] the university" each time they sit down to write become graduate student writers. Do we ever stop inventing the university? Kelly describes several moments of "inventing" and "reinventing" based on her mother's research in order to navigate her spaces. For instance, watching her peers move through academic spaces helped her find a path to follow and build her own understandings of her spaces. Further, as she attributes, Kelly's upbringing and mother, in particular, taught her how to navigate the world around her such that she could apply these life skills to how she approaches academic spaces.

Carter, Samantha, and Kelly's stories show the impact of persistent parental encouragement on gaining their respective education. Varying degrees of financial support impacted all three of these participants, but through watching their own workingclass parents survive, they each learned strategies to handle financial situations by getting 
jobs (Carter) and/or educating themselves on the systems they were working within through available resources their parents helped identify (Kelly and Samantha). Though not the case with all participants, Carter, Kelly, and Samantha all described supportive parental relationships such that their parents hoped their attainment of their education could help support more financially secure futures.

\section{Pressure 2: Communicating with and including our families in our academic lives}

While parents might be helpful in some ways in pursuing our educational goals and are largely described as supportive, many participants described communicating what work in academia entails with their family members as an ongoing challenge. In my own experiences, this challenge typically presents itself when family members speak to others about what I do. For instance, when speaking with extended family on the phone, my father continually refers to me as a "teacher" or "professor." While these identity labels are factual, they are just one part of the equation. The idea of my work primarily entailing "research" or the term "scholarship," or "editorial work," etc. are not present in his descriptors of what his daughter does. Even at present as I complete this dissertation and regularly attempt to describe it, I have found the understanding that my family latches onto is that I'm writing a book as evidenced by my parents regularly asking whether I've "finished my book yet." Lance describes similar feelings about communicating his work with his family noting removing academic jargon from his descriptions. During our conversation, I asked Lance to engage in an exercise where I asked if he could, in a sentence, describe what he does to a few different audiences including his family after he noted the challenge of communicating his work to his family: 
Ashanka: So, thinking about these two concepts, identities, metaphors, roles, et cetera, what have you, that you've listed [in response to one of my writing prompts], do you feel like any of them are intersected by class?

Lance: Yeah, definitely when we get to "brother" and "son", then I'm thinking about my immediate family, and they still live the same life that I lived growing up. They're still in [midwestern city]. I still visit often, but they're still ... it's still a separate world in a lot of ways.

Ashanka: Can you say more about that?

Lance: Yeah, they're ... everyone in my family's genuinely happy for me for being a $\mathrm{PhD}$ student and getting to teach at universities, but I never really get to talk about my research interests with my family. Those are conversations that just don't happen for reasons that I think are pretty obvious ... so they can't happen, right? So, the interest really isn't there, but then also none of the language to discuss those kinds of things are there, and then we got to talk about different ideologies that they're less familiar with. I don't know. It just doesn't happen very often.

Lance describes a common issue among many students - first-generation or otherwisein trying to communicate their work with non-academic family members or friends that resonates further in many academic disciplines pushing to create and design their research such that it better communicates, connects, and serves larger publics outside the ivory tower. To this effect, I asked Lance to try an activity I often ask undergraduate writing students to engage in thinking about how we communicate research to different audiences wherein they must describe their work, in one sentence, to a given rhetorical 
audience such as someone in their discipline or a family member as Lance demonstrates here:

Ashanka: [...I]n a sentence, tell me what you do to me who's in the field.

Lance: Okay, "I research and write about the rhetoric of science communication and the rhetorics of technologies."

Ashanka: Now how would you say it to your brother and parents?

Lance:Yeah, that's where the difficulty lies, right? [...] Short conversations. But I can talk to them about artificial intelligence, right? Because they've heard about ... it's just in social media, these terms pop up, right? [...] I get to introduce them to the idea then tell them why it matters for the humanities, or I would say it just matters for people in their everyday lives. [...] None of the jargon, really. All of the jargon has to go.

[... In a sentence,] "I'm researching how professional scientists are able to communicate their ideas to people who aren't scientists, and also how technology, like the Facebook algorithm that you probably heard about and artificial intelligence may be embedded with human values in some way. It might not be really neutral like we think they are."

Ashanka: Yeah, I like the point you made about jargon, or we often think of it as discourses within the field, right? So, we speak "rhet/comp speak," but even people in other disciplines don't speak what we speak, right. Certain terms don't translate the same. [...] But it just makes me think a lot about what you're saying that we often deal with especially coming from a first-generation background, or working class, and having to come up with clever ways to translate what we do ... I don't get beyond, "I write, I read, I teach," and that's it, "I teach writing." That's 
about as far as I often get with my parents. I don't get into ... they don't know what my dissertation's about. They think it's about English and how English works, and I'm like, "No, I'm studying people. I interview people," and [...] because I used to be a journalist and they get how newspapers work, so they're like, "Oh you're writing news stories about people," and I'm like, "No. It's not that, but it's this thing," and it's hard to explain, and I still haven't found the terms to get at what my project is to my parents, and I don't know if I ever will. It's complicated, but they very much inform my project because everything that I am is because of my background $[\ldots]$

Lance: I would say that my family [...] what they'll talk about every time they bring it up themselves ... is that I'm a professor, right? That's what it is, right? "He's a professor," so, "My brother's a professor," ... my brother would say stuff like that, "He knows what he's talking about," so then that thing happens.

Ashanka: Because it's tangible right?

Lance: [...] It's never like, "He's a researcher," right? Which in a lot of ways, as a PhD student, I feel like is what I am right now. I really enjoy my teaching, and even on the list I put "educator" first. I stand by that, but [...] I feel like that's what I'm doing, and if I described myself, it would be as a researcher right now who's going to become a professor, and teaches at the same time, so. It's a complicated thing, but they would never say what I'm doing to someone. [...] It's just going to be, "He teaches college courses."

Lance and I, among other participants, wrestle with our family's conception of who we are and what we do. As Lance notes, we often have to eliminate specificities and "jargon" from our descriptions of our work. Lance notes that this challenge might partly stem from 
a lack of interest on the part of our families. I would take this a step further and indicate that it is not necessarily a lack of interest, but rather absence in language. In other words, our families might not describe our work the same way we do simply because the terms we engage are not a part of their own vocabularies and understandings of what academic work looks like. Bronwyn T. Williams and Amy A. Zenger (2007) similarly describe the impact of representations of literacy within several popular films on public conceptions of literacy. For the most part, unless people are integrated into the spaces themselves, many of our perceptions of different career paths come from popular representations, many of which are not accurate.

What our families might understand about our work can sometimes be misconstrued. Trinity, for instance, describes how communicating facets of work outside the classroom with her family becomes complicated by their understandings of what leaving university walls might entail. She describes what happened when asking her family for some money to help pay for a conference, a reminder for her that she is a firstgeneration student, which she notes she typically does not remember until moments describing her work with her family:

Ashanka: So, throughout all of this how has your positionality or your identifying as a first-generation student impacted the way you went about your school experiences or how those went?

Trinity: When you're in process of completing it at least for me you don't remember that you're first generation until you have to remember. [...] There are things that you just don't know how to do but they don't make sense to you, or just the culture just feels foreign. I guess in that way every student could feel these things because it's a new territory [...] There's a certain level of newness that is 
additional when you're first generation but then also interacting with family, them understanding how things go or me having to explain things. I remember the first couple semesters that I went to conferences, my parents just thought I was on vacation. I know it looks like I'm just hanging out but there's actually things happening here. [...] Or when I had to say “can I borrow some money I don't get reimbursed until I get back," they were just "well you don't need to go on the trip." It's not that easy. [...] Because, they just saw you're going on a trip maybe you should slow down. Those types of things. Just navigating the space and sharing it with other people.

As Trinity describes, explaining our work to our family members who don't have shared experiences or understandings can create tension. The concepts of attending conferences or conducting qualitative research, among other work associated prominently with academia, typically do not occur outside of academic spaces. Additionally, they are dependent upon a lot of contextualization. For instance, to explain a conference setting requires a certain understanding of conference themes, the genre of a conference presentation, and the process of writing proposals and getting accepted in the first place. Further, sometimes academic labor does not appear as work to those outside the ivory tower since it is not as physically involved as traditional labor. To my parents, for instance, sitting with my laptop and writing does not appear as work whereas cleaning my home does. Here, Trinity echoes feelings about the complex nature of explaining financial issues as a graduate student to family members who might not understand why certain expenses are made in the process.

Cultural expectations of adulthood can also complicate how we communicate our academic roles with our family. During my conversation with Pera, a Southeast Asian 
man who immigrated to America in the early 90s, we discussed how our family'sthough from different Asian cultures_-expectations of our familial roles as adults often look different from our white colleagues while describing the role "caretaker of logistics" he listed in response to a writing prompt asking him to list his professional and personal roles. He begins his description of roles by clarifying how he perceives his roles broadly before moving into discussing each role specifically. Here, I share part of our conversation about cultural expectations during his description of himself as a "caretaker of logistics":

Pera: $[\ldots]$ To become a caretaker of logistics, household issues, everyday things for my parents and pets. I think this too feeds back into my identity. When you are a first-generation immigrant, for me at least, I didn't come from a big family. It's just my sister and me. She has her own family and she lives in [Western American city]. My mom lives in [Midwest state]. My dad is in [Southeast Asian country]. We don't, for me, because my mom who lives here isn't a native English speaker, because she's an immigrant and I told you about her limited educational background, a lot of everyday things fall on me because of language issues. And the older I get, the more I realize how she has to face discrimination and microaggression because of a) her age, b) because of her ethnicity, c) because of her gender. All these intersectional things collide to impact how people view her and treat her.

I don't have a choice except to become a caretaker to my mom. I have to handle some of the things when things get complicated. When she has to deal with difficult bureaucracies, it's on me. I have to pretty much set up things for her. And that is a role, and how does that impact my day? Well it can be very stressful as a 
scholar. I live in [East Coast City], I'm far away from [Midwest City his mom resides], but I still have this time, I have this responsibility that I have to take care of. [...] When my colleagues ... I hate to say this, but my colleagues, some of them when they're white or they grew up here, they can just say, "You know what? I'm just gonna take time to do this research and whatever." I'm like, "Well, that's great, but I also have this other obligation. I do have to do that too. But you know what? There are other things I have to take care of."

Pera's story of balancing taking care of his mother long distance with his academic work mirror my own experiences taking care of my parents throughout my life as the primary language-broker for my family, which Pera similarly describes. In my own experiences, I continue to serve as my parents' go-to language broker, especially because of my now advanced knowledge in English studies. Like I teach my students to engage with iMovie and the Purdue OWL, I teach my parents how to use their computers, smart phones, and printers - I spend these interactions thinking about my students' and my parents' own literacies, particularly digital literacies. I regularly receive phone calls asking for help filling out forms. During my master's, my mom began her pursuit of earning her American citizenship. I would call her regularly and quiz her on the questions she would be asked while breaking down concepts like the right to bear arms or the role of senators. Not all academics or all students of color work with their families this way; however, Pera's and my own experiences reflect additional pressures that come with communicating with our families as first-generation academics, immigrants, or children of immigrants. For Pera, communicating what he does with his family is less of an issue than explaining why he can't work on academic materials during breaks when other, primarily white, colleagues might capitalize on this time. As we note, time does not 
operate the same for all academics and it does not reflect that of a traditional 8 to 5 job. While time does not reflect an issue common to just first-generation students, the perception of what we do on off hours and how we prioritize our personal lives might appear different.

Lance, Trinity, and Pera's stories in this section show different conflicts that often arise for many first-generation students communicating their academic work-life with their families as well as our colleagues. From varied understandings of what our work is and entails to the impact of familial and/or cultural expectations on when we can work, these relationships require several moments of negotiation that might misalign with the expectations of academic or familial labor.

\section{On Our Relationship to the Institution}

\section{Myth 3: Being first is source of all challenges for first-generation students}

While being the first in their family to earn a college education might be a primary challenge for undergraduate students in the humanities (among other disciplines) navigating college, I argue this becomes less the case at the doctoral level. Once students attain their bachelor's degrees, pursuing higher education stems more from career choices and interests. Students might continue to be the first in their families to pursue degrees beyond their undergraduate, but the system they are now navigating extends beyond the oft-cited challenges first-generation students face such as being "more likely to grow up in low-income families, receive less support from their family related to college enrollment, hold a full-time job during college, and spend less time interacting with faculty" (Gardner \& Holley, 2011, 77). Most of my participants indicated having moved past living with the family that raised them and beginning to build their own. Several of 
my participants identified as parents, as husbands/wives/partners, and mentioned developing their own financial and personal independence from those that raised them. As such, at the doctoral level, the notion of being the first becomes less significant than does navigating one's upbringing and instilled values with those of academia. Further, the motivation for pursuing one's doctorate often stems beyond being the first in their family to do so.

Participants cited genuine interest in teaching and research as well as upward career and class mobility most among reasons for why participants chose to specifically pursue their PhD in Rhetoric and Composition. Many participants noted growing up with interest in reading, writing, and beginning to compose their identities as teacher-scholars in Rhetoric and Composition as early as their undergraduate work. In what follows, I share the stories of participants Zeke and Tina who offer two different perspectives for why they pursued their PhDs.

\section{Zeke}

At the time we spoke, Zeke was completing his comprehensive exams and beginning to write his dissertation with plans to be on the job market as he finished his $\mathrm{PhD}$ in the following year. Zeke, a self-described "queer cat dad" who "teach[es] graduate students how to teach underclassmen" in his administrative role as a $\mathrm{PhD}$ student, notes being homeless 12 times throughout his upbringing in the southeast and working numerous jobs since high school. Zeke, a white man, says he "resisted" his “staunchly religious" father's side of his family especially after experiencing much abuse from him. He cites his mother as "one of the biggest literacy sponsors I have in this lifetime. She read to me. She was predominantly one of the reasons I did go to college. 
My dad didn't want me to. [...] He thought that I should learn a skill set, I don't know, be a plumber or some shit. That's a waste of my ability. My mom has always supported the notion. She knew I was smart, and I could get out, and so she's predominantly the reason I did it."

For Zeke, a desire to survive is why he chose to pursue his graduate degree: "I wanted to make sure I had a degree that would make me money," he said, "I think my whole life has been about survival." Like many participants, Zeke describes falling into rhetoric and composition both in response to a mentor's advice about graduate degrees in English and his interest in the location of his $\mathrm{PhD}$ program. Zeke describes school as "one of the most stable areas in my life," further highlighting the impact of his education, and interest in pursuing a $\mathrm{PhD}$ and career in rhetoric and composition. He says teachers positively impacted him because he saw and engaged with them regularly despite his unstable living or life situation in a given moment. For instance, he says that while it's hard for him to pinpoint a single location as his home growing up, he attributes staying in "the same high school, gratefully" as "part of the reason [he] think[s] [he] continue[d] with education because it was so important. That was [his] ticket out, so to speak." Several participants point to this kind of stability of school as part of the reason for continuing their education. The increased career possibilities and job stability that graduate degrees afford for students like Zeke indicates one of many reasons for pursuing higher education.

However, Zeke sees his experiences living in "the real world" contributing a critical lens to his feelings about working in academia that he feels many others do not have. Ultimately, Zeke identifies his pursuit of higher education as a way "out" of 
poverty, though he notes that these actions are due to his identity as a queer person and less so his identity as a first-generation student:

Ashanka: How has identifying as first generation, going through college... Maybe perhaps other people you don't know haven't done that. So how has it impacted your personal experiences?

Zeke: [...I]t's hard for me to separate professional and personal now. I mean, so, I guess, I'm having difficulty answering this. But in my personal life, I suppose, being the first generation, the family that I do talk to, I quote, unquote, "made it out." I did something with my life, so to speak. I'm not just recreating my parents' mistakes. I'm not squeezing out babies and working in a factory. I moved. I'm able to go places and do things. But I think that has less to do with me being a firstgeneration person and more to do with my queer self. I don't think it has anything to do with me just being a first-generation college student. I think I'm just a smart queer person.

For Zeke, going to college was a matter of survival first.

Ashanka: You kind of started to get at this a little bit, but why a graduate program in composition and rhetoric?

Zeke: Well, one, I wanted to make sure I had a degree that would make me money. I think my whole life has been about survival, and I knew that it's unlikely that I'm going to make money as a poet. Literature isn't going to get me much because, [name of colleague], she's [in] lit, and she's stressed and emphasized over and over how difficult that field is. Then I wanted to stay in English because I've always been drawn to the power of language, but I didn't really know about rhetoric and composition until my last semester in my undergrad. I knew it was 
something ... It bridged the gaps between my degrees that I had. It made philosophy more practical. I took this one course with [Professor's name], who is actually an [alumni of Zeke's PhD-granting institution]. She was like, "You know what? If you are a strong writer, strong mind, you like philosophy, have you heard about this thing, rhetoric?" It just went from there.

Additionally, obtaining his college education allows him career mobility in a more stable way than his family before him seems to have had. For instance, if Zeke continues to follow his path and pursue a tenure-track job in rhetoric and composition, his future can be more financially stable than his family before him. The concept of being first in his family to attend college was less relevant to his success, but it marks him, according to his relatives, as someone who "made it out" and who won't be "recreating [his] parents' mistakes.”

Zeke attributes his movement through educational spaces primarily to being a "smart queer person." Zeke points to numerous moments where his queer identity impacted his educational experiences and helps him survive as he pursues a career in writing studies. For example, Zeke says that although he knew "nothing, honestly" about graduate study prior to his master's and $\mathrm{PhD}$ program experiences, he "did know that [he] wanted to write about queerness and embodiment and technology." Further, he describes working on and talking with a close friend about queer theory and philosophy texts that influenced his decision to get his $\mathrm{PhD}$. Pursuing these research interests that he draws from personal and lived experiences helps him find his place and remain committed to work in the discipline. Zeke's survival instincts reflect in his pursuits and attitude as a burgeoning scholar. Further, his experience with blue-collar jobs gives him a perspective on academic work that, he feels, has helped him be more resilient than his peers: 
Ashanka: How has identifying as a first-generation college student impacted your educational experiences?

Zeke: Well, I think, one, I've lived in the real world. I wasn't coddled. I know how the 40-hour week job... I know how pervasive that is outside of the academy. I understand that my students aren't going to follow the same path that I've been on, as far as getting a $\mathrm{PhD}$. But, otherwise, I've lived outside the academy. I know what it's like to struggle. I know what it's like to clock in and out. I don't know if that's answering your question or not, but as far as being firstgeneration, fuck, I don't complain as much as most academics whenever we've got to do the work that we do. I'm not trying to say it's hardened me, but maybe it has. I don't know.

Zeke's description of living in "the real world" comes with traditionally working-class descriptors such as the notion of "clock[ing] in and out," a metaphor not typically used when describing an academic job where the expectations and preparation often leave many of us working beyond a 9 to 5 schedule. And yet, it is Zeke's past experiences with work that inform how he approaches and balances his present workload with optimism, one that the term "first-generation student" only begins to help him identify.

\section{Tina}

Ten years into an industry career as a creative director, graphic designer, and writer, Tina decided to quit her job and return to school to pursue her graduate education in Rhetoric and Composition. Tina says she was drawn to Rhetoric and Composition as a "practical outlet for [her] love for literacy and education and English." Today, she works 
as an assistant professor and writing program director at a northeastern university. She describes earning her $\mathrm{PhD}$ as something she perhaps forecasted as a young child:

Ashanka: So, what drew you to going to college, especially being the first one in your immediate family?

Tina: This is a question I've often wondered myself. I remember when I was moving 20 years ago and doing the move purge, I found some old books from when I was a kid. I was a voracious reader. My aunt was a librarian, I think was part of that answer. She gave me tons of books to read. My parents were always very supportive of reading, and were largely self-educated in a way, especially my dad. I found a couple of books from when I was a kid, and I had printed in my awkward kid handwriting on the inside cover "[Tina's real name], PhD." And I don't even know how I knew what that meant, and maybe I didn't really know what it meant, but I thought it was so fascinating. And even when I found those books, I was still in industry, I wasn't an academic. And so, I think some part of me was always drawn to the life of the mind, as they say, and to education, and to getting paid to think and read and teach, and I think that was largely due to my aunt and my teachers. But I didn't have a role model of what a professional academic or professor looked like.

Tina, along with Trinity, is one of two participants who indicated participating in the McNair Scholars program as an undergraduate student. She described transferring colleges a few times due to challenges paying for tuition out of state. With help from strong women mentors in her undergraduate English department, she successfully completed her college degree as a first-generation student earning numerous scholarships along the way to help fund her degrees. 
Unlike most participants, Tina describes feeling less apprehensive about applying to graduate programs, a feeling she attributes to having a partner who served as a literacy sponsor for her graduate degree pursuits - her partner went through the same process a year prior and her experience helped Tina navigate the process. She also describes the more openness to non-traditional students like her in the nature of the institutions to which she applied as one aspect of feeling less afraid to apply:

Ashanka: Were you ever afraid of applying to graduate programs?

Tina: No, I wasn't, because I think that I already had at that point a literacy sponsor in the form of my own partner, who had just gone through it a year before, and I walked through all of that with her. And so, it took the unknown out of it a bit. Obviously, there's the fear of you're not gonna get in, but I think that I've always been an overachiever, like many people in our discipline, and so I think I was driven by this coping mechanism of I will succeed somehow if I work hard enough. Kind of the protestant work ethic that white people have the luxury of having in our society. So even though I come like working-class background, I think that I was just ignorant enough of the obstacles that that would present that I was kind of bold. And I think [her PhD-granting institution] was also, like [another institution], open to non-traditional students, more students who weren't from a traditional background. Not all programs are, and I think I just was a good fit for them, just seeing about looking at other people who are in my cohort and years around when I was there. So yes and no. Yes, I didn't know where I would get in, and I didn't get in to two of the places I applied, and I was really heartbroken, but in retrospect I'm glad. But I knew what to expect in terms of the process, which helped. 
Tina's challenges attaining her education stem less from being the first in her family and more from feeling out of place as an older student returning after many years:

Ashanka: Similarly [to a question about her relationship with faculty], what did you see as your relationship to other graduate students in the program?

Tina: I felt a bit like a fish out of water when I first arrived, because I was the only one in my cohort who went to the teaching practicum who is a bit older. There were people who were two or three years ahead of me who are also nontraditional students, that I connected with pretty quickly. But out of ... I think there were six of us in my cohort, in my doctoral cohort [...] I was the only female in the teaching practicum. And I've since still kept in touch with all the guys, and we've hit off really well, but at first, I was like, "Oh man." I didn't know how I would fit.

And I'm older and ... I had been an assistant WPA as a master's student because I was a little older. It was kind of an unusual opportunity. So, I'd already helped, I helped teach the summer workshop and the teaching practicum, so I came in thinking, "Oh, I know a lot of this." So, I quickly had to learn the lesson that many grad students have to learn, which is you really don't know a lot. And you have to be open to learn.

I think that in terms of on a friend level and emotionally, I connected a great deal to the rhet/comp female grad students who were a year, two, three years ahead of me. The people who were in my year ... I hung out with some of them but they really ... It wasn't until later we were kind of are kind of in the trenches together, to use a bad metaphor, that we really connected. At first, I was ... I just thought, "Gosh, everyone is so young and what am I doing here?" 
As Tina describes, her age partly served as an asset for her in obtaining unique opportunities for junior writing program administration work as a graduate student; however, she felt less connected with other graduate students initially. Though Tina, like all participants in this study, identifies as a first-generation student, she did not note the conventional challenges that many first-generation students face as she gained her $\mathrm{PhD}$. To further characterize Zeke and Tina's stories, I consider them as counterstories. A concept from critical race theory (CRT), counterstory in Rhetoric and Composition, as Aja Y. Martinez (2014) argues, emphasizes that "experiential and embodied knowledge of people of color," specifically, "is legitimate and critical to understanding racism that is often well disguised in the rhetoric of normalized structural values and practices" (p. 37). Though Zeke and Tina do not identify as people of color, they both identify as queer, another historically underrepresented population whose stories and experiences are not often told. Both Zeke and Tina describe other areas of their lives and identities that perhaps had a larger impact on their educational journeys than their first-generation student status, which scholars writing about first-generation students historically allude as the primary challenge for first-generation students. Zeke and Tina reflect, among many stories, counterstories to the dominant narratives about the challenges first-generation students face that we should consider when designing programs and mentoring graduate students.

\section{Pressure 3: Navigating graduate education and our discipline as a system}

Graduate study remains filled with challenges for everyone, regardless of how we identify or what fields we pursue; however, our identities and positions are among reasons for why some things might be more challenging for some than others. For first- 
generation-to-college doctoral students such as the 21 represented in this project, an oftcited challenge remains navigating the system of graduate study without models from our upbringings and previous experiences of what it can look like. For many of us, pursuing doctoral degrees comes out of a desire for financial stability for our future lives unlike that we might have been raised in. Additionally, we choose to pursue career paths out of our passions for teaching and research surrounding concepts of writing and rhetoric rather than solely for a substantial paycheck. Graduate study and, more specifically, Rhetoric and Composition as a discipline are not spaces designed for us to learn how to navigate as first-generation-to-college students. In this section, I present stories of how some participants found their ways through graduate education in Rhetoric and Composition to

illuminate how participants ultimately find ways to navigate using knowledges from lived experiences.

\section{First-Generation Culture Shock}

\section{Samantha}

Earlier in this chapter, I introduced Samantha, a working-class white woman who works as a writing center director in a southwestern university, and her explanation of how her parents impacted her educational pursuits. Here, I share more of her response to this question to illustrate one experience of the kind of culture shock that comes from arriving to college in the first place that many first-generation students experience.

Ashanka: In your opinion, how did being identified as a first-generation college student impact your educational experiences, both before graduate school but also in graduate school? 
Samantha: [... (the first part of this response is shared earlier in this chapter in which she describes the ways her parents pushed her to pursue a college education, something she interprets as their guiding her to gain upward class mobility.) ...]

But I didn't know how to negotiate college campuses. I didn't know that we even had [introductory course], which was like a seminar for students that were freshmen. My roommate in college my first semester, which was a freaking nightmare, was an upper middle-class snooty girl from [larger southwestern city]. From the richest part of [larger southwestern city]. And it was just so disturbing how condescending she was, and how judgmental she was towards pretty much everything. And it wasn't outright, either. It was so underhanded. I'm trying to remember exactly examples of that, but I just remember feeling so inadequate around her, because I didn't have the stereo that she brought, and I didn't have jewelry and all the clothes that she had. She even had a car, and I even looked at her like why do you have a car? I don't have a car. My parents drove me seven hours in my dad's pickup truck, with no air conditioning, all of my shit in Hefty bags, no suitcases. As I said, seven hours from [southern part of state to eastern part of state where college was located]. Put all of my stuff in my dorm room and said "Okay, bye" and left. And just left me there.

Cause they don't know, they don't know about Parents' Day, and to go to the parents' thing so they can learn more about school. They didn't know anything about that. They were just like "Okay, your life is now here, we'll come pick you up for Thanksgiving. We're gonna pick up your friends that are coming to school with you too[... .]" 
So, yeah. It was rough, and my grades sucked that first semester because I didn't know how to balance all these classes. I had to take remedial math, because I did terrible on the SATs and the ACTs in math, and I still feel bad. I didn't know about tutoring, I didn't know any of that stuff. I just thought I need to do this, I don't know how, I'll figure it out myself.

Here, Samantha describes in detail how she arrived at college, some of the differences between her and her roommate, and the impact of her not knowing the culture on her first semester studies. The resources she describes her roommate having - a car, stereo, a larger amount of clothes and jewelry—make Samantha feel inadequate when she thinks about her own experience arriving to college with her things in garbage bags and her parents leaving rather abruptly after dropping her off. While I do not have the perspective of her roommate, we can imagine her roommate navigated her first semester much differently than Samantha who describes not knowing where or what guidance to seek to help her thrive in her a college setting. Samantha's experience echoes that of a participant in Gardner's (2013) article who describes similar feelings, especially when comparing himself to other students around him, concluding that he felt "strange because [he] didn't have a reference" like other students with "parents who were headmasters at private schools and all sorts of things" while his own "mom work[ed] at Wal-Mart and [his] dad [was] an electrician" (p. 49-50). Likewise, Samantha could not turn to those she knewher parents - to help her gain some insight as they did not have their own college experiences to share.

Navigating new spaces like college necessitates some level of literacy sponsorship in regard to the culture and spaces. Samantha's experience shows an absence of literacy sponsors in this moment that could have helped her move through college more 
smoothly, and possibly a reason for her rough first semester. For students like Samantha, this lack of understanding of what college entails can be a reason to not complete one's education, contributing to fewer first-generation students completing their college education. In 2017, the U.S. Department of Education published a study of "FirstGeneration and Continuing-Generation College Students: A Comparison of High School and Postsecondary Experiences" (Redford \& Hoyer, 2017). In this report, Redford and Hoyer (2017) engage data from the National Center for Education Statistics (NCES) to offer both a targeted look at first-generation college students and a comparison between first-generation students and their continuing-generation peers based on a longitudinal study of high school sophomores in 2002. According to the report:

Ten years after they were sophomores in high school, a lower percentage of firstgeneration college students than continuing-generation students had obtained either a bachelor's degree (20 vs. 42 percent) or a master's degree or higher ( 3 vs. 13 percent). Conversely, a higher percentage of first-generation college students than continuing-generation students had obtained some postsecondary education, but had not completed a postsecondary credential (47 vs. 30 percent), an undergraduate certificate (17 vs. 7 percent), or an associate's degree (13 vs. 8 percent). (p. 11)

While Samantha did ultimately complete her bachelor's degree, these statistics demonstrate that this is not always the case. In fact, while Samantha has completed her bachelor's and her master's over time, she has not yet completed her $\mathrm{PhD}$ despite being post-exams for several years at the time of the interview.

Finding Ways to Navigate the Culture 
While parents can partly assist us in obtaining our college education that then can help set us up to enter graduate study, participants attribute their own understandings to a network of mentors. Outside of self and some familial guidance for first-generation students, programs like the McNair Scholars program strive to prepare first-generation and other underrepresented groups for doctoral studies from the start of their undergraduate programs. Trinity is one of two of 21 participants in my study who participated in the McNair Scholars program. Trinity self-identifies as a black woman raised in the South in a single-parent home. When we spoke, she was finishing up her $\mathrm{PhD}$ in Rhetoric and Composition and had recently accepted a job as an assistant professor. Like most participants in this study, she grew up attending public schools. She chose to attend an HBCU (historically black colleges and universities) as an undergraduate student where she participated in numerous study abroad and study away programs and engaged as a student leader. Additionally, along with participating in the McNair Scholars program, Trinity participated in an Andrew Mellon funded program through which she studied abroad. She cites these experiences as solidifying her desire to pursue a graduate degree while discussing her time in the McNair program:

Trinity: [McNair] gave me the actual tools to do graduate education like GRE prep and pairing with a mentor, writing a project, and meeting with them. [...] So McNair made it possible for me to get a fellowship when I got to my [master's institution]. So then it put me in this network to make it to graduate school, the transition to graduate studies was much easier.

This network of mentors and resources offered Trinity a crucial foundation to pursue her graduate studies and ultimately earn her $\mathrm{PhD}$. Trinity points to many moments of 
mentoring, especially from other black women, as significant moments for both her decision to pursue her $\mathrm{PhD}$ and also in helping her succeed in her pursuits along the way: Ashanka: What were some of your experiences working with faculty before graduate school?

Trinity: [...] One of my professors who was my advisor [in undergrad] and now a definite lifelong mentor told me that I was going to go to graduate school. She was the first person I met with a PhD ever, first black woman. So, I don't know, it was things like that, that were really directive and really I think an extension of the black community is that if a professor tells someone that, that was not to a black woman, that it could be read a certain way like she was trying to control my life or something. I was just like “OK, grad school, maybe." It just really started to take form. She saw something that I couldn't see. [...] Really meaningful, really personal types of interactions. When I got to the master's program, I had a similar experience. [...] It's been the case that black women have definitely been influential. It wasn't also that I didn't have relationships with other faculty during the master's program, but those just stood out a bit more.

Trinity points to the impact of mentors who look like her in her educational choices and journey. Networks of mentors who look like us help us visualize the possibility of attaining our degrees. Additionally, from a first-generation standpoint, when we don't have family members who have their educational experiences to share with us as we navigate our own, having mentors who look like us, with shared upbringings and backgrounds, can often be the closest thing to our family members.

But what about moments beyond family and mentoring? How do first-generation students navigate conversations within their disciplines? Jaidev's story below features a 
self-motivated approach to fit into the language of Rhetoric and Composition. At the time of our conversation, Jaidev was an assistant professor awaiting a tenure decision from his northeastern institution. He grew up in Southeastern Asia where he attended private schools throughout his upbringing. After high school, continual praise of his Englishlanguage skills led to him changing his academic pursuits from science to English; however, this path came with financial challenges. Jaidev continued to pursue graduate degrees in Southeast Asia, but says he grew tired of teaching and learning English literature, because the society did not know how to make it especially meaningful. In a sense, we were just teaching, but I didn't know how that, beyond us just being the English people, how that makes any sense in a society of professional academics. And that did sort of become a bubble of its own, which I didn't like. [...] Another reason was corruption, which wouldn't allow me to make any professional growth in that setting around that time. And the third reason is that when I discovered that there was this new field called rhetoric and composition, I was like "I am made for it. I really want to study this because you can translate this into skills for everybody. You can educate the next generation to communicate and to write and to research." Jaidev applied for his $\mathrm{PhD}$ in Rhetoric and Composition in America thereafter and the rest is history. Along with his work as a "multilingual, multicultural, transnational, and secular" individual, Jaidev describes himself as a person shaped by the particularities of [his] family, the complex social relationships and dynamics of friends and colleagues in many different contexts around the world, and [his] own values and beliefs, which put [him] in connections and tensions as to what education and educating means and does. 
Jaidev reflects deeply on his identity as a Rhetoric and Composition teacher and scholar, one that he built through developing strong connections to both existing scholarship and other scholars in the discipline; however, this path did not come naturally. In the excerpt of our conversation below, Jaidev describes his interest in pursuing a $\mathrm{PhD}$ in Rhetoric and Composition at an American university and how he taught himself some of the disciplinary discourses to navigate his graduate courses:

Ashanka: So what did you know about graduate study and rhetoric and composition before you started your $\mathrm{PhD}$ program?

In response to my question, Jaidev shared a detailed story about discovering the discipline while developing study guides with his wife to help students write and work through literature courses, and engage other areas of English studies during his time working in Southeast Asia. He learned that the best kinds of guides were those that guided students to pass writing exams. Reflecting on this work, Jaidev says he essentially wrote textbook sections about oft-taught writing concepts such as rhetorical analysis and research synthesis. Jaidev read numerous texts to build these textbook sections and in the process discovered the St. Martin's Guide to Writing and Rhetoric and Composition as a larger disciplinary area.

Jaidev: These essays were introducing the discipline to us, but the St. Martin's Guide was basically introducing a systematic approach to teaching and learning how to write, which we had never been doing. [After this, Jaidev started teaching writing courses in Southeastern Asia.] Jaidev: I volunteered based on [student] interests. I would go study the books and teach them. Because teachers were just transcribing, translating, summarizing the books, anyway, for ages. Because the discipline itself was created somewhere and 
we were adopting it. In fact, it was easier to teach writing studies because it was easier to translate. And that's when I had a moment of epiphany. I'm like, “OK, I can get this." It is not about a particular society, it is easier to transfer and translate. This is a discipline I'd like to pursue. So I was literally entering the door of the discipline while teaching, which is a shame that I was teaching it. But I don't think I was the worst teacher there. While studying composition textbooks, and when I came to [PhD-granting institution state], the first thing I did was find out that was $60,80,90$ other kind of types of textbooks.

You know what? I went into the basement of the composition program where there's a whole big truckload of books, and I took a sample back to the writing center. Sometimes I stayed there because I didn't want to take too many samples out of the room. And I read composition textbooks for six months when I came here.

Through reflection, Jaidev found his way to the discipline and his $\mathrm{PhD}$ program. Once there, he took advantage of the spaces within and took the initiative to read textbook resources available to him. Of the 21 participants in this project, Jaidev is the only one who described this kind of self-motivated journey into the discipline and graduate study, through textual mentors he pursued knowing they might be helpful after his prior experiences with the genre. As many of the participants in this study indicate, however, our backgrounds offer us alternative perspectives for navigating the expectations of graduate study and jobs in the field (all of my alumni participants currently pursue careers in writing centers or as professors in writing, rhetoric, and composition programs). How might graduate student experiences differ if we began with the literacies 
students bring with them to programs as jumping off points for success in completing their degrees?

\section{Chapter Conclusions}

So what does the term "first-generation student" afford as a heuristic for thinking about a student's institutional position and relationship to the academy? For universities, this term designates a specific set of students who might need more resources and support. However, because of the complicated nature of defining who counts within the designation, resources and support services may not reach all students who might fit the term. Institutions can do more work to develop outreach and awareness programs to help students learn more about what it might mean to identify as a "first-generation student" with attention to intersectional identities and varied cultural and class experiences.

The 12 excerpts of participant stories in this chapter highlight and move beyond three common myths associated with first-generation students regarding their finances, families, and relationships to the institution. In the first myth, I emphasized existing scholarship to highlight that first-generation students, students of color, and workingclass students are not the same students, despite a common misunderstanding that occurs from these terms being used synonymously or alongside one another across much scholarship about first-generation students. However, as several participants describe, many first-generation students learn to pass in middle-class academic settings through dress and appearance choices. Next, I described the different kinds of interactions among first-generation students and their family members toward emphasizing the ways in which parents and other family members are helpful despite typically not knowing college systems or having the same educational and cultural capital as the parents or 
family members of continuing-generation students. However, the lack of educational and cultural capital creates pressures for first-generation students when it comes to communicating facets of what their work entails. Finally, in the third myth I explore in this chapter, I demonstrate that being the first in their families to obtain a college degree is not the root of all challenges for all first-generation students. This background, however, comes with a steeper learning-curve when navigating educational systems. While shared pressures exist among first-generation-to-college doctoral students such as the three highlighted in this chapter, these are only one part of larger, complex identity negotiations.

Further, these stories have several implications for educators. This research further supports Gardner and Holley's (2011) call for guidance and more professional development for educators to both understand and respond to first-generation student needs (p. 88). Educators across levels beginning as early as high school can do more to integrate discussions of financial aid and college enculturation as part of curricula toward college preparation. Additionally, educators can do more to share and show common challenges students face towards helping students, particularly from underrepresented populations, recognize that what they are going through and/or challenged by does not mean they do not belong. Though resources like the McNair Scholars program are in place to support first-generation-to-college students, the 21 participants in this study show that these were largely misunderstood or absent in their own experiences. Since a first-generation status is not a physical trait and depends very much on family background, it can be challenging for students who fit this designation to self-identify, and if they do, they might not know how to proceed. Educators can do more to build in resources about navigating college broadly such as successfully completing a college 
course earlier to better prepare students about what to expect and how to complete their college degrees, and if they choose, graduate education towards careers in their chosen disciplines.

For the students within this designation, the associations with being a "firstgeneration" student remain complicated but offer a way to understand their educational experiences. As participant stories in this chapter illustrate, first-generation student status comes in conjunction with many other facets of their intersectional identities. In Chapter 4, I point to many moments when participants highlighted their background as an asset for them, particularly as teachers as they connect with their students through shared lived experiences. As institutions continue to design programs for underrepresented populations including and beyond first-generation students, we must consider who counts or matters within our understanding of the terms we use to classify groups.

I want to conclude this section with a few words from Zeke who, near the conclusion of our conversation, chatted with me about whether "first-generation" is still the best term to acknowledge our experiences:

Ashanka: Do you have anything to add about your perspective as a first gen or anything that you think, maybe like a question maybe you wish I'd asked or, or even questions for me, I'm super welcome to them.

Zeke: I guess it's the terminology, and like we just said a while ago, maybe first gen isn't... maybe there needs to be like a slash or some further like fleshing out because I would've never thought of myself, like I said, first gen and it seems like other people had sort of come out to you that way too. I wonder if there is just another way to frame it. Not that you have to get rid of first gen, but I wonder what, like.... Yeah, I guess that's where that metaphor and the listing roles come 
into play too. I see where you're going with that. Trying to sort of figure out like a common lexicon amongst us all, in certain capacities.

Perhaps we can consider "first-generation student," as he put it, "a common lexicon amongst us all, in certain capacities" while recognizing that we must attend to intersectionality when addressing the needs of this population. 


\section{CHAPTER FOUR \\ EMPOWERING EMPATHETIC RELATIONSHIPS: FIRST-GENERATION STUDENT EXPERIENCES AS AN ASSET FOR PROFESSIONAL LIVES IN RHETORIC AND COMPOSITION}

"What has become apparent to me the more I teach is that our lives are so intertwined in our learning that whatever we do in the classroom both as teachers and students has some reference, no matter how small, to an individual's lived experience." - Morris Young (2001), p. 312.

As is the case with many first-generation-to-college academics, the culture and values within which I was raised do not mirror those of the academy. However, my upbringing and experiences serve as tools to navigate academic spaces. While I cannot speak for all first-generation experiences, I will offer a brief narrative of my own to illustrate some of the key differences in my upbringing and the values of academia. Although my parents wanted to have an educated daughter, they also wanted to raise me to be their good Indian daughter. In the introduction to Good Girls Marry Doctors, an edited collection of essays written by and about South Asian American women about their experiences navigating, rebelling, and/or disobeying cultural expectations of South Asian upbringings, Piyali Bhattacharya sums up the typical prospects for "good" South Asian girls: 
Success is a funny thing for us Good Girls. Most of us have been schooled by our parents and communities since we were children not only to strive for but also to desire a certain kind of life; academic rigor, followed by a well-respected job, but within a career which might allow us to stay at home and raise our children once we marry a hard-working, respectful, and high-earning Desi man. [...] It is on the shoulders of Good Girls to carry forward cultural legacies. (p. vi)

Along with gaining academic literacies, I regularly learned household literacies, ones my traditionally-minded parents knew would make me a good marital candidate when my time came. My mother grew up with (and still follows) the understanding that women should serve their men, that our job is to get married, have children, and support our families. I completely disagree with my mom on this view and began rebelling early on, arguing that women should be treated as equals and could do anything men could do. For years, my mom and I have argued whenever the topic of doing chores, especially dishes, comes up in our household; whenever my brother offers to do dishes, he's immediately told not to worry about it and sit down; I am expected to do dishes because I am a woman.

Like the many South Asian women in Bhattacharya's collection, getting our education opened our eyes to feminist ideals that often make it difficult to fit in with our families. An oft-noted challenge for first-generation college students is feeling "separated from their families and communities when they returned home" (Gardner \& Holley, 2011, p. 85). For me, this extends to my cultural expectations. For one, I married an American man—during my second year of my $\mathrm{PhD}$ program—out of love rather than having an arranged marriage, partially a product of growing up with American values and society. This relationship presented many challenges for my family who expected me to 
follow the arranged marriage custom. For instance, my parents dissuaded me from the idea of dating in middle and high school; we didn't talk about it. I met my husband in college; the distance from my parents allowed me to determine my personal relationships more wholeheartedly and telling my mom about my choice to begin dating felt less daunting over the phone.

And second, at family gatherings, other married women in my age group occasionally talk about their studies or past schooling and jobs; however, it becomes clear that they gave up these past careers after marriage. While my extended family expresses pride in my pursuing a $\mathrm{PhD}$ and working as a teacher, it often comes as a shock to most family members that I continue to do this even after marriage. In the midst of preparing to move to a new city and beginning my $\mathrm{PhD}$ program, I got engaged. Among the many expected questions that come following an engagement—when is the wedding? Where will you live after? Do you want children? My Nani Ma (mom's mom) asked whether we would survive on my fiancé's income. Our conversation, originally in Hindi, went like this:

"We'll have my income too. I'll be in a PhD program, but I'll get paid to teach and through an assistantship, like a scholarship. We'll be fine," I assured her.

“What do you mean? You can't be in school and be married. You have to stay home and take care of your husband," she said without missing a beat.

I stared at her, stunned. How could Nani Ma seriously think that getting engaged meant I would give up my academic goals? My mother came to the rescue:

"She's staying in school. A marriage won't disrupt her education. She can take care of him and get a PhD." 
Nani Ma shook her head. "That's impossible. She has to stay at home and take care of the house and her husband. She can't do both. She won't have time."

I knew my choice to break my family's tradition of arranged marriage especially with a white, American man would create challenges for my Nani Ma who came from a more traditional Indian upbringing than my mom; yet, I found myself speechless at the notion that I couldn't pursue both my education and marriage at the same time. I felt frustrated also by my mom's response expecting me to "take care of" my future husband. Aside, my mom told me that I needed to remember that Nani Ma grew up in a more conservative country and that, around her, I might need to mention my studies less in conversation and focus more on my household activities. Around Nani Ma, I more actively take on household duties like cooking and cleaning to keep her respect. These rhetorical choices to suppress my feminist values for my family act like a set of masks, or aprons in this case, I wear at home similarly to masks many scholars wear when navigating "imposter syndrome" or "feeling[s] that one's ability is not sufficient to warrant one's position" in academia (Hamilton p. 2-3; see also Boehm \& Lueck, 2016; Gardner \& Holley, 2011; Kniffin, 2007; Okawa, 2002). Traditional dress, oven mitts, and wedding jewelry function rhetorically as parts of my "good Indian-American daughter" persona like cardigans and dress pants enact my "teacher" one.

In academic settings, I also put on a critical thinking lens and find myself getting lost in stacks of books rather than dishes. I move between these spaces relatively seamlessly today as an adult, Indian-American daughter and teacher-scholar in Rhetoric and Composition. However, I continue to challenge the norms of what it means to be a "good girl" in the culture I was raised and a "teacher-scholar" in academia through my own existence as a person of color and a first-generation student in academia. I grew up 
learning how to improvise through social situations across languages and cultures; and how to complete required documents and materials to gain access to many different spaces. I navigate these movements across my personal and professional spaces using concepts and attributes I learned from growing up in a working-class household to immigrant parents who taught me how to value each and every opportunity I am afforded and give everything my best attention and attempt knowing that nothing is guaranteed. These are the skills and concepts I take and ask of my students, seek in my writing partners and collaborators, and offer in return to my academic pursuits. My relationship to the academy comes with a determination to think outside the box of all the spaces I enter where I continually shape and re-shape my understandings to meet the communities I am part of while, in return, (re)shaping them.

In this chapter, I explore how the first-generation-to-college doctoral student and recent alumni participants understand their place in the academy. To do this, I offer an analysis of portions of interview conversations discussing responses to a writing prompt asking study participants to list professional and personal roles they see themselves filling. I analyze both the lists of roles and our conversations about the lists together alongside other contextual or relevant pieces of our conversations. After offering more context on my approach to engaging participants with these writing prompts as well as some brief discussion about relevant trends, I analyze responses to two types of roles participants regularly associated with their professional selves: TEACHER roles and MENTOR roles. While participants listed and spoke at length about familial roles, I spend less time analyzing these directly in this chapter as they vary across a broad spectrum of types of familial roles for each participant. For instance, several participants identified themselves as FATHER, MOTHER, SON, DAUGHTER, SISTER, and/or 
BROTHER indicating a position within their family, but these roles connect less to their conception of their relationship to the academy. Of course, these familial roles inform the values and worldviews first-generation-to-college students bring to the academy as I've described in the opening narrative to this chapter, and they reflect how participants understand their place in the academy. After discussing the trends and how they align or are in tension with other aspects of participant stories and experiences, I analyze one final role typically in tension for most participants: WRITER, a role often left out of lists or one many participants felt conflicted with despite working in a discipline that studies writing.

Too often, when scholars write about first-generation students, they often frame this writing around "challenges," "barriers," and "struggles" that first-generation-tocollege students face (Gardner, 2013; Gardner \& Holley, 2011; Stephens \& Townsend, 2019). Many scholars writing about first-generation students use these terms, though their goals for doing so are different than mine in writing this dissertation. For instance, Gardner and Holley (2011) focus on factors that tend to relegate first-generation students to an "at-risk" population, emphasizing the degree to which these traits negatively impact their experiences (p. 77). While challenges are a reality for the majority of this population, we should also consider what being first-generation can afford students and professionals alike in order to highlight the many valuable parts of this identity. Rather than seeing a first-generation background as leading to entering academic spaces with a deficit or hindrance, we can do better to frame the benefits that come from this background and the ways it influences how first-generation students engage in the academy. Participant stories reflected in this dissertation, of course, do include many of the challenges that coming from a first-generation background brings (see Chapter 3); 
however, in this chapter, I would like to focus on the impact of this background on firstgeneration-to-college students as professionals in Rhetoric and Composition, particularly in their roles as teachers and mentors.

\section{Data Collection and Analysis}

During interviews, I asked all participants to respond to two writing prompts given to them during the conversation. Because of the nature of using digital communication tools such as Skype or Google Voice, I chose to have participants engage these prompts through a Google Doc so we could both easily access and see the document together. I stayed relatively consistent in how I asked participants to participate in the prompt. I copy/pasted the same language at the top of each Google Doc_- "Make a list. What professional and personal roles do you see yourself filling?"- and told participants they were welcome to use the bullet point tool to make a straightforward list or they could play with any other tools of their choosing and "break the doc," my way of telling participants they were welcome to make a list in any form they chose. Some participants broke the prompt down into "professional roles" and "personal roles" and made two lists, but for the most part, participants made a single list with varying levels of specificity or explanation within their lists. While participants were told they were welcome to take as long as they needed to respond to the prompt, on average, this took 10-20 minutes. Though this was not intentional and a response to time or schedule constraints, half of the participants completed the writing prompt in the moment during our conversation and the other half were given the prompt and asked to complete it prior to a second-session when we focused on discussing their responses. 
Deeply embedded in our conversations is the context of the academy. I operate in spaces of academia as did all of my participants. Even though many interviews were conducted over Skype or Google Voice, most participants and I were typically in their campus or home offices surrounded by books or other signifiers of learning and academic work. In-person interviews were always conducted in libraries, meeting rooms, or campus offices as well. Occupying and speaking in spaces of learning, scholarly discourse, and the nature of the study are reflected in many conversations. In fact, in our conversations, the professional academic context often crowded out the personal. For instance, when participants were asked to write these lists of "professional and personal roles they felt they occupied," many wrote entirely professionally grounded roles. When I asked about the types of roles they listed, some would comment that because of the context of our conversation, they assumed that I was looking for professional roles and had forgotten or overlooked the personal ask in the prompt despite identifying that the personal roles were often more significant to them in the grand scheme of things. While these roles can, of course, blend together, I recognize, as Pat Thomson and Barbara Kamler (2016) do when describing the use of an academic "I" rather than a personal one when writing for an academic context, that we inflect our identities differently in response to varying rhetorical situations; in other words, "the 'I' who writes an academic article is not the same 'I' who makes dinner, picks the kids up after school, goes shopping, and chats with their friends on Facebook" (p. 151). When engaging participants in this writing prompt, I expected everyone would list more than one role knowing the constellating nature of identity.

It was only in response to specific questions about their lives before graduate study or about what they did outside of academic work when participants began to 
engage other parts of their identities outside of academic positions. Regardless of whether a participant was a faculty member or graduate student at the time of our conversation, each person told me about themselves though different aspects of their identities rather than focusing entirely on their job descriptions. Perhaps the responses within conversations mirrored the one-on-one nature of conversations or simply their comfort level with me as a colleague and peer in the discipline. Regardless, the choices to naturally focus on the professional over the personal without specific probing should be taken into account when considering the analysis of participant stories.

Figures 1 and 2 below offer visualizations of the primary dataset used within this chapter. Figure 1 is a word cloud created using the root terms in each participant list to illustrate the kinds of professional and personal roles that came up; in other words, participants who offered more explanatory sentence-length responses were refined to a keyword (teacher, writer, researcher, etc.) for the purposes of generating this visual. I also removed more identifying roles particularly specific to a participant such as "teacher of a [class title]" or "member of [specific-to-participant group]." While these roles are also significant, to retain participant anonymity, I chose to remove this level of specificity. 


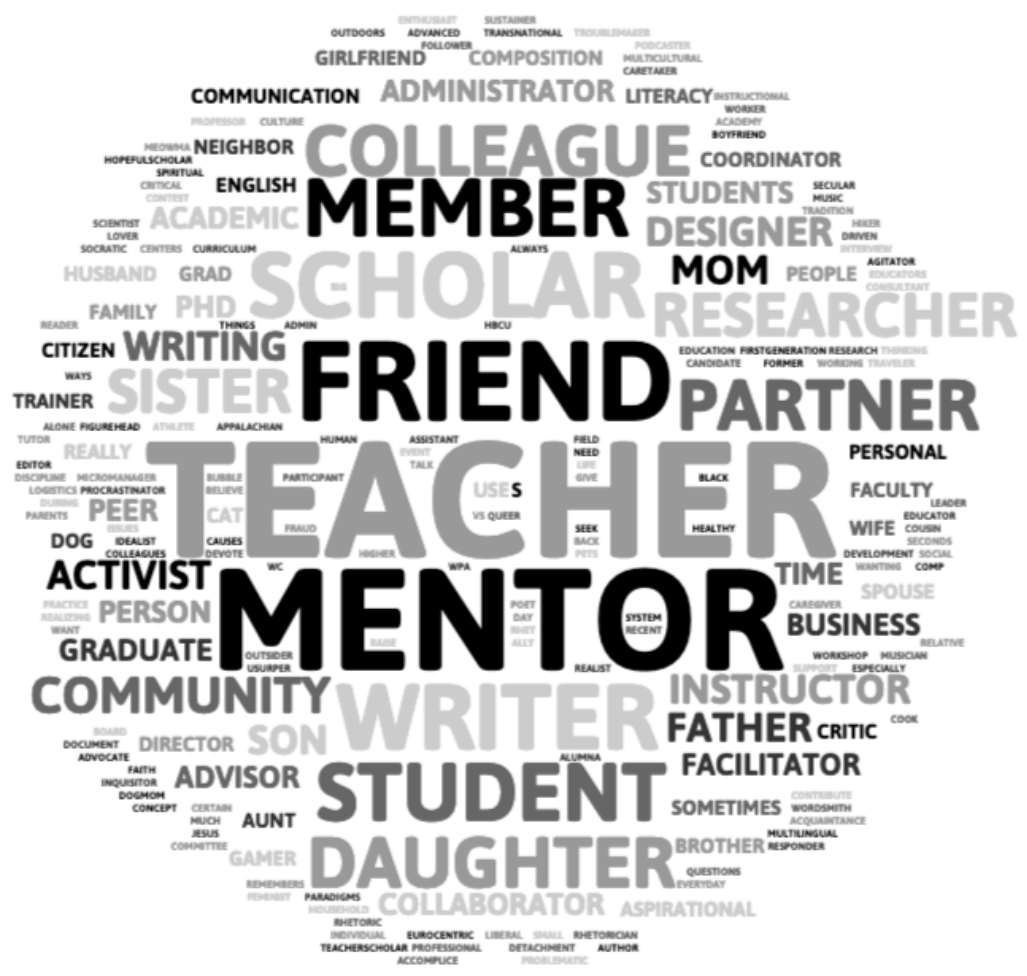

Figure 1: A word cloud visualizing all of the roles participants listed. The size of each word reflects the frequency the role appeared across lists.

Figure 2 is a bar chart that features the 10 most frequently listed roles and the percentage of participants who listed each role across the 21 participants in this study.

For instance, FRIEND was listed by $52 \%$ of participants (or 11 out of 21 ). 


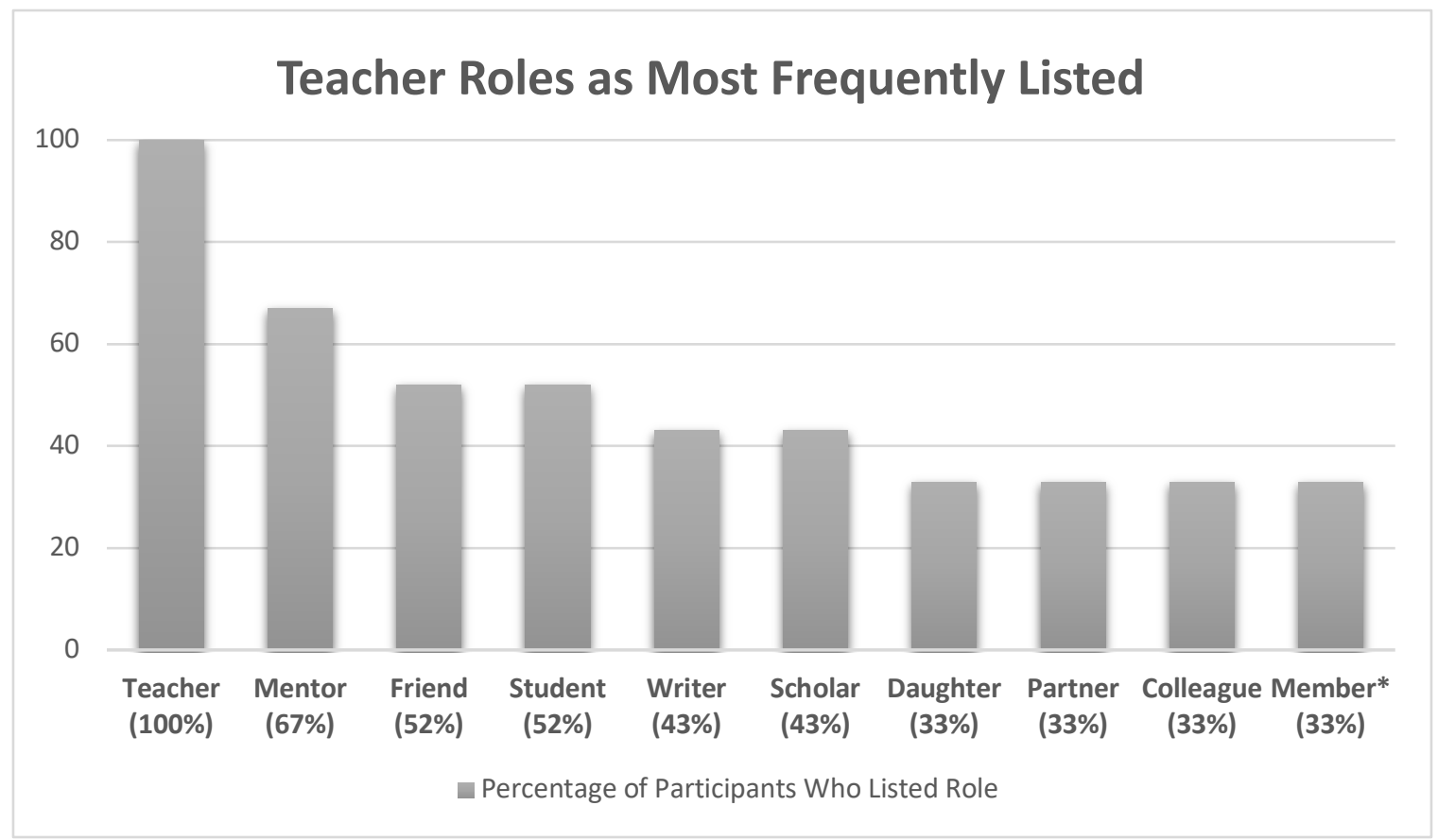

Figure 2 A bar chart showing the 10 most frequently listed roles across 21 participants.

As this visual and chart show, the roles TEACHER (100\%) and MENTOR (67\%) appeared most frequently among lists followed by STUDENT (52\%), FRIEND (52\%), SCHOLAR (43\%), and WRITER (43\%). The terms DAUGHTER (33\%), PARTNER (33\%), COLLEAGUE (33\%), and different kinds of MEMBER* $(33 \%)$ roles (i.e. Community Mentor, Member of Discipline, Board Member) appeared the next most frequently. Specifically, all 21 participants (100\%) listed TEACHER or a similar role (educator, instructor) within their list(s). Additionally, two thirds of participants (67\%) listed MENTOR. With the exception of FRIEND, the most frequent roles lend themselves to a traditionally professional connotation reflecting, as many participants noted, the time spent engaging their professional work versus their personal lives as often becomes a trend of an academic work schedule that is not framed within an 8 to 5 
schedule as is common with most professions. A few participants noted the timeflexibility that comes with an academic work schedule as one key reason for pursuing a career in this field. Diane summarizes a common feeling among some participants when she says "I need[ed] a mix of autonomy and support, and flexible scheduling, and writing. And I was like, OK, what matches that? Academia. That was really my motivation above anything else." This autonomy that comes with self-driven, selfmotivated academic work meets many participants' desire to control their pursuits as much as possible while also choosing when and how they engage in their work.

The most listed professional roles also align with many of the goals of Rhetoric and Composition, a discipline that, in terms of traditional careers, emphasizes teaching writing. However, it is notable that no participants listed RHETOR, RHETORICIAN, COMPOSITIONIST or anything related to this area of focus within the discipline despite this work playing a significant role in the discipline itself. In what follows, I focus on participant descriptions of their alignment with TEACHER roles, one most participants lauded as where they feel most comfortable and valuable as Rhetoric and Composition professionals. On the other hand, MENTOR roles were prominently listed by those occupying faculty positions or more senior doctoral candidates, perhaps reflecting their own experiences taking on mentoring positions within their job descriptions.

\section{TEACHER Roles}

As first-generation-to-college students themselves, most participants pointed to this quality of their identities as one that helps them connect to students in their classes especially in moments of distress or struggle. For the most part, these conversations focused around experiences working with undergraduate students since most participants 
chose to focus on these classroom experiences in particular or simply had not taught (m)any graduate seminars at this stage in their careers. Kevin Roozen et al. (2015), in their observations of three teachers' identities informing their pedagogical practices, argue that "as much as students' histories with literacy beyond school can enrich classroom learning — teachers' histories can likewise play a crucial role in shaping pedagogical practices in ways that can reconfigure student learning" (p. 206). Participants noted numerous past experiences that shape the way they approach students in their classes such that they can relate to students' own motivations and frustrations. For instance, Peter, a white man who was in the early stages of his $\mathrm{PhD}$ program at the time of our conversation, describes a moment of recognizing student issues with work-life balance during an in-class writing prompt at an institution with a heavily working-class undergraduate student population:

Ashanka: Do you ever share stuff about your background with your students?

Peter: I do, yeah. [... describes in-class activity where he had students, in a shared in a shared Google Doc displayed on the main classroom projector, list everything that bothers them] A lot of their issues were about workload, work/life balance, managing their jobs and like professors giving them too much stuff. And attending to that has shaped my pedagogy a lot because I remember working parttime in construction and driving a fork-lift at [company name] and putting stuff in boxes at [different company name] and all this stuff when I was an undergrad student. And remembering that predicament is why I send an email after every class with all the links they need because it's annoying to chase up all this information and look at the syllabus and get involved. I can send them an email and it's cool. And asking about the workload, how it's going, is it too much or too 
little, when is a good time to have a draft ready? Is that enough time? [...]

because I always wanted teachers that did that.

Peter's pedagogy continues to be informed by his own background. His foresight to ask his students to tell him about anything bothering them and taking time out of class to do so reflects, as he notes, a desire for his own teachers to check in on him from time to time. In the next part of Peter's response to my question, he describes what happened during the discussion of student responses to his prompt:

Peter: [describes in-class discussion with students after they listed things that bothered them] I said, "I remember having those exact same complaints and that's why I do x, y, z." And it was really nice because they saw that I was doing those things. Maybe there were complaints about my class they didn't want to share with me, fine, but by and large, they were noticing that this was responsive to them and open to them. And I think they would have told me if something wasn't going right and to me it was a nod that this is a valuable way to teach students and they are recognizing it and seeing that you're being kind of decent.

Here, Peter describes how his own experiences prompt him to not only ask students how they are doing, but also take specific approaches to how he engages with students outside of in-class hours by sending reminder emails that include helpful links to navigate the class and get involved in the university. Finally, Peter describes this activity of asking students to respond to a prompt about what bothered them led to humanizing connections between his own experiences and his students' that allowed him to continue to foster honest, empathetic dialogue:

Peter: And they had questions like "When did you do undergrad, and did you have a job too?" And I was like "Shit yeah. I worked 30, 40, hours a week.” [...] 
And I told them like "I kind of freaked out and dropped out of school and started traveling and working [at job] and doing all these other kinds of things. [...] And they were just like "Woah, what? That's so cool!" Totally not the intention, but they were just curious about how I did it. But that meant I was always working a lot to do all these things cause I was living on a budget wanting to do all these other things. Ended up being a great chat that opened up a lot of other good chats. While I am not necessarily advocating that all teachers should share intimate details about their lives and experiences, Peter describes sharing these small pieces of his own work experiences as ones that helped students see more than the body and authority figure at the front of the classroom, but rather, a multifaceted person who has a similar working-class background to many of the students in the room and cares for students. Further, as bell hooks (1994) warns in Teaching to Transgress, "professors who expect students to share confessional narratives but who are themselves unwilling to share are exercising power in a manner that could be coercive" (p. 21). Peter's choice to share pieces of his own story, along with that of many participants in this study, not only allows for connections with students' experiences, but also fosters a pedagogy that engages reciprocity in communication and learning. Donna Dunbar-Odom (2007) further describes the impact of sharing our stories and experiences as a way for those we share with to begin to make sense of their own positions and worlds (see also LeCourt, 2004; Rose, 1989; Sullivan, 1998). Stories continually “[work] on us, and we, in turn, are working on them, trying on different ways of being in the world and different ways of understanding the world around us" (p. 111). Likewise, as I share my own stories in this dissertation or participants share their stories with me, we reflect and gain new perspectives on how to read our own experiences. 
Roozen et al. (2015) similarly note the impact of the "laminated trajectories of practices and identities that teachers bring to school" as "deserv[ing] close attention" and operating as "a key resource for pedagogies that create classroom spaces in which students are invited and encouraged to weave together multiple, seemingly disparate voices, and practices from their repertoires" (p. 213). In this case, Peter could connect to the "issues" that students listed in response to the writing prompt and offer solutions in his own classroom to help students thrive in that space. Tina, additionally, describes her background affording her insight into the impact of her own first-generation experiences relating to students at the Northeastern institution where she teaches:

Ashanka: What about with your students? What aspects, if any, of your background do you share with your students, the ones you teach?

Tina: All of it. All of it. They love it. They love it. It's one of the reasons I wanted to be here because most of the students here are poor. Most of the students here are first-generation, so I feel like it's one of the main reasons why I fit in well where I'm at, even though I'm not from [northeastern state] and it's been a culture shock for me. I feel like my students really, really respond when I talk about my background, and I talk about it often.

Tina's understanding of her own background gives her insight into the kind of "culture shock" university spaces often are for first-generation students. Notably, as composition teachers, we are in unique positions to help students navigate their experiences as they continue to evolve and grow as writers and professionals. Our typically small class sizes, as well as the fact that non-majors in our classrooms usually take our classes to meet general education requirements, allow us to form personal connections with an array of students across disciplines. Our classrooms cultivate opportunities for students to share 
their experiences through dialogue and writing as they grapple with course materials and their own lives both in and outside the university. What if we extended this kind of space to other spaces at the university?

Along with Peter's and Tina's descriptions of engaging their first-generation backgrounds within their pedagogy, Ashley, Carter, Charlie, and Elliott additionally noted sharing facets of their backgrounds and first-generation experiences with students they teach, but they each also specified this choice often being a response to the population of students they were teaching. For instance, Carter describes sharing more with students at his current institution where the student population includes a larger group of first-generation-to-college and working-class students than he did at his $\mathrm{PhD}$ granting institution where the student population was starkly more middle-class. Sometimes, choosing whether or not to disclose reflects attempts at managing the way one is perceived. In this case, this decision whether or not to disclose can be a result of the broader perception of a first-generation and/or working-class background as "less than" another. Tara Wood (2017) describes this phenomenon through the idea of “impression management," a term sociologists Miall and Herman (1994) define as "selfpresentation and/or public display of identities created through the management of personal information" (p. 208 qtd. in Wood [2017], p. 85). While Wood's chapter focuses on disclosure in regard to disability in particular where disclosing one's disability further operates as a form of risk management, she acknowledges that "we might characterize all students (disabled and nondisabled alike) as consistently managing the impressions they put forward" (p. 85). The choice to disclose facets of our identities is shaped by numerous factors. 
While several participants described sharing their backgrounds with students especially at institutions where undergraduate populations are heavily working-class and/or first-generation, most did not feel the same about sharing their backgrounds with their peers or faculty. They cited numerous reasons, from not feeling their backgrounds mattered in scenarios with their peers or faculty, not wanting to reveal their firstgeneration and/or working-class backgrounds, or not feeling welcome to share their stories. Of course, in all kinds of contexts, people may think that their experiences may not be shared with their peers, and they may feel hesitant to disclose any number of aspects of themselves, not just those related to education or class status. Tina, for instance, feels her first-generation background was not as valuable as her experiences working in industry. Additionally, these feelings are part of her ongoing imposter syndrome as an academic coming from a working-class and/or first-generation background:

Ashanka: So what aspects, if any, of your background, such as your firstgeneration, your working-class background, other aspects of your identity, did you share or not share with faculty or other graduate students?

Tina: I didn't really share a whole lot of it at first because [...] I didn't really see it as an asset, except I did see my work in writing scenarios and in industry as an asset. I think I saw my industry work as too much of an asset at first, because I kind of had this mentality of $[\ldots]$ work in the industry as almost making me over qualified for the academy. I kind of had the attitude, and I don't have this at all anymore, but I had this kind of almost efficiency attitude that's grilled into you in corporate, which is people who can do, do, and people who can't do, teach. Or like if you can't really make it in the industry or in the outside world, you're in the 
academy. [...] I think that now I'm fully immersed in the academy and I have almost the opposite view of what an incredibly privileged wonderful life choice and career, and I feel really lucky. [...] I've seen both sides of the coin, I guess. Personally because of my working-class background and I think in a way it's made me value the academy more, and I'm pretty open about it now. I feel much more intimidated now as a faculty member about my background than I did as a graduate student because I feel like part of why [PhD-granting institution] wanted me was because of my background. I think they valued that diversity, and in terms of age and background. And, I think I've really struggled with this as a faculty member. [...] So, I think that everybody faces imposter syndrome, but I think especially women do and especially working-class people ... Just based on my own experience I think it's huge. I think it's a big thing that we don't often talk about. And, I still fight it to this day.

Here, Tina echoes Zeke's sentiments in Chapter 3 who indicated their background helping them value their academic work in ways that peers who don't share their firstgeneration and/or working-class experiences don't value academic work. Further, Tina's industry experiences impact her attitude toward academic work as well, as she describes initially feeling she was "over qualified." Tina's story presents another way to consider the literacies graduate students bring with them to graduate programs-Tina is a nontraditional student in the sense that she returned to get her $\mathrm{PhD}$ after spending years in another professional field. She brings many life and professional experiences to graduate school and, as she describes in Chapter 3, some of this leads to feeling alienated or less connected with her typically younger peers. 
Additionally, some participants described a tension between their own professional understanding of their work versus that of their institution or department. Jack depicts this tension while talking through his understanding of my first writing prompt. For context, the conversation that follows began after I directed Jack to the writing prompt on Google Docs. After addressing a few questions he had about timing and the prompt, I told Jack that he was welcome to speak aloud as he wrote knowing that some writers, such as myself, process externally and he should feel welcome to process however he wants during the time. Here, Jack's initial thoughts show his tension with his TEACHER and RESEARCHER roles among other professional roles as a tenure-track faculty member at an R1 institution

Jack: Yeah. I don't know. I don't know how to term sort of what a role...I am like sort of...what role would just the kind of massive amounts of like...I guess I could just call it committee member. That's sort of a multiple...I feel like that sort of teacher/research is what I think of myself as, but I think the institution forces me to put the other first, for the most part. I think if I were somewhere else it would not maybe be the case, but I'm not sure.

Ashanka: So, to clarify, you're saying that you see yourself as a TEACHER/RESEARCHER, but the university would probably say you're a researcher first?

Jack: Yeah. For sure. I think even more than that... yeah. The university definitely... I am human capital and primarily for whatever sort of research capital that I can bring to the university. I think even more than that it's risky to define myself as a TEACHER/RESEARCHER even among my own colleagues in my department. It is a politically sort of charged label, and I think there's a strict 
hierarchy, at least here, between graduate and undergraduate sort of education. And so when I say TEACHER/RESEARCHER, I think I even more closely identify with undergraduate teacher.

Jack summarizes a common feeling among many participants, and academics across backgrounds, that research-labor is traditionally academic currency to move forward in their careers though their passion is more aligned with their teaching. The foundational Research-Teaching-Service tiering for progress in a tenure-track position does not place value on teaching over research, which creates frustration or tension for many participants and members of the discipline who find they spend more energy and time as teachers and like to work with students. The majority of participants, like Jack, described and listed TEACHER first above RESEARCHER or SCHOLAR, a role that was left out entirely in some cases. Participants often pointed to their RESEARCHER-selves as in flux and felt more grounded in TEACHER roles as professionals. This trend to list TEACHER above RESEARCHER or SCHOLAR presents an interesting pattern among the first-generation participants in this study. Future studies could explore whether this trend is consistent among other populations within Rhetoric and Composition. How do different populations value their roles as teachers compared to researchers?

These feelings about TEACHER versus RESEARCHER roles reflect an alignment with facets of participant identities and training in the discipline. Doctoral training in Rhetoric and Composition generally includes a large focus on teacher training in the form of seminars and numerous classroom experiences through assistantships funding doctoral degrees. Alternatively—and arguably—-the majority of participants in this study indicated that their doctoral training in Rhetoric and Composition features (and, for alumni, featured) less training towards producing and publishing research that 
would meet the demands of the oft-lauded tenure-track career goal. In other words, these programs emphasized teacher-training through their graduate program requirements and offering classroom experiences as part of graduate stipends, but participants typically were/are not given the same kind of field experience for research. With the exception of fellowships or similar competitive programs where students are given a leave from teaching and/or administrative work with the idea that they will focus their time on producing and publishing research, the two institutions where the 21 participants in this study did their graduate study did not seem to emphasize research in the same vain as teaching. However, a few participants did note the existence of publishing-focused classes designed to give students space to revise seminar papers for publication or research assistantships that led to collaborative publications with faculty.

I argue further that these notions align well with Burgess and Ivanic's (2010) five facets of WRITER identities that operate on varying timescales. While they do not focus on TEACHER or RESEARCHER identities, their concepts remain applicable and offer one way of thinking about participant responses to this writing prompt about their professional and personal roles. Roles do not equate to identities, but they often align with pieces of one's identity; for instance, when many participants list TEACHER as a role, their particular TEACHER role aligns with values informing their own identities as professionals in Rhetoric and Composition and what being a teacher means within their own particular structures. No two TEACHER roles, like no two people, are entirely identical. Burgess and Ivanic's model highlights these five facets of identity (2010, p. 236-241) defined as follows:

1. Socially available possibilities for selfhood - what or who a person can be based on discourses within the contexts in which one is writing; 
2. the autobiographical self of the writer - what values, beliefs, positions a writer brings with them to the act of writing;

3. the discoursal self - The self that is inscribed in a text;

4. the authorial self - The presence a writer creates of themselves within their writing; and,

5. the perceived writer - The impression of a writer a reader creates when engaging with their writing.

Here, I would like to apply these to facets of TEACHER identity to show the impact of disciplinary discourses and values in how participants in my study perceive their TEACHER roles. Jack's and Tina's responses describe different “socially available possibilities" that then dictate how they identify themselves in TEACHER roles alongside professional work in Rhetoric and Composition. Jack notes the prevalence of a RESEARCHER role over his TEACHER role as what his institution, the social space in which he operates as a professional, values and primarily bases upward mobility in his career on. Though Tina similarly mentions this misalignment with institutional values with her own when describing content in her curriculum vitae during another part of our interview, she also notes that she "first and foremost see[s herself] as a TEACHER and as a MENTOR. The other work that [she does] just enhances that and is a sort of outgrowth of that in many ways." Their autobiographical selves remain grounded in discourses surrounding their training and experiences within Rhetoric and Composition. Since I did not focus on textual features, I cannot adapt Burgess and Ivanic literally to consider Jack's and Tina's discoursal and authorial selves; however, within our discussions of the roles they listed, these selves are influenced by their institution's perception of them as RESEARCHERS and SCHOLARS first, a kind of "human capital," as Jack describes. 
Some participants went further to break down what TEACHER as a role means to them. Jeff, a white man, part-time $\mathrm{PhD}$ student, and full-time writing instructor in a business school, says he has always identified as a teacher rather than a scholar or researcher. When listing roles, he composed two lists of roles: a professional and a personal one. The professional list began with and focused entirely on his TEACHER role, which he broke down to describing himself as an instructor of specific business writing courses and included his role as a $\mathrm{PhD}$ student as part of the professional development for his work as a teacher. This understanding of his STUDENT role reflects a shift in his status as a TEACHER at his PhD-granting institution. When we began our conversations, Jeff's instructor position was not permanent; however, over the weeks between parts of our conversation, Jeff was promoted to a permanent position as a business writing instructor at the same institution where he continues to earn his $\mathrm{PhD}$ part time. In our early conversations, Jeff said the $\mathrm{PhD}$ was never really... it wasn't a goal. Maybe this fits into the first-generation, or the working-class part of it, to me the $\mathrm{PhD}$ is primarily about job security for me and being able to be at [PhD-granting-institution] because I live in [place] where the university is, that's what everybody does. [...] That doesn't mean that I'm resistant to it or feel like I'm doing it because I have to; I'm genuinely interested. And I'm sure my perceptions will shift a little bit when I get the PhD. After being promoted, Jeff highlighted that the $\mathrm{PhD}$ continues to serve as a point of "professional development, job security" for him that, while not required for his permanent position, he feels his pursuit of helped him secure the position and shows a "certain dedication... [...] I think that seeing that I was in the PhD program made me, I don't know, I can't help but think that it had some kind of indicator of my interest in 
staying on [as an instructor]." Likewise, many participants felt the $\mathrm{PhD}$ would afford them job security to continue teaching in tenurable or permanent positions at the college level and move past more significant financial challenges as some might have experienced growing up.

Overall, TEACHER roles as the first-generation-to-college Rhetoric and Composition doctoral students and recent $\mathrm{PhD}$ participants in this study describe are a primary motivator for their work in the field. As we train writing teachers, we should engage and value the upbringings and perspectives teachers bring with them into the classroom as we do the literacies students bring as they are often an asset for working with students especially at institutions with large first-generation and/or working-class student populations. Lived experiences first-generation-to-college writing teachers navigating academia and re-inventing the university throughout their education and careers offer unique perspectives and an empathetic response to considering the challenges undergraduate students might face.

\section{MENTOR roles}

MENTOR, in this study, appears as frequently as TEACHER on participant role lists, both of which are the most listed roles across all 21 participants. While TEACHER roles were often modified in writing or verbally described with specific courses or course levels such as "First Year Writing Teacher" or "English 101 Teacher," MENTOR roles were often modified with adjectives describing the kind of MENTOR participants saw themselves as. For instance, when listing MENTOR on my own role list as a participant, I modified it two different ways writing "ASPIRING MENTOR" and "PEER MENTOR." When considering my role as a MENTOR, I felt I could confidently identify as a PEER 
MENTOR based on experiences mentoring numerous peers over time; however, I felt there was a line between this kind of mentoring and mentoring students, something that I continue to develop an understanding of in my TEACHER and ADMINISTRATOR roles. In other words, because I have not yet progressed to faculty status, I feel my role as a MENTOR primarily functions within a peer-to-peer space rather than with students, though I do spend a fair amount of energy mentoring undergraduate students in my courses.

The modifying terms participants paired with MENTOR roles reflect the different and complex shapes that mentoring can take in the academy. For example, Nora lists a broader sense of her mentor role both in and outside of the university when she describes herself as a COMMUNITY MENTOR. An administrator, chair of an English department, and associate professor at a southern institution, Nora wears many hats. In addition to mentoring students, she feels this role extends to her personal leadership practices as a leader of an Ultimate Frisbee team in her local community. Nora is not the only participant to describe MENTOR roles connected with community leadership roles outside of the institution. Overall, Nora's expansive description of her MENTOR roles reflects different levels of commitment and attention to both her academic and nonacademic communities.

Before delving more deeply into participant responses about mentoring in academia, I want to briefly highlight some of the scholarship on forms of mentoring in the academy to present some of the issues and potential mentor roles for navigating academia scholars propose. Fugate, Jaramillo, \& Preuhs (2001) expand on what they describe as "traditional mentoring" by moving toward more peer-mentoring in their local political science graduate program, which they describe the benefits of in their article. 
Here, I offer their definition of "traditional mentoring" as a grounding point for thinking about what mentor roles historically look like: "traditional mentoring involves two players: the graduate student, who needs direction on which steps to take, and an advisor, who provides the direction" (p. 132). In their piece, like many contemporary scholars who write about mentoring, they argue that mentoring relationships can and should expand beyond this traditional model, advocating for fellow students or peers as "invaluable sources of information on how to successfully navigate the steps a faculty advisor directs students to take" (p. 132, see also Boehm \& Lueck, 2016).

In addition to peer mentorship at the local level, Vanhaitsma and Ceraso (2017), in their article focusing on mentoring feminist early-career academics, share a model of "horizontal mentoring," a form of mentoring "that is carried out within horizontal rather than hierarchical relationship[s] (between peers, as opposed to a more and less experienced mentor and mentee)" (p. 211). This differs from localized peer mentorship as it is focused more on creating relationships across institutions. Though this model focuses on early-career feminist academics, it is applicable for graduate students to similarly engage the seven-step model wherein they 1) choose a horizontal mentor, 2) hold regular skype sessions, 3) make lists and set goals, 4) exchange book project (in this case dissertation or thesis) writing, 5) discuss and reframe the concept of work-life balance, 6) acknowledge and celebrate successes (even small ones), and 7) develop a network or team to support us on our academic journeys. Like Fugate et al., (2000) and Boehm \& Lueck, (2016), Vanhaitsma and Ceraso stress that horizontal mentoring cannot and will not solve all problems but operates as an additional strategy to navigate the academy (see also Driscoll et al., 2009 for narrative from an autoethnographic study of five pre-tenured 
women faculty engaging in a similar style of peer/colleague mentoring across institutions).

A consensus among many scholars on mentoring is that a one-size-fits-all model of mentoring does not exist, and it is crucial to adapt strategies to meet different needs. Gail Y. Okawa (2002), for instance, through conversations with Geneva Smitherman and Victor Villanueva on the status of mentoring scholars of color, shows that "mentoring must become an activist practice" for scholars of color as "it is critical to the survival and success of graduate students and junior faculty of color in the academic culture, especially in fields like English that attempt to perpetuate the discourse of that culture, and especially at predominantly white institutions, which seem, and in some ways are, uninviting and unfriendly to those who have been historically underrepresented or absent" (p. 509). Okawa highlights that mentoring practices must be reciprocal between mentors and mentees such that it is "shared, reflective, and democratic" (p. 528). Overall, Okawa argues, through the stories she shares from Villanueva, Smitherman, and their mentees, that academic mentoring "can serve as a cultural and activist practice. Especially among scholars of color, the cultural terrain can be heavily political, the political aimed at achieving a more_or less_-socially just society” (p. 529, original emphasis).

The mentoring experiences of several of the first-generation-to-college participants in my study mirror many of the concepts of mentorship presented above. For instance, Ashley, a soon-to-be-newly minted $\mathrm{PhD}$ at the time of our conversation and now an assistant professor at a Western institution, describes her listing of ADVOCATE as one of the professional and personal roles she takes on connected to both her public advocacy work and how she perceives herself working for students. This understanding 
operates like the kind of activist work that mentoring can take as Okawa alludes. While Ashley didn't go into any specific examples of mentoring students, she described how her ADVOCATE role aligned with her ACTIVIST role in terms of the level of participation she takes with the populations within which she works. Ashley takes active steps to advocate for students similar to what she does in her community: she describes being "super active," speaking "on the phone every day with [her] congressperson" to advocate for change. Later in our conversation, Ashley remarked that she wanted to add CITIZEN as an additional role to reflect her advocacy and activism.

From another perspective, Pera, an assistant professor at a Mideastern institution at the time of our conversation, articulates specific kinds of MENTOR roles reciprocating the kinds of mentorship he found helpful and wants to continue to offer for future teacher-scholars. Among other concepts on his list, Pera wrote these three roles I characterize more specifically as different kinds of MENTOR roles:

- "To mentor and advise students about the job market as a mission and reward in this career"

- "To help students work through issues when they feel stuck"

- "To become a person and to help others understand that at the end of the day, it's not the doctoral degree that matters but your degree of humanity in how you relate and treat others, including things"

Pera elaborated further on these roles in our conversation, pointing to the first of these as one way he wants to reciprocate "the support that [he] got from other people. People were there for me, this is where I need to pass it forward.” This approach to mentoring students reflects the kind of "linear and cyclical" process of mentoring that Okawa describes as “intergenerational (handed 'down' and vertical) and inherited (in a sense, embodied) - 
even cross-culturally)" (p. 518). Pera wants to continue to foster a culture of job market mentoring that helped him thrive in and survive his own experience to help future scholars on the market. The remaining two MENTOR concepts on his list further echo the kind of active listening and support he strives to offer as a MENTOR:

I deliberately used the word 'issues' because for me, I don't feel like to be a good mentor, you can't be a good mentor if you don't get to know the person holistically [...] So I want to be someone that students can come to and work through their issues with, whether that's academic, whether that's personal. I'm not trained in psychology, but I mean I'm happy to be a listener and be a sounding board.

Pera's perception of himself as a mentor aligns with building on the positive parts of his experiences on the job market and navigating graduate study while striving to lessen any of the negative aspects such as burnout or isolation many graduate students face along the way.

Elliott, a lecturer at a Western institution, alternatively, describes himself as a PROBLEMATIC MENTOR, referring to the feeling of uncertainty about whether he is the best suited person to mentor students on particular topics. During our conversation, he described a mentoring relationship with an undergraduate student working on a social science research project:

In a lot of ways, I am introducing [the student] to social science and how it works and what it means to be a researcher and a scholar and how to think about doing those things. And then I think to myself about how much I suck at all those things. And I'm giving this advice and wondering to myself "am I really the kind of person that should be giving this advice?" 
Elliott's feelings about his MENTOR role as "problematic" reflects a tension with his professional training and some imposter syndrome with his perception of himself as a research expert. Though he describes numerous helpful mentors along his educational journey, he does not reference any formal training in mentorship. I argue that our field can do more to engage graduate students in thinking about these kinds of professional roles as part of our training so we can more confidently take on mentor roles. Rhetoric and Composition programs can do more to discuss mentoring relationships more candidly with graduate students as part of their professionalizing as not just future teachers and scholars, but also mentors to future undergraduate and graduate students as well as colleagues and peers, because this role will be inevitable in their future. Like most academic disciplines, we value research and teaching labor, but often administrative and mentoring labor does not get the same kind of attention when determining what is valued in tenure and promotion documents or training graduate students or early-career scholars. Mentor roles often fill gaps in one-on-one or small group settings that help navigate structures and systems while providing emotional support that formal training or programming such as a seminar or workshop might not cover and thus should be valued more highly alongside teaching and research labor.

As participant descriptions of MENTOR roles indicate, these roles take many shapes that work to meet varying demands and populations both in and out of academic settings. Each participants' approach to their MENTOR roles reflects what they found productive or unproductive in their own experiences. Many participants indicated deep investment in their mentoring relationships similar to how they approach their teaching. In fact, participants often listed or described MENTOR roles alongside TEACHER ones, signifying an alignment between these roles. Rhetoric and Composition graduate 
programs should incorporate more formalized mentorship training as part of teacher training. We can build on existing scholarly mentorship models alongside lived experiences to enrich and help develop teacher-scholars who are also more confident mentors.

\section{Another notable trend: WRITER}

Though TEACHER and MENTOR roles were most frequently listed on participant lists, in this section I want to briefly highlight another notable trend across descriptions of WRITER roles. All participants in this study are either current $\mathrm{PhD}$ students or recent alumni of Rhetoric and Composition programs, a discipline that focuses on writing teaching and research; however, a significant absence among the majority of participants came in identifying in WRITER roles. As a researcher, I came into this writing prompt with some expectations - I assumed people would list familial roles (PARENT, FATHER, MOTHER, SISTER, BROTHER, SON, DAUGHTER) as well as TEACHER, RESEARCHER, and WRITER, an understanding I had from the nature of people in general and the relationships we often identify with as members of Rhetoric and Composition. Though TEACHER and familial roles appeared frequently, I was struck by the number of times I didn't see WRITER roles appear; only 10 out of 21 participants listed WRITER either in their original lists or upon discussion. I often asked participants to think about absence in our discussions of their role lists and frequently brought up this absence of WRITER roles. It was not necessary, of course, for participants to list WRITER, but I want to acknowledge its significance for scholars in writing studies. 
When I brought up the absence of WRITER, in some cases, participants responded in surprise or clarification, like Elliott's response here:

Ashanka: I noticed you didn't write WRITER, which is one I'd almost expect from anyone in our field. Do you identify as a writer or do you lump it as a scholar or...?

Elliott: It's interesting that I didn't think about that! Of course I'm a writer, I write all the time. But to be honest with you, the writer part of my identity comes with the scholar part of my identity.

Elliott's response is characteristic of a handful of participants who felt their understanding of their WRITER roles was implied in their SCHOLAR or RESEARCHER identities. Charlie, Lance, and Sharon responded similarly when prompted about the absence, adding it to their lists during our discussion or clarifying it with their SCHOLAR or RESEARCHER role within their lists.

Kelly, alternatively, pointed to her confidence as a WRITER as one potential reason she may have left it off her original list, though she ultimately added it and POET to her final response.

Ashanka: I also noticed that when you described your dissertation, you said you were working on it, but the word WRITER is missing, or absent, it's not necessarily missing since we're not all comfortable with it.

Kelly: I can't believe I left that off!

Ashanka: You can add it. It's not too late.

Kelly: I would actually like to add that because honestly that is the huge internal thing I still don't talk about. And I'll add one more. WRITER and POET. These are things you dream about is like publishing a chapbook, publishing articles, 
publishing a book. That is ultimately what's behind all that. But I think honestly I know exactly— this anxiety and I are old friends. [laughter] I am not a confident person and for me to confidently come out and say "I am a writer" feels really pretentious still. Like I can work, and it's almost like I'm allowed. I also wonder if that's part of my cultural background that "real work" is not writing. "You can teach and that's work, you can mentor people and that's work, but you're not allowed to say that writing is work" even though, oh my gosh, it's so hard and so much work. It almost feels like a luxury to get to have that as an identity. And really it is. I am a writer. I have published poems. I have published articles. [...] And it's hugely important to who I am. I wrote my first poem when I was 8 years old and I've been writing ever since.

Kelly's explanation of her feelings about herself as a WRITER point to several notions about what WRITER roles might look like or entail to family members or non-academic relationships among first-generation students. Kelly describes the notion that writing labor is often not seen as "work" to people outside of academia such as her family. This idea of academic work not being seen as "work" by non-academics is not new, especially when thinking of "writing" labor. In her essay "Why I Ride," author Jana Richman (2003) describes a tense relationship with her father who does not approve of many things Richman takes on throughout her life. One instance of this occurs during a flashback to her childhood when she tells her father that she wants to be a writer:

When I was growing up, my father considered reading and writing a waste of time when there was "real work" to be done. Get off your ass and do something for Christ's sake! When I heard my father stomping down the hallway toward my closed bedroom door intent on catching me in petty pursuits, I jumped up, shoved 
my book under the bed, and busied myself with dusting the dresser. (p. 400, original emphasis)

Though Kelly and I both point to supportive family relationships, we can connect to this concept of parents who do not equate the work that comes with the humanities or academia as "real work." When, for instance, I visit my parents and spend hours at a time sitting with a book or working on my laptop, my parents occasionally scold me for "spending the day doing nothing on the couch," when in fact I have been working the entire day. My and Kelly's working-class parents as well as Richman's father value disciplines that produce visible work and require physical energy in ways that reading and writing do not. We have been raised to think of writing labor as "less than" in our households and this feeling can impact our confidence as writers.

Additionally, Kelly notes that a WRITER role can feel "like a luxury to have as an identity," one that Zeke echoes in his response to my prompt about the absence of WRITER on his list:

Ashanka: So one thing I noticed that is also like absent here is the idea of being a WRITER. Do you consider yourself as a WRITER?

Zeke: I don't know. I am a writer, because I write. By its very definition. I guess I just took that for granted, I suppose, you know, I'm not like well published or anything, so I don't know if that would qualify, you know? Yeah, I mean that's kind of what our field sort of totes as it's sort of mantra, right? It's like "we're all writers, you could be a writer too!"

Zeke's response identifies the "we can all be writers" conception common among writing teachers. Additionally, Zeke indicates misalignment with a WRITER identity because of a lack of publications, which might offer recognition of him as a WRITER. 
Zeke and Kelly's responses lead me to question how we consider WRITER identities as a discipline, while other responses leave me with the question of what kind of writing is valued in order to identify as a WRITER. Many participants pointed to not aligning with WRITER identities because they did not engage in creative writing as well as lacking publications. Cydney Alexis (2017) offers a critique of how the concept of “creative writing" gets taken up in English departments and what this means for our understanding of writing. She argues that the image of "creative writing" continues to "dominate the popular imagination and is weighted with value more heavily than all [other kinds of writing]" (p. 187). Similarly to the results I include here, in her own study of 48 people and their writing processes, Alexis found that most of her participants continually answered "no" when asked whether they considered themselves writers. Alexis presents an alternative to push against this binary of creative writing (which refers primarily to poetry and fiction) vs. all other writing by calling English and related departments to "banish the use of creative writing in titling disciplines, tracks, and departments," and shifting to "the banner of writing studies, writing, or writing arts" (p. 192). Alexis illuminates some of the reasons behind the tensions surrounding WRITER roles and identities. While participants in this study might operate in disciplines that focus on writing, many of our conceptions of what being a WRITER is or could be remain clouded or veiled by particular popular representations and understandings.

Carter articulates this tension further when he offers his own understanding of what a WRITER looks like to him in response to my prompt about the role being absent on his list:

Carter: When I think of a writer, I think of a creative writer, a fiction writer, or a poet. For me, all of the writing I'm doing... I mean I do a lot of writing, but 
mostly, especially again, because I'm at a teaching-intensive school, so mostly what I'm doing is, I'm designing documents, or I'm writing assignments, designing courses, or I'm writing emails. I do lots of writing, but I don't think of those as making me a WRITER, instead these are things that make me an ADMINISTRATOR, an ADVISOR, a TEACHER.

Carter's ideas that a WRITER role reflects creative writing in particular reflects across several participants. Hannah, for instance, distinguishes herself as a WRITER in both her separate "professional" and "personal" lists she made. In conversation, she noted that her professional WRITER role reflects writing she does for her job such as Carter describes above, while her personal WRITER role aligns with her creative works, one that has become more aspirational over time. Kevin Roozen et al. (2015), in their study of three teachers' identities informing their pedagogical practices, describe their participant Lisa sharing similar feelings about creative writing vs. other academic writing. Specifically, Lisa is described as struggl[ing] with her own writerly authority and identity. Her struggles highlight the need to further explore how deeply rooted cultural conceptions of writing (where print literacies are often valued over digital and networked literacies) and authorship (where sponsored publication often links tightly to identity) informand disrupt — teachers' identity work and classroom practices. (p. 208)

In other words, because of how published or creative writing is traditionally valued or touted by academia, many teacher-scholars identify less as writers themselves and more so as teachers of writing because they have received more direct training and recognition of their authority in these roles. 
Finally, I want to return to Jeff who adds another complexity to adopting or identifying in a WRITER role as a writing TEACHER and as a PhD student where much of the writing we do responds to completing a requirement for our degrees:

Ashanka: I noticed that of the standard things that as a researcher I might expect to see are like "writer" and I was curious about why "writer" doesn't show up on any of these lists.

Jeff: Yeah. I don't think of myself as a writer. If there's a creative writer side of me, it's music. Like I'm a songwriter, though I haven't written a song in probably four or five years. In terms of the creativity side of writing, you know I'm not a creative writer. You're right, that's really interesting. I think of myself as someone who teaches writing, but a lot of what I think of as teaching writing is teaching people how to get their ideas onto paper. I don't know. I understand writing is a craft and all that, but in these introductory courses, I'm not teaching English majors. And even when I was in English, most of those composition classes, very few of those kids were going to be English majors. And I'm not really interested in teaching upper division classes. To me, I like getting people comfortable with writing as like "you can do it. It's thinking on paper," you know. As a PhD student, the papers I write for classes... our instructors are encouraging us to submit them, and I guess I probably will at one point. And then I guess I will think of myself as a writer cause then I might be published. But I don't know. I think the writing I do is more to demonstrate an understanding of the course materials.

Jeff's descriptions here show his aligning WRITER roles with creative writing in particular or with writing that an English major might produce—writing that sounds like 
it might be more valuable to students than what they might produce as nonmajors. In other words, what English majors or creative writers produce would have more value for them as professionals, whereas most of the nonmajor students Jeff teaches are more likely in his classes to fulfill a requirement. Likewise, he sees the writing he produces in his own experiences as a $\mathrm{PhD}$ student as fulfilling various requirements for his degree such as writing seminar papers. Overall, these conceptions of WRITER roles show several misalignments or tensions with identifying as a WRITER.

\section{Chapter Conclusions}

I opened this chapter with a story about navigating a moment of difference in understanding what my goals were between me, my Nani Ma (grandmother), and my mother. As I near the final days of my $\mathrm{PhD}$ program, I find myself continuing to work through my own conceptions of who I am as a TEACHER, a MENTOR, and WRITER and the ways my upbringing, background, evolving and growing literacies, and spaces continue to impact my understanding of my identities and roles. In this chapter, participants' own reflections and connections in aligning themselves primarily with TEACHER and MENTOR roles are informed by their own experiences. From Diane's search for autonomy in her career, which informed both her choice to enter the discipline and how she moves within it, to Tina's decision to share aspects of her background in order to create and bridge connections with the students she mentors, participants in this study largely pointed to their backgrounds as affording several qualities that allow them to be more empathetic and compassionate teachers, mentors, and people in academia. Ultimately, participants approached their teaching and mentoring practices by focusing first on what they desired or liked from their own experiences as students (such as Peter's 
in-class writing prompt and check-ins with students), and then forwarding what they found most helpful into their own classrooms and work.

Though a first-generation background as shared in this study arguably offers many affordances for participants navigating academia, tensions remain. In this chapter, I highlighted the tension of taking on or identifying with WRITER roles; future studies could consider how, why, and whether similar tensions exist when this population and others are asked about RESEARCHER and SCHOLAR roles. For instance, and notably, only one participant listed ACADEMIC as one of their roles. In what ways do these tensions with particular roles reflect the larger expectations or goals of academic work, particularly at research-intensive institutions such as those granting the PhD's of all of the participants in this study? Although the stories in this chapter begin to illuminate the unique perspective participants' first-generation backgrounds bring when thinking and working as professionals in Rhetoric and Composition, future research on this population could include a deeper exploration of students' relationships with their mentors and teachers to better understand when and under what circumstances students disclose features of their background. 


\section{CHAPTER FIVE \\ CONCLUSION AND FUTURE MATTERS: SO WHAT DO WE DO NOW?}

I started this project with the story of how and why I chose to pursue my doctorate in Rhetoric and Composition and this dissertation broadly. My choices were heavily motivated by my parents' choices and journey. The choices of our family members before us similarly reflect across all of the participants in this dissertation. I've learned through this project that completing this dissertation, and, subsequently, my $\mathrm{PhD}$ are only the beginning of my work with graduate students. This dissertation began in response to my frustration with the absence of graduate student voices across scholarship on navigating graduate study. More specifically, I wondered how so much written guidance continued to ignore the lived realities of the people aspiring to graduate degrees. And I wondered why voices like mine continued to be absent in the scholarship and handbooks I had been directed to read, the scholarship designed to aid in my training as a future professional and $\mathrm{PhD}$ in the discipline and in academia.

After a pilot study of three Rhetoric and Composition doctoral students, it became clearer that I wanted to focus on one particular population that appears even less in scholarship - first-generation-to-college students who choose to continue their education and ultimately earn PhDs. I interviewed 21 first-generation-identifying doctoral students and recent alumni from two Rhetoric and Composition doctoral programs and asked them 
about their stories — what draws them to academia, to this work? How did/do they understand and navigate the connections between their identities/positionalities (e.g., class, race, ethnicity, gender, sexuality, religion, dis/ability) and the goals of graduate study in Rhetoric and Composition? Additionally, how do/did these goals and their emerging identities as academics in Rhetoric and Composition fit with their other personal, academic, and professional goals?

I listened to these 21 participants, and I learned. I learned, as I detail in Chapter 2, that engaging in this research requires me to engage in critical self-reflection throughout the process. Orienting this project through a cultural rhetorics methodology allowed me to focus on recognizing and acknowledging my participants', as well as my own, embodied lives, practices, and orientations together in a constellating relationship. I learned that the term "first-generation student" operates as a heuristic, albeit an imprecise one. In Chapter 3, I shared stories across three themes about what it means to identify as a first-generation student working to or holding a $\mathrm{PhD}$ in Rhetoric and Composition. I relayed and broke down myths and pressures common in scholarship and present in data toward offering new perspectives on first-generation student status. I learned that, regardless of where we started, all of the participants in this project identified as teachers. By exploring how the first-generation-to-college doctoral student and recent alumni participants in this project understand their place in the academy, in Chapter Four, I found that this background comes with many affordances for participants' roles as teachers as well as mentors.

In this chapter, the concluding chapter of this dissertation, I discuss implications for mentoring first-generation students by offering potential strategies for rethinking and building stronger mentoring relationships in Rhetoric and Composition graduate 
programs. I reflect on my work co-writing the forthcoming Conference on College Composition and Communication's “Statement of Professional Guidance for Mentoring Graduate Students" alongside the findings presented from the data at the center of this dissertation. I offer a framework for engaging mentoring relationships with an emphasis on first-generation students as well as other historically underrepresented populations.

\section{On the Status of Mentoring Graduate Students}

To gain a better understanding of the implications of this project for the field overall, I spent my time at the 2018 Conference on College Composition and Communication attending Special Interest Group (SIG), Standing Group, and Caucus meetings related to graduate students, identity, and working-class issues. I recognized this conference as a moment to learn about the larger conversations surrounding graduate students in Rhetoric and Composition especially as I neared the end of the data collection phase of the study at the center of this dissertation. Additionally, I wanted to take a more active role in these conversations as my pursuit of this project helped me solidify my understanding of my future career goals as a professional-I knew that I wanted to continue working with graduate students post-PhD. Among the SIGS, Standing Groups, and Caucus meetings, I attended a meeting of a SIG on the Status of Graduate Students in Rhetoric and Composition. I quickly learned that this SIG was transitioning into a task force known as the "CCCC Task Force to Create a Position Statement on Graduate Students." I volunteered to help with the writing of this position statement when asked and was later formally invited onto the team by then CCCC Chair Carolyn CalhounDillahunt. The final task force comprised of myself, Hannah Rule (committee chair), 
Dawn Opel, Temptaous Mckoy, and Karrieann Soto Vega—five early-career scholars (assistant professors and graduate students).

Building from the 2014 "Report and Recommendations on the Status of Graduate Students" developed by the Committee on the Status of Graduate Students prior to this task force, we chose to focus our statement on mentoring graduate students in response to dissatisfaction with the lack of mentoring indicated within survey results. Particularly, we discussed how students from historically underrepresented backgrounds may have needs for mentoring beyond the scope of the survey, which did not have enough representation of historically underrepresented students among survey participants. As a result, we conducted research and co-wrote the "CCCC Statement of Professional Guidance for Mentoring Graduate Students"4 (Appendix 2) that could at least raise some of these concerns intended as guidance for faculty engaged in the mentoring of graduate students in Composition and Rhetoric and related fields (Rule, Kumari, Mckoy, Opel, \& Soto Vega,forthcoming). Yet, we know that more is needed and that, perhaps, more than one position statement might be needed to address the multiple and varying circumstances, audiences, and stakeholders involved in graduate student mentoring. In what follows, I quote portions of this statement and build on key ideas that also serve as implications for this dissertation.

\section{Implications for Future Work on and Mentoring of Graduate Students}

\footnotetext{
${ }^{4}$ The complete text of the recently approved (as of March 2019) statement, forthcoming from the Conference on College Composition and Communication is available in the dissertation Appendix \#2 and is reprinted here with permission from the committee chair.
} 
I take away from this research and my work with the CCCC Task Force to Create a Position Statement on Graduate Students the following conclusions:

Mentorship is "robust guidance responsive to an individual student's differences and needs in a range of domains related to working toward and beyond a masters or doctoral degree in rhetoric and composition and related fields" (Rule, Kumari, Mckoy, Opel, \& Soto Vega, forthcoming). For mentoring first-generation students, this means having an understanding that, like mentoring relationships overall, a one-size-fits-all model does not and cannot exist for meeting all students. Instead, we argue in the statement that faculty should practice mentoring that is "responsive to individuals' differentiated needs and at the same time systematic, inclusive, and equitable." For instance, in Chapters 2 and 3, Jack describes how focused mentoring led him to consider and ultimately pursue a career in Rhetoric and Composition after a mentor responded to his work in such a way that guided him to this discipline. The key here is that Jack's mentor paid attention to his story and responded with relevant advice and resources.

We argue that "mentoring relationships should be flexible and multiple. $[\ldots]$ Effective mentorship emerges through a range of supportive relationships between graduate students and others in different positions and with ranging experience, a broad coalition of the dissertation or thesis director, other faculty, program chairs, administrative personnel, other graduate students, scholars at other institutions, and others that can provide strategic guidance," a practice Vanhaitsma and Ceraso (2017) refer to as "horizontal mentoring" (see Chapter 4). For mentors who serve as committee leaders, this requires numerous check-in moments, the frequency of which should be determined in conversation with the mentee and reassessed regularly. Samantha's story throughout this dissertation shows one example of a student who needed a different kind 
of mentoring at later stages of her $\mathrm{PhD}$ program, which today continues to make completing her dissertation while working a full-time academic job difficult. Samantha could benefit from a mentor who checks in more regularly and helps her set deadlines towards completing her project and earning her $\mathrm{PhD}$. Overall, "mentoring practices, programs, and relationships should not disproportionately place the labor, burden, and responsibility on graduate students themselves to be mentored nor on the generosity of individual mentors” (Rule, Kumari, Mckoy, Opel, \& Soto Vega, forthcoming).

Additionally, we wrote that mentoring practices should "validate and help students prepare for diverse careers. Graduate students should be encouraged, validated, and celebrated for career outcomes beyond conventional academic tenure-track positions." For first-generation students, this practice is especially crucial because it offers a glimpse at the diverse careers available to those with a graduate degree in Composition and Rhetoric beyond the historically lauded tenure-track model. Diane, for instance, describes primarily understanding her job market goals as focusing on earning a tenure-track job as a professor because her training did not include focused mentorship about alternative academic or other career aspirations. These "choices should be supported at all steps of the graduate experience. Mentorship toward diverse careers will likely require that mentors continue to learn alongside their students about ranging career options and preparatory experiences" (Rule, Kumari, Mckoy, Opel, \& Soto Vega, forthcoming).

Thus, "we argue that the field should strive to enact practices and stances that can help sustain equitable support for graduate students from recruitment through postgraduation." This includes, but is not limited to, providing "adequate financial support for critical professionalization events in graduate student careers, such as conference travel, 
summer support, and job market support, considering varying degrees of students' own material constraints." As numerous participants noted throughout this dissertation, financial stress continues to be a key challenge for gaining one's education. This financial support must also include resources about and strategies for budgeting and being financially responsible (see Diane's story about learning “financial irresponsibility” in graduate school in Chapter 3). Likewise, mentors must "advise graduate students to pursue varying opportunities (e.g., what conferences to attend, how many academic jobs to apply to, the nature of those jobs, research endeavors, and course materials assignments, etc.) in a manner mindful to students' varying financial situations and other factors" (Rule, Kumari, Mckoy, Opel, \& Soto Vega, forthcoming).

Finally, we wrote that the field must "strive for inclusion and diversity through differentiated mentoring practices. To facilitate inclusive practices, we propose emphasizing diversity and inclusion when mentoring historically marginalized or underrepresented groups" (Rule, Kumari, Mckoy, Opel, \& Soto Vega, forthcoming). "We underscore especially that the recruitment of students with diverse backgrounds (based upon gender, sexuality, race, ability) does not mean there are spaces of inclusion within the department, institution, or broader discipline." In short, diversity is what a space looks like; inclusion is what it feels like. "At some institutions, there may be a gap between institutional commitments to diversity and moves to create and sustain inclusion when 'statements of commitments to diversity are understood as 'non-performatives' that do not bring about what they name' (Ahmed, 2012, p. 119). Instead of allowing diversity statements or position statements like this one to serve in Ahmed's terms, as "an institutional desire for good practice" —or, as a drive to hear "happy stories of diversity" rather than face "unhappy stories of racism" (Ahmed, 2007, p. 164) —statements and 
other documents that call for change within communities should be used strategically and with focus on action not merely sentiment. Programs and mentors should thus assess how they curate spaces for mentorship in order to sustain inclusiveness for a diverse scholar population."

"Mentorship is never a one-size-fits-all or even a fits-most model, and in recognizing this, while we may here provide relevant mentorship knowledge, it is mentors, departments, and institutions that must attune and adjust to the needs of their particular students and programs. For example, students coming from undergraduate and graduate work at minority serving institutions (such as Historically Black Colleges /Universities [HBCUs], Hispanic Serving Institutions [HSIs], Tribal Colleges/Universities [TCU's], Alaska Native-Serving Institutions or Native HawaiianServing Institutions, Predominantly Black Institutions, Asian American and Native American Pacific Islanders-Serving Institutions, and Native American-Serving NonTribal Institutions) will have specific needs in navigating their graduate institution and program of study. Students of color, moreover, that enter Predominately White Institutions (PWIs), may experience the academy as a brave space (Arao \& Clemen, 2013, p.141), a positioning which leaves them to take on additional emotional and mental labor, as brave spaces require the giving up of a former condition in favor of a new way for seeing and understanding (Arao \& Clemen, 2013, p.141). While every graduate student works to become socialized into their varied roles as graduate students (Golde,1999), there is an institutional obligation to meet the additional needs of historically underrepresented and marginalized groups through mentorship in and outside of the classroom" (Rule, Kumari, Mckoy, Opel, \& Soto Vega, forthcoming) 
Overall, I want to highlight some initial practices for mentorship with students from historically marginalized and underrepresented groups further described in the statement (see Appendix 2). In the statement, we wrote that

though every graduate student must work to become socialized into their roles as student, professional, and scholar, departments have a special obligation to assist in these processes through mentorship with historically minoritized groups, students of color, those from historically underrepresented groups or sexual and gender minority communities, first-generation students, international students, and others. Listening, standing as an ally, assisting in building a network of mentors, and amplifying the voices of the marginalized are, for one, key ways to increase student retention. But more importantly and broadly, concerted efforts to enact a culture of equitable, accessible, networked mentoring is in the interest of all stakeholders in higher education to realize a diverse future scholar population that will continue to enact change throughout our field and varied institutions (Rule, Kumari, Mckoy, Opel, \& Soto Vega, forthcoming).

Regardless of which approach one takes toward mentoring, we must re-evaluate mentoring practices with mentees for different bodies and minds, at different stages of learning and career processes.

\section{Implications for Future Research}

Although I covered a lot of ground and data in this dissertation, I recognize the need for further research on graduate students in Rhetoric and Composition. First, future research should further consider ethical methods and methodologies for fruitfully researching graduate students, especially as graduate students. To this end, researchers 
can do more to write explicitly about their methodological approaches to studying individuals in shared positions and backgrounds such as I have done here. How might we consider power disparities across participants and researchers? In what ways would this project have differed, if, for instance, I were a tenured professor engaging doctoral student participants? In future scholarship on graduate students, researchers across backgrounds and disciplines can do more to describe their approaches to engaging this population.

Additionally, future research could include additional factors and writing samples to gain a greater sense of participants' constellating identities. For instance, researchers could ask participants to share different kinds of writing they do both for academic and non-academic purposes to get a sense of whether and how graduate students perform their identities across their writing practices. For this dissertation project, I collected professional writing samples (i.e. CVs, personal statements, job letters) from participations to get a sense of how/whether the identities and roles participants described during our conversations reflected in these writings; however, researchers can do more to engage participants writing practices beyond these sorts of documents to consider whether and how participant identities reflect in the subdisciplines and topic areas participants pursue within Rhetoric and Composition. For instance, it is clear I am inspired and directly reflect on my own lived identities throughout this dissertation- do other graduate students do the same? How do research areas reflect one's identity?

While this project responded to Gardner and Holley's (2011) call for disciplinefocused research on doctoral students, this project is only the beginning. Future research should continue to explore the impact of disciplinary trajectories on first-generation-tocollege doctoral student experiences. Researchers can do more to understand how 
different kinds of institutional, programmatic, and curricular structures impact how emerging teacher-scholars train for careers both in and outside of academia. Further, researchers should collaborate with participants in future work to gain a deeper sense of how participants write their identities.

\section{Conclusion}

In the process of speaking with and amplifying the stories of the graduate students involved in this dissertation, many Rhetoric and Composition graduate students nationally have become active participants in disciplinary dialogues surrounding equity and inclusion. I have and continue to witness and contribute to these conversations both locally and nationally. I stand as an ally, do my best to rhetorically listen, and amplify the voices of colleagues and fellow graduate students from historically marginalized and underrepresented groups when possible. Most significantly, I have lead the charge, alongside nine other Rhetoric and Composition scholars (both graduate students and faculty), in founding and moderating the nextGEN Listserv. With nearly 500 subscribers today, nextGEN came in response to both a kairotic moment during racist and sexist conversations that transpired on the WPA-Listserv in April 2018 as well as a need for a safe/r space for graduate students to contribute, inquire, and respond to conversations in the field. However, much work remains in the hands of the next wave of Rhetoric and Composition scholars remaking identities and graduate study. 


\section{REFERENCES}

Adichie, C. N. (2009, July). The Danger of a Single Story [Video file]. Retrieved from: https://www.ted.com/talks/chimamanda_adichie_the_danger_of_a_single_story? $\underline{\text { anguage }=\text { en }}$

Ahmed, Sara. (2012). On being included: Racism and diversity in institutional life. Durham, NC: Duke University Press.

Ahmed, S. (2007). A phenomenology of whiteness. Feminist Theory, 8(2): 149-168.

Alexis, C. (2017). Creative writing is a unique category. In Ball, C., \& Loewe, D. (Eds.) Bad Ideas About Writing, 187-193. Morgantown, WV: West Virginia University Libraries Digital Publishing Institute. Retrieved from https://textbooks.lib.wvu.edu/badideas/badideasaboutwritingbook.pdf?utm_content=bufferee $7 \mathrm{~b} 7 \&$ utm_medium $=$ social\&utm_source=faceboo $\underline{\text { k.com\&utm campaign }=\text { buffer }}$

Anderson, V., \& Romano, S. (Eds.). (2006). Culture shock and the practice of profession: Training the next wave in rhetoric and composition. New York, NY: Hampton Press.

Arao, B., \& Clemens, K. (2013). From safe spaces to brave spaces. In L. M. Landreman (Ed.), The art of effective facilitation: Reflections from social justice educators, 135-150. Sterling, VA: ACPA—College Student Educators International. 
Ballif, M., Davis, D., \& Mountford, R. (2008). Women's ways of making it in rhetoric and composition. New York, NY: Routledge.

Banks, William P. (2003). Written through the body: Disruptions as personal writing. College English, 66 (1), 21-40.

Bartholomae, D. (1985). Inventing the university. In M. Rose (Ed.), When a writer can't write, 134-165. New York: Guilford.

Berkenkotter, C., Huckin, T., \& Ackerman, J. (1988). Conventions, conversations, and the writer: Case study of a student in a rhetoric Ph.D. program. Research in the Teaching of English, 22(1), 9-44.

Bhattacharya, P. (Ed.). (2016). Good girls marry doctors: South Asian American daughters on obedience and rebellion. San Francisco: Aunt Lute Books.

Boehm, B., \& Lueck, A. J. (2016). Graduate Student Peer Mentoring Programs: Benefitting Students, Faculty and Academic Programs. In G. Wright (Ed.), The mentoring continuum: From graduate school through tenure, 187-202. Syracuse, NY: Syracuse University Graduate School Press.

Borkowski, D. (2004). "Not too late to take the sanitation test": Notes of a non-gifted academic from the working class. College Composition and Communication, 56(1), 94-123.

Bourdieu, P. (1984). Distinction: A social critique of the judgement of taste. Boston, MA: Harvard University Press.

Bousquet, M. (2015). Condemned to repeat: On the racism and sexism of failing to address structure. Pedagogy, 15(1), 157-168. 
Bratta, P., \& Powell, M. (2016). Introduction to the special issue: Entering the cultural rhetorics conversations. Enculturation. Retrieved from $\underline{\text { http://enculturation.net/entering-the-cultural-rhetorics-conversations }}$

Brooks-Gillies, M., E.G. Garcia, S.H. Kim, K.Manthey, and T.G. Smith. (2015).

Graduate writing across the disciplines, introduction. Across the disciplines: A journal of language, learning, and academic writing, 12(3). Retrieved from: https://wac.colostate.edu/atd/graduate_wac/index.cfm

Burgess, A., \& Ivanic, R. (2010). Writing and being written: Issues of identity across timescales. Written Communication, 27(2), 228-255.

Byrnes, H. (2001). Reconsidering graduate students' education as teachers: "It takes a department!" The Modern Language Journal, 85(4), 512-530. Retrieved from http://onlinelibrary.wiley.com/doi/10.1111/0026-7902.00123/abstract

Carr, A.D., H.J. Rule, K.T. Taylor (2013). Literacy in the raw: collecting, sharing, and circulating graduate literacy narratives. Computers and Composition Online http://cconlinejournal.org/winter2013/literacy_raw/index.html

Casanave, C. P. (2002). Writing games: Multicultural case studies of academic literacy practices in higher education. Mahwah, NJ: Lawrence Erlbaum Associates.

Casanave, C. P., \& Li, X. (Eds.). (2008). Learning the literacy practices of graduate school: Insiders' reflections on academic enculturation. Ann Arbor, MI: The University of Michigan Press.

Casanave, C. P. (2014). Before the dissertation: A textual mentor for doctoral students at early stages of a research project. Ann Arbor, MI: University of Michigan Press.

Chiseri-Strater, E. (1991). Academic literacies: The public and private discourse of university students. Portsmouth, NH: Boynton/Cook Publishers. 
Cotterill, P. (1992). Interviewing women: Issues of friendship, vulnerability, and power. Women's Studies International Forum, 15(5-6), 593-606.

Covino, W. A., Johnson, N., \& Feehan, M. (1980). Graduate education in rhetoric: Attitudes and implications. College English, 42(4), 390-398.

Creswell, J. W. (2016). Developing theme passages. In J. W. Creswell (Ed.), 30 Essential Skills for the Qualitative Researchers, 174-180. Los Angeles, CA: Sage.

Crisco, V., Gallagher, C. W., Minter, D., Stahlnecker, K. H., \& Talbird, J. (2003).

Graduate education as education: The pedagogical arts of institutional critique. Pedagogy: Critical approaches to teaching literature language composition and culture, 3(3), 359-376.

Dews, C. L. Barney, and C. L. Law, (Eds). (1995). This fine place so far from home: Voices of academics from the working-class. Philadelphia, PA: Temple University Press.

Driscoll, L. G., Parkes, K. A., Tilley-Lubbs, G. A., Brill, J. M., \& Bannister, V. R. P. (2009). Navigating the lonely sea: Peer mentoring and collaboration among aspiring women scholars. Mentoring \& Tutoring: Partnership in Learning, 17(1), $5-21$.

Dunbar-Odom, D. (2007). Defying the odds: Class and the pursuit of higher literacy. Albany, NY: State University of New York Press.

Eble, M.F and L. Lewis Gallet (2008). Stories of mentoring: Theory and praxis. Anderson, SC: Parlor Press.

Edwards, K (2006). Aspiring social justice ally development: A conceptual model. NASPA Journal 43(4), 39-60. 
Elder, C. L., Schoen, M., \& Skinnell, R. (2014). Strengthening graduate student preparation for WPA work. WPA, 37(2), 13-35.

Foucault, M. (1977). Discipline and punish: The birth of the prison. New York, NY: Vintage Books.

Fugate, G., Jaramillo, P., \& Preuhs, R. (2001). Graduate Students Mentoring Graduate Students: A Model for Professional Development. PS: Political Science \& Politics, 34(1), 132-133.

Fussell, P. (1983). Class. New York, NY: Ballantine.

Gardner, S. K. (2013). The challenges of first-generation doctoral students. New Directions for Higher Education, 163, 43-54.

Gardner, S. K., \& Holley, K. A. (2011). "Those invisible barriers are real”: The progression of first-generation students through doctoral education. Equity \& Excellence in Education, 44(1), 77-92.

Gee, J. P. (1989). Literacy, discourse, and linguistics: Introduction. Journal of Education, 171(1), 5-17.

Golde, C. M. (1998). Beginning graduate school: Explaining first-year doctoral attrition. New Directions for Higher Education, 1998(101), 55-64.

Goodburn, A., LeCourt, D., \& Leverenz, C. (Eds.). (2013). Rewriting Success in Rhetoric and Composition Careers. Anderson, SC: Parlor Press.

Grady, R. K., Touche, R. La, Oslawski-lopez, J., Powers, A., Grady, R. K., Touche, R. La, ... Simacek, K. (2014). Betwixt and between: The social position and stress experiences of graduate students. Teaching Sociology, 42(1), 5-16. 
Grant-Davie, K. (1992). Coding data: Issues of validity, reliability, and interpretation. In Kirsch, G. E., \& Sullivan, P. A. (Eds.), Methods and methodology in composition research, 272. Carbondale, IL: Southern Illinois University Press.

Hall, L., \& Burns, L. (2009). Identity development and mentoring in doctoral education. Harvard Educational Review, 79(1), 49-70. Retrieved from: http://doi.org/10.17763/haer.79.1.wr25486891279345

Hamilton, S. J. (1995). My name's not Susie: A life transformed by literacy. Portsmouth, NH: Boynton/Cook Publishers.

Hauman, K., Kastner, S., \& Witte, A. (2015). Writing teachers for twenty-first-century writers: A gap in graduate education. Pedagogy, 15(1), 45-57.

Herrington, A. J., \& Curtis, M. (2000). Persons in process: four stories of writing and personal development in college. Urbana, IL: NCTE.

Hertel, J. B. (2002). College student generational status: Similarities, differences, and factors in college adjustment. The Psychological Record, 52, 3-18.

Holley, K. A., \& Gardner, S. (2012). Navigating the pipeline: How socio-cultural influences impact first-generation doctoral students. Journal of Diversity in Higher Education, 5(2), 112-121.

hooks, bell. (1994). Teaching to transgress: Education as the practice of freedom. New York: Routledge.

hooks, B. (2000). Where we stand: Class matters. New York, NY: Routledge.

Horner, B. (2000). Terms of work for composition: A materialist critique. Albany, NY: State University of New York Press.

Horner, B., \& Lu, M. (2010). Working rhetoric and composition.” College English, $72(5), 470-94$. 
Horner, B. (2016). Rewriting composition: Terms of exchange. Carbondale, IL: Southern Illinois University Press.

Ivanič, R. (1998). Writing and identity: The discoursal construction of identity in academic writing. Philadelphia, PA: John Benjamins Publishing Company.

Kamler, B., \& Thomson, P. (2014). Persuading an octopus into a jar. In Kamler, B. \& Thomson, P. Helping doctoral students write: Pedagogies for supervision, 30-48. New York, NY: Routledge.

Kirsch, G. E., \& Sullivan, P. A. (Eds.). (1992). Methods and methodology in composition research. Carbondale, IL: Southern Illinois University Press.

Kirsch, G. E. (2005). Friendship, friendliness, and feminist fieldwork. Signs: Journal of Women in Culture and Society, 30(4), 2163-2172.

Kniffin, K. M. (2007). Accessibility to the $\mathrm{PhD}$ and professoriate for first-generation college graduates: Review and implications for students, faculty, and campus policies. American Academic, 3, 49-80.

Kopelson, K. (2008). Sp(1)itting images; or, back to the future of (rhetoric and?) composition). College Composition and Communication, 59(4), 750-780.

Kosut, M. (2006). Professorial capital: Blue-collar reflections on class, culture, and the academy. Critical Studies_Critical Methodologies, 6(2), 245-262.

Lauer, J. (1994). Constructing a doctoral program in rhetoric and composition. Rhetoric Review, 12(2), 392-397.

Lave, J., \& Wenger, E. (1991). Situated learning: Legitimate peripheral participation. Cambridge, MA: Cambridge University Press.

LeCourt, D. (2004). Identity matters: Schooling the student body in academic discourse. Albany, NY: SUNY Press. 
Linkon, S. L. (1999). Teaching working class. Amherst, MA: The University of Massachusetts Press.

Lopez, M. (n.d.) On mentoring first generation and graduate students of color. MLA Commons. https://clpc.mla.hcommons.org/on-mentoring-first-generation-andgraduate-students-of-color/

Lovitts, B. E. (2001). Leaving the ivory tower: The causes and consequences of departure from doctoral study. Landham, MD: Rowman and Littlefield.

Lubrano, A. (2004). Limbo: Blue-collar roots, white-collar dreams. Hoboken, NJ: John Wiley and Sons, Inc.

Lunsford, A., Moglen, H., \& Slevin, J. (1989). The future of doctoral studies in English. Modern Language Association of America.

Mack, N. (2017). Emotional labor as imposters: Working-class literacy narratives and academic identities. In G. M. Carter \& W. H. Thelin (Eds.), Class in the Composition Classroom: Pedagogy and the Working Class, 140-160. Logan: UT: Utah State University Press.

Manthey, K. (2015). Wearing multimodal composition: The case for examining dress practices in the writing classroom. Journal of Global Literacies, Technologies, and Emerging Pedagogies, 3(1), 335-343.

Martinez, A. Y. (2018). The responsibility of privilege: A critical race counterstory conversation contextualizing CRT and counterstory. Peitho Journal, 21(1), 212233.

Merriam, S. B. (2016). Qualitative research: A guide to design and implementation, $4^{\text {th }}$ edition. San Franscisco, CA: Jossey-Bass. 
Miall, C. E., \& Herman, N. J. (1994). Generic processes of impression management: Two case studies of physical and mental disability. In N. J. Herman, \& L. T. Reynolds, (Eds.), Symbolic interaction: An introduction to social psychology, 208-223. Dix Halls, NY: General Hall.

Micciche, L.R. with A. Carr. (2011). Toward graduate-level writing instruction. CCC 62(3), 477-501.

Moss, B. J. (1998). Intersections of race and class in the academy. In A. Shepard, J. McMillan, \& G. Tate (Eds.), Coming to class: Pedagogy and the social class of teachers, 157-169. Portsmouth, NH: Boynton/Cook Publishers.

Mukavetz, A. M. R. (2014). Towards a cultural rhetorics methodology: Making research matter with multi-generational women from the Little Traverse Bay Band. Rhetoric, Professional Communication and Globalization, 5(1). Retrieved from http://www.rpcg.org/index.php?journal=rpcg\&page=article\&op=view\&path\%5B $\% 5 \mathrm{D}=98 \% 5$ Cnpapers3://publication/uuid/22606F13-24D8-4F4D-B2BA182A1E5FD5E3

National Science Foundation. (2015). 2014 Doctorate recipients from U.S. universities. Alexandria, VA: National Center for Science and Engineering Statistics Directorate for Social, Behavioral and Economic Sciences.

Newkirk, T. (1992). The narrative roots of case study. In G. E. Kirsch, \& P. A. Sullivan (Eds.), Methods and methodology in composition research, 130-152. Carbondale, IL: Southern Illinois University Press.

Newkirk, T. (1996). Seduction and betrayal in qualitative research. In P. Mortenson, \& G. E. Kirsch (Eds.), Ethics \& Representation in Qualitative Studies of Literacy, 3-16. Urbana, IL: NCTE. 
North, S. (2000). Refiguring the Ph.D. in English studies: Writing, doctoral education, and the fusion-based curriculum. Urbana, IL: NCTE.

Norton, B. (2013). Identity and language learning: Extending the conversation. Multilingual Matters.

Okawa, G. Y. (2002). Diving for pearls: Mentoring as cultural and activist practice among academics of color. College Composition and Communication, 53(3), 507-532.

Osborn, J. (2015). Community colleges and first-generation students: Academic discourse in the writing classroom. New York, NY: Palgrave Macmillan.

Ostrove, J. M., Stewart, A. J., \& Curtin, N. L. (2011). Social class and belonging: Implications for graduate students' career aspirations. The Journal of Higher Education, 82(6), 748-774.

Pascarella, E. T., Pierson, C. T. Wolniak, G. C., \& Terenzini, P. T. (2004). Firstgeneration college students: Additional evidence on college experiences and outcomes. Journal of Higher Education, 75(3), 249-284.

Peckham, I. (2010). Going north, thinking west: The intersections of social class, critical thinking, and politicized writing instruction. Logan, UT: Utah State University Press.

Pemberton, M. (1993). Tales too terrible to tell: Unstated truths and underpreparation in graduate composition programs. In S. Fontaine \& S. Hunter (Eds.), Writing ourselves into the story: Unheard voices in composition studies, 154-176. Champaign, IL: University of Illinois Press. 
Penrose, A. M. (2002). Academic literacy perceptions and performance: Comparing firstgeneration and continuing-generation college students. Research in the Teaching of English, 36(4), 437-461.

Potter, J., \& Hepburn, A. (2012). Eight challenges for interview researchers. The SAGE handbook of interview research: The complexity of the craft, 555-570. Retrieved from: http://doi.org/10.4135/9781452218403.n39

Powell, M. (2012). Stories take place: A performance in one act. College Composition and Communication, 64(2), 383-406.

Powell, M., Levy, D., Riley-Mukavetz, A., Brooks-Gillies, M., Novotny, M., FischFerguson, J., \& The Cultural Rhetorics Theory Lab. (2014). Our story begins here. Enculturation. Retrieved from enculturation.net/our-story-begins-here

Prior, P. (1998). Writing/Disciplinarity: A sociohistoric account of literate activity in the academy. New York, NY: Routledge.

Prior, P. (2006). A sociocultural theory of writing." In C. A. MacArthur, S. Graham, \& J. Fitzgerald, Handbook of writing research, 54-66. New York, NY: The Guilford Press.

National Center for Educational Statistics. (2017). First-generation and continuinggeneration college students: A comparison of high school and postsecondary experiences. Washington, DC: J. Redford \& K. M. Hoyer.

Patel, V.S. (2011). Moving toward an inclusive model of allyship for racial justice. The Vermont Connection 32, 78-88.

Ratcliffe, K. (2005). Rhetorical listening: Identification, gender, whiteness. Carbondale, IL: Southern Illinois University Press. 
Richardson, E. (2013). PHD to Ph.D.: How education saved my life. Anderson, SC: Parlor Press.

Richman, Jana. (2005). Why I Ride. In L. Gutkind, (Ed.), Fact: The Best of Creative Nonfiction, 395-418. New York: W.W. Norton \& Company.

Rodriguez, C. M. (1998). Color and Class. In A. Shepard, J. McMillan, \& G. Tate (Eds.), Coming to Class: Pedagogy and the Social Class of Teachers, 143-156. Portsmouth, NH: Boynton/Cook Publishers.

Roozen, K., Woodard, R., Kline, S., \& Prior, P. (2015). The transformative potential of laminating trajectories of pedagogical practice: Three teachers' developing practices and identities. In T. Lillis, K. Harrington, M. R. Lea, \& S.Mitchell, (Eds.), Working with academic literacies: Case studies towards transformative practice, 205-215. Fort Collins, Colorado: WAC Clearinghouse.

Roozen, K., \& Erickson, J. (2017). Expanding literate landscapes: Persons, practices, and sociohistoric perspectives of disciplinary development. Logan: UT: Computers and Composition Digital Press/Utah State University Press. Retrieved from http://ccdigitalpress.org/ebooks-and-projects/expanding

Rose, Mike. (1989). Lives on the boundary: The struggles and achievements of America's underprepared. Detroit, MI: The Free Press.

Rule, H., Kumari, A., Mckoy, T., Opel, D., \& Soto Vega, K. (Forthcoming). CCCC Statement on Professional Guidance for Mentoring Graduate Students. Urbana, IL: NCTE.

Saldaña, J. (2009). The coding manual for qualitative researchers (2nd ed.). Thousand Oaks: SAGE. 
Sano-Franchini, J. (2016). "It's like writing yourself into a codependent relationship with someone who doesn't even want you!": Emotional labor, intimacy, and the academic job market in rhetoric and composition. College Composition and Communication, 68(1), 98-124.

Semenza, G. C. (2005). Graduate study for the $21^{\text {st }}$ century: How to build an academic career in the humanities. New York, NY: Palgrave Macmillan.

Semenza, G. C., \& Sullivan Jr., G. A. (2015). How to build a life in the humanities: Meditations on the academic work-life balance. New York: Palgrave Macmillan.

Simpson, S., \& Matsuda, P. (2008). Mentoring as a long-term relationship: Situated learning in a doctoral program. In C.A. Casanave \& X. Li, Learning the Literacy practices of graduate school: Insiders' reflections on academic enculturation, 90104. Ann Arbor, MI: The University of Michigan Press.

Sinanan, A. (2016). The value and necessity of mentoring African American college students at PWIs. The Journal of Pan African Studies (Online), 9(8), 155-166.

Skinnell, R., Holiday, J., \& Vassett, C. (Eds.). (2015). What we wish we'd known: Negotiating graduate school. Southlake, TX: Fountainhead Press.

Sternglass, M. S. (1997). Time to know them: A longitudinal study of writing and learning at the college level. Mahwah, NJ: Lawrence Erlbaum Associates.

Stephens, N., \& Townsend, S. (2019). The unseen reason working-class students drop out. Politico. Retrieved from: www.politico.com/agenda/story/2019/01/16/firstgeneration-low-income-students-drop-out-000873.

Sullivan, P. A. (1998). Passing: A Family Dissemblance. In A. Shepard, J. McMillan, \& G. Tate (Eds.), Coming to Class: Pedagogy and the Social Class of Teachers, 231-251. Portsmouth, NH: Boynton/Cook Publishers. 
Tokarczyk, M. M. \& Fay, E. A. (1993). Working-class women in the academy: Laborers in the knowledge factory. Amherst, MA: The University of Massachusetts Press. Vanhaitsma, P., \& Ceraso, S. (2017). "Making It" in the Academy through Horizontal Mentoring. Peitho Journal, 19(2), 210-233. Retrieved from: http://peitho.cwshrc.org/making-it-in-the-academy-through-horizontal-mentoring/ Williams, B. T. (2006). Identity papers: Literacy and power in higher education. Logan, UT: Utah State University Press.

Williams, B. T., \& Zenger, A. A. (2007). The Triumph of the Word. In Popular Culture and Representations of Literacy (pp. 145-161). New York: NY: Routledge.

Wilson, S. (2008). Research is ceremony: Indigenous research methods. Canada: Fernwood Publishing.

Wood, T. (2017). Rhetorical disclosures: The stakes of disability identity in higher education. In Kerschbaum, S., Eisenman, L., \& Jones, J. (Eds.), Negotiating Disability: Disclosure and Higher Education, 75-92. Ann Arbor: University of Michigan Press.

Wright, G., ed. (2016). The mentoring continuum: From graduate school through tenure. Syracuse: Graduate School Press Syracuse University.

Yancey, K. B. (2009). Re-designing graduate education in composition and rhetoric: The use of remix as concept, material, and method. Computers and Composition, 26(1), 4-12. Retrieved from: http://doi.org/10.1016/j.compcom.2008.11.004

Young, M. (2001). The Anxiety and Nostalgia of Literacy: A Narrative about Race, Language, and a Teaching Life. In D. H. Holdstein, \& D. Bleich (Eds.), Personal effects: The social character of scholarly writing, 298-316. Logan: UT: Utah State University Press. 
Young, R. E., \& Steinberg, E. R. (2000). Planning graduate programs in rhetoric and departments of English. Rhetoric Review, 18(2), 390-402.

Zebroski, James T. (2006). Social class as discourse: The construction of subjectivities in English. In B. T. Williams (Ed.), Identity papers: Literacy and power in higher education, 17-28. Logan, UT: Utah State University Press. 


\section{APPENDICES}

\section{Appendix 1: Interview Questions for Current (Early and Mid-Late Stage) Rhet/Comp Graduate Students}

1. Can you tell me your name, age, and year in the [institution] program?

2. Can you tell me a little about yourself?

1. Follow-up: What was your life like before graduate school? Where did you live? Where did you grow up? Did you have a job? If so, what did you do?

2. Follow-up: What did your parents do?

3. Follow-up: What was your schooling like? That is, where did you go to school? What kinds of classes were your favorite?

4. Follow-up: How has being a first-generation college student impacted your educational experiences? Personal experiences?

5. Follow-up: What were your experiences with writing and working with faculty before graduate school?

3. What drew you to pursuing a graduate degree in Composition and Rhetoric? What brought you to [PhD-granting institution]?

4. Can you tell me a little bit about your admissions and application process? Were you afraid of applying to graduate school? How did you find your college(s)? 
5. What did you know about graduate study in this field before beginning your program?

1. Clarifying comment: Did you participate in any programs such as the McNair Scholars Program, for instance?

2. Follow-up: How is graduate school the same or different than what you expected?

3. Follow-up: What did you wish you had known before you started your program?

6. What do you see as the goals of graduate study? Of a PhD? Do you think the institutional structure of the university facilitates or hinders these goals? Do you have suggestions to make life at the university better for others in similar situations?

7. What do you feel your doctoral program is training you to do? Is anything missing for you in this training?

8. How do you perceive the general culture of your program?

1. Follow-up: What do you see as your relationship to faculty? How would you describe them? What do and don't you like about faculty, for instance?

2. Follow-up: Similarly, what do you see as your relationship to other graduate students? Who are/are not first-generation?

9. How do you negotiate your personal life with the expectations of the graduate program? Can you tell me a specific story for example?

10. What aspects of your background (e.g., first-generation college student, working class) do you share with peers? Faculty? Students you teach? Why or why not? 
11. Let's turn to your documents. What purpose does this $\mathrm{X}$ document play for you? When did you compose it?

12. How has $\mathrm{X}$ document evolved? What stands out to you now/strikes you? What part of this text was hard to write at the time, and why?

13. How do you see yourself as a member of the larger PhD program?

14. Have participant make a list: What professional and personal roles do you see yourself filling? Can you describe them? How and when does class intersect with these roles?

1. Follow-up: Why did you start with ?

2. Follow-up: How do you describe yourself as ?

3. Follow-up: [How] has this role shifted since or during your time in the graduate program?

4. Follow-up: It's interesting that you didn't say . Can you say more about that?

15. What metaphors would you use to describe yourself? Can you list them?

1. Follow-up: Can you tell me more about $?$

16. What kind of writing do you do to understand or make sense of what you need to do each day (at work, at school, at home, etc.)? Would you mind sharing examples with me in the future?

17. Do you have any other thoughts you'd like to add and/or questions for me?

\section{Interview Questions for Alumni of PhD Programs}


1. Can you tell me your name and current institution? Can you describe your current job—what are your responsibilities? Teaching load? Admin responsibilities? What are the publication expectations?

2. Can you tell me a little about yourself?

1. Follow-up: What was your life like before graduate school?

2. Follow-up: What were your experiences with writing and working with faculty before graduate school?

3. Which program did you receive your $\mathrm{PhD}$ from? What drew you to pursuing a graduate degree in Composition and Rhetoric? What brought you to that program?

4. Can you tell me a little bit about your admissions and application process? Were you afraid of applying to graduate school? How did you find your college?

5. What did you know about graduate study in this field before beginning your program?

1. Clarifying comment: Did you participate in any programs such as the McNair Scholars Program, for instance?

2. Follow-up: How do you feel about graduate study now as a faculty member?

3. Follow-up: What advice would you give those considering graduate study and a $\mathrm{PhD}$ program in Rhetoric and Composition that you wish you had received before you entered graduate study?

6. What do you feel doctoral programs in Rhetoric and Composition train students to do? Reflecting back, was there anything missing for you in your training? 
7. How did you perceive the general culture of your program when you were a graduate student?

1. Follow-up: What do you see as your relationship to faculty? How would you describe them? What do and don't you like about faculty, for instance?

2. Follow-up: Similarly, what do you see as your relationship to other graduate students? Who are/are not first-generation?

8. How did you negotiate your personal life with the expectations of the graduate program? Can you tell me a specific story for example?

9. Did you share your background with peers? Faculty? Students you teach? Why or why not? Do you share it now as a faculty member?

10. Have participant make a list: During your $\mathrm{PhD}$ program, what professional and personal roles did you see yourself filling? Can you describe them?

1. Follow-up: Why did you start with _ _ ?

2. Follow-up: How do you describe yourself as___ ?

3. Follow-up: How/has this role shifted since your time in the $\mathrm{PhD}$ program? Can you tell me a specific story for example?

4. Follow-up: It's interesting that you didn't say___. Can you say more about that?

11. On a similar note, what roles do you see yourself filling now? Can you describe them? (Similar follow-up questions)

12. During your doctoral study, how did you negotiate your personal life with the expectations of your $\mathrm{PhD}$ program? 
13. What kind of writing did you do to understand or make sense of what you needed to do each day (at work, at school, at home, etc.)? What kind of writing do you do now? Would you mind sharing examples with me in the future?

14. As a [current position] now, how do or don't you feel your doctoral training prepared you for your work today?

15. Do you have any other thoughts you'd like to add and/or questions for me?

\section{Interview Questions for Relevant Administrators}

1. Can you tell me your name and official title?

2. How many years have you been (or were you) in this position?

3. Can you describe the typical duties of your position?

- Follow-up: How do you interact with graduate students in this role? (e.g., for DGSs, do you formally advise every student, or do you meet with students only when they seek out a meeting?) What are some of the typical reasons graduate students might seek out a meeting with you?

4. Can you tell me a bit about the doctoral program [at PhD-granting institution]? What makes it distinctive? When prospective students visit, what do you talk about as the program's selling points?

5. When you lose prospective applicants to other programs, what tend to be the reasons they go elsewhere?

6. In your position as [Director of Graduate Studies or Department Chair], what changes have you seen in the $\mathrm{PhD}$ program?

- Follow-up: What changes do you see coming in the future? 
7. Have there been any college or university-wide pressures or mandates that have affected $\mathrm{PhD}$ program policies?

8. Are all doctoral students funded? For how many years? What health insurance and/or other benefits do they receive?

9. How many courses do they typically take per semester, and how many do they typically teach per semester? Has it always been this way?

10. Does your department provide students with formal preparation or support (e.g., workshops, preparation materials) for...

- their exams

- their dissertations

- publishing

- presenting at conferences

- the job market?

11. Do you have any other thoughts you'd like to add and/or questions for me?

\section{Appendix 2: CCCC Statement of Professional Guidance for Mentoring Graduate}

\section{Students}

CCCC offers the following statement of guidance for faculty engaged in mentoring graduate students in composition and rhetoric and related fields. To contextualize the professional conditions for graduate students upon completion of their degree programs, this statement is best read alongside the statements Professional Guidance for New Faculty Members and Working Conditions for Non-Tenure-Track Writing Faculty. 
The purpose of the following statement is to recommend principles that can guide graduate student mentoring, practices that are attuned to local conditions, program structures, university and other professional stakeholders' interests and values. These recommendations are intended for graduate faculty as well as administrators and other graduate program participants, with the goal of achieving sustained and robust efforts to enact effective and equitable mentoring.

\section{The State of Mentoring in Graduate Programs: A Call for Change}

We situate this statement within a longstanding complex period in higher education, a time which calls for ethical reexamination of commonplaces and businessas-usual practices in the training and mentoring of graduate students. The conventional reproduction model of the academy whereby faculty mentors replicate in their students similar scholarship and career trajectories to their own is no longer, if ever, tenable. This traditional replication model is ad hoc and exclusionary, inherently wed to institutional biases and systemic discrimination manifest on axes of racism, classism, ableism, sexism, and other processes of exclusion and privilege. Moreover, the landscape of both study and employment in the academy today increasingly operates in terms of scarcity, contingency, overloads, privatization and corporatization, and labor exploitation. The position articulated in this statement asserts that in this climate the ethical mentoring of graduate students is a critical imperative. Ethical mentorship requires significant institutional as well as interpersonal changes in the ways students are trained and mentored both toward degree completion and in their movement from degree into satisfactory job placement beyond or within the academy. 


\section{Defining Mentoring and Mentorship}

Mentorship is robust guidance responsive to an individual student's differences and needs in a range of domains related to working toward and beyond a masters or doctoral degree in rhetoric and composition and related fields. Domains in need of mentoring include (but are not limited to) field knowledge expertise; research practices; classroom, tutoring, program administration, and other institutional work opportunities, experience, and training; life-work balance; time-to-degree planning; plans to secure employment in a range of potential settings (i.e., institutes of higher learning (IHLs), nonprofit sector, education, staff/administrative roles, etc.).

Mentoring relationships should be flexible and multiple, as students require different kinds of expertise based on their differentiated and intersectional needs and the varied stages of their studies. Effective mentorship emerges through a range of supportive relationships between graduate students and others in different positions and with ranging experience, a broad coalition of the dissertation or thesis director, other faculty, program chairs, administrative personnel, other graduate students, scholars at other institutions, and others that can provide strategic guidance. Mentorship is interpersonal, but it must also be institutionalized; it should be responsive to individuals and at the same time systematic, inclusive, and equitable.

Mentoring practices, programs, and relationships should not disproportionately place the labor, burden, and responsibility on graduate students themselves to be mentored nor on the generosity of individual mentors. Rather, there is an ethical imperative for all graduate faculty and other graduate program stakeholders to engage in sustained, differentiated, and collaborative mentorship with graduate students 
from the beginning to the end, and even after completion of, students' degree programs.

Toward realizing this imperative, we affirm the following principles and example practices for ethical and effective mentorship. These principles can assist graduate program stakeholders in redirecting resources; shifting attitudes and investments toward creating a culture of mentorship; changing curriculum; shaping extracurricular panels, sessions, and workshops; provoking discussion and change among graduate faculty; and other creative applications.

\section{Guiding Principles for Graduate Student Mentorship}

Practice mentoring as transformation not replication: Models of mentoring in which the mentor relies on their situated knowledge (often as a white, tenured faculty member at an R1 university) as the sole basis for mentoring does not enable a graduate student to meet their own needs and respond to a radically changing climate postgraduation. It is no longer, if ever, possible or desirable to mentor in terms of replication; instead, it is critical to imagine new pathways to success that embrace the diverse needs of contemporary students and the worlds in which they live and work. This shift may require retraining and/or reacclimating on the part of graduate faculty to advise beyond what is familiar or comfortable in their roles.

To enact mentorship as transformation, graduate mentors can practice:

- Differentiated mentorship: Mentorship relationships should not be a one-size-fitsall model. Flexible relationships of mentoring are encouraged, as students typically require different kinds of knowledge based on their differentiated needs, as well as their varying stages of study, and the changing climates and economic 
and material realities of graduate study and the job market (forces which should be considered when advising about applying for internal and travel funding, adapting to market trends, etc.). While the primary responsibility of mentorship remains in students' home departments, graduate mentors should build resources to facilitate their students' mentorship across their institution, and across institutions, to help meet varying needs. This network of mentors (more on this practice below) is especially critical when there is not a person in the home department that can provide direct support for some aspect of student need. For example, in the case that a graduate student is the only woman of color in her cohort or amongst the graduate faculty, she should be expressly encouraged and assisted in expanding her mentorship network to seek out mentors that can support her intersectional positionalities, interests, and concerns.

- Commitment to learning: Those involved in the mentorship of graduate students should learn about varying options and the state of the academic and humanities careers; why each student has chosen to pursue graduate education; how to (re)imagine "the field" and its varied work in ways that exceed mentors' own; model and advise toward helping graduate students build a supportive mentoring network within and outside of their institution.

\section{Redefine and enact advising as collaborative, coalitional, networked mentoring:}

Advising graduate students should not be realized in strictly one-to-one relationships. Rather, graduate students, graduate faculty, and other mentors benefit from a, networked, coalitional approach. Networked mentoring can involve the expertise of various stakeholders including alumni networks, alt-ac or humanities careers resources, 
university career services, work-life and mental health professionals, as well as the entire university community, beyond the department and the broader discipline. Networked mentorship should be, in other words, collaborative: It should not be assumed that certain students should be mentored by certain faculty. Mentorship relationships can and should exceed shared scholarly interests. All faculty and program stakeholders have a responsibility to enact mentoring in varying forms for every graduate student.

To practice more expansive networked mentoring (rather/in addition to one-toone advising relationships), graduate mentors can:

- Enact advising schemes which intentionally build mentoring relationships with multiple faculty and program stakeholders (e.g., students are assigned first-year advisors then a different second-year advisor before selecting a dissertation or thesis director advisor).

- In co-advising relationships, faculty should maintain a professional and aligned approach in dealing with conflicting suggestions (whether scholarly of professional) without putting burden on the student to manage and resolve potential instances of conflict.

- Recognize graduate mentoring more prominently in faculty annual review schemes. In addition to providing legible support for faculty promotion, making the labor and investment of mentoring more visible incentivizes students to be involved in building academic environments that value mentoring labor at various levels.

- Initiate conversations within your program among faculty, graduate students, and program administration about the specific needs and challenges around mentoring in your program. 
- Encourage and facilitate horizontal mentoring relationships among graduate students at varying levels of study (see, e.g., VanHaitsma and Ceraso).

Validate and help students prepare for diverse careers: Graduate students should be encouraged, validated, and celebrated for career outcomes beyond conventional academic tenure-track positions. Students' career aspirations and choices should be supported at all steps of the graduate experience. Mentorship toward diverse careers will likely require that mentors continue to learn alongside their students about ranging career options and preparatory experiences.

Towards mentorship that imagines a range reasons to pursue graduate study as well as a range of post-graduation options, we recommend that:

- Prospective, new, and advanced graduate students should have information available from their department about their program's placements, the present state of the academic job market, and the casualization (i.e., the current climate of non-tenure track and contingent labor) of the academic workforce.

- Faculty along with their graduate students should actively learn about resources for quality positions outside of the academy. Some resources that can help begin these efforts include MLA's Connected Academics initiative (https://connect.mla.hcommons.org/); Versatile $\mathrm{PhD}$ (https://versatilephd.com/); or Workmonger, a site focused on non-teaching jobs in education (https://workmonger.com/).

- Graduate programs should work closely with graduate schools to bring in speakers who can present their perspective on working in/with digital humanities and public humanities initiatives. 
- Faculty should move beyond invoking or implying damaging, unrealistic, and persistent myths about what success on the (academic) job market must look like. Myths are myriad but include, for example, that a national search is the only way to secure a job, that taking a non-academic job rather than adjuncting eliminates opportunities to secure academic employment, that R1 tenure-track jobs are the "best" or the only truly desirable or acceptable positions, etc. Often these myths are only implied by mentors but are no less received by students. Instead, faculty should work with graduate students to imagine post-degree options and follow students' lead on working to meet their goals.

- Graduate programs should make a concerted effort to track and make available student job placement during and after graduation; programs should attempt to build rich networks of graduates and current students for the purposes of horizontal mentoring.

Create a sustained, equitable, and supportive climate for mentoring: Creating an ethical climate for mentoring may also include labor that is not manifested as direct mentoring but that scaffolds the conditions for that mentoring to take place. This includes practicing vigilance against, and intolerance for, implicit or explicit bias and actively disrupting institutional hierarchies and established systems of privilege. Cultivating an inclusive supportive mentorship climate, we underscore, should not and cannot manifest only in future-oriented concerns (i.e., exclusively in concern about students' time-todegree and/or job placement). Rather, mentorship participates in and can positively shape the long arc of graduate training and enculturation in field or discipline. Working in academia positions graduate students to take on new languages, discourses, and ways of being. Graduate students face challenges and disorientations in navigating varying, 
unfamiliar, and often hostile spaces and discourses. For example, a student coming from undergraduate training at a minority serving institution such as an Historically Black College or University (HBCU) into a Predominantly White Institution (PWI) for graduate training may experience a dissonance in academic culture that will impact the way that student adapts, assimilates, and contributes to their graduate program. As such, mentorship networks should aid students in identifying, acclimating to, and pushing back against norms and discourse practices.

Some practices and stances that can help sustain equitable support for graduate students, from recruitment through post-graduation, could include:

- Mentorship should help demystify and provide access to, for example, academic discourses, genres, research methods, and networking, especially for minority, first-generation, and historically underrepresented or marginalized students who may disproportionately labor to acclimate to and work within institutional academic culture as a "foreign place with a different language" (Sinanan, 2016, p.156).

- Mentorship should extend into the classroom with explicit instruction in disciplinary ways of being, doing, critically writing, and researching. Rather than a model of osmosis, graduate faculty should expressly mentor students in critical writing and publishing (see Micciche with Carr (2011); Carr, Rule, and Taylor (2013); Brooks-Gillies, Garcia, Kim, Manthey, and Smith (2015)).

- Departments or unit should work to they provide adequate financial support for critical professionalization events in graduate student careers, such as conference travel, summer support, and job market support, considering varying degrees of students' own material constraints. 
- Advise graduate students to pursue varying opportunities (e.g., what conferences to attend, how many academic jobs to apply to, the nature of those jobs, research endeavors, and course materials assignments, etc.) in a manner mindful to students' varying financial situations and other factors.

\section{Enact Commitments to Inclusion and Diversity through Differentiated}

Mentorship: To facilitate inclusive practices, we emphasize diversity and inclusion when mentoring historically marginalized or underrepresented groups. We underscore especially that the recruitment of students with diverse backgrounds (based upon gender, sexuality, race, ability) does not mean there are spaces of inclusion within the department, institution, or broader discipline. At some institutions, there may be a gap between institutional commitments to diversity and moves to create and sustain inclusion when "statements of commitments to diversity are understood as 'non-performatives' that do not bring about what they name" (Ahmed, 2012, p.119). Instead of allowing diversity statements or position statements like this one to serve in Ahmed's terms, as "an institutional desire for good practice"--or, as a drive to hear "happy stories of diversity" rather than face "unhappy stories of racism" (Ahmed, 2007, p. 164)--statements and other documents that call for change within communities should be used strategically and with focus on action not merely sentiment. 20. Programs and mentors should thus assess how they curate spaces for mentorship in order to sustain inclusiveness for a diverse scholar population.

Mentorship is never a one-size-fits-all or even a fits-most model, and in recognizing this, while we may here provide relevant mentorship knowledge, it is mentors, departments, and institutions that must attune and adjust to the needs of their particular students and programs. For example, students coming from undergraduate and 
graduate work at minority serving institutions (such as Historically Black Colleges /Universities [HBCUs], Hispanic Serving Institutions [HSIs], Tribal Colleges/Universities [TCU's], Alaska Native-Serving Institutions or Native HawaiianServing Institutions, Predominantly Black Institutions, Asian American and Native American Pacific Islanders-Serving Institutions, and Native American-Serving NonTribal Institutions) will have specific needs in navigating their graduate institution and program of study. Students of color, moreover, that enter Predominately White Institutions (PWIs), may experience the academy as a brave space (Arao \& Clemen, 2013, p.141), a positioning which leaves them to take on additional emotional and mental labor, as brave spaces require the giving up of a former condition in favor of a new way for seeing and understanding (Arao \& Clemen, 2013, p.141). While every graduate student works to become socialized into their varied roles as graduate students (Golde,1999), there is an institutional obligation to meet the additional needs of historically underrepresented and marginalized groups through mentorship in and outside of the classroom.

Thus, we highlight below some initial practices for mentorship with students from historically marginalized and underrepresented groups:

- Stand as an Ally: Allies strategically use their privileged positioning to assist those that lack certain privileges and/or are vulnerable within the institution and in order to actively change broader systems which perpetuate privilege. Practicing allyship means different things (see also Edwards; Patel), but to start, allies should reflect on their own privileged positions and work to understand the experiences of those they're allying themselves with; publically identify their allyship efforts by marking their own and others positionalities of privilege, practice rigorous self-reflection, "initiate the change toward personal, institutional, and societal 
justice and equality" (Kendall, 2003; see Kendall for a full list, which we have adapted here). Allyship, it is emphasized and we echo, is not about taking "care" of those that are Othered. Allyship is undertaken, again in Kendall's words, because, "we, as well as others, will benefit. We do not step forward because we think we should or because the people of color can't speak for themselves or because we want to look good to the people of color around us. We are allies because we know that it is in our interest."

- Rhetorically Listen: Mentors (particularly mentors from different backgrounds, identity positions, and experiences from their mentees) must listen rhetorically to graduate students from marginalized and underrepresented groups. Rhetorical listening "signifies a stance of openness that a person may choose to assume in relation to any person, text, or culture" and combats how whiteness may function as an invisible racial category that influences the lens through which the listener may hear certain voices (Ratclifffe, 2005). Mentors must learn to listen across difference and respond in meaningful ways.

- Amplify Voices of Students from Historically Marginalized and Underrepresented Groups: Mentoring graduate students, faculty members and graduate program personnel should never engage in exclusionary practices, such as using stereotypical language, engaging in microaggressions, or enacting privileged acts of socialization. Instead, mentors should make and protect spaces for graduate student issues and concerns.

Every graduate student must work to become socialized into their roles as student, professional, and scholar, but departments have a special obligation to assist in these processes through mentorship with historically minoritized groups, students of color, 
those from historically underrepresented groups or sexual and gender minority communities, first-generation students, international students, and others. Listening, standing as an ally, assisting in building a network of mentors, and amplifying the voices of the marginalized are, for one, key ways to increase student retention. But more importantly and broadly, concerted efforts to enact a culture of equitable, accessible, networked mentoring is in the interest of all stakeholders in higher education to realize a diverse future scholar population that will continue to enact change throughout our field and varied institutions. 


\section{CURRICULUM VITAE}

Ashanka Kumari

Department of English, 315 Bingham Humanities, Louisville, KY 40292

(256) 710-6579 // ashankakumari@gmail.com // ashankakumari.com

\section{Education}

PhD

May 2019

(anticipated)

MA May 2015

BA May 2013

BAC May 2013
Rhetoric and Composition, University of Louisville

Dissertation: Remaking Identities: Perceptions of First-Generation-to-College Rhetoric and Composition PhD Students on Navigating Graduate Study

Committee: Andrea R. Olinger and Bronwyn T. Williams (chairs), Beth A. Boehm, LuMing Mao

English, Composition and Rhetoric, University of Nebraska-Lincoln, Digital Humanities Certificate

English, The University of Alabama, Magna Cum Laude

University Honors, International Honors, Minor in Italian

Journalism, The University of Alabama, Magna Cum Laude

University Honors, International Honors, Minor in Music

\section{Publications}

\section{Books}

Horner, Bruce, Megan Faver Hartline, Ashanka Kumari, and Laura Sceniak Matravers, editors. Mobility Work in Composition: Translation, Migration, Transformation. Utah State UP, Under Advanced Contract. 


\section{Peer-Reviewed Journal Publications}

Alvarez, Sara P., Michael Baumann, Michelle Day, Khirsten L. Echols, Layne M.P. Gordon, Ashanka Kumari, Laura Sceniak Matravers, Jessica Newman, Amy McCleese Nichols, Caitlin E. Ray, Jon Udelson, Rick Wysocki, and Dànielle Nicole DeVoss. "On Multimodal Composing." Kairos: A Journal of Rhetoric, Technology, and Pedagogy, vol. 21, no. 2, 2017, http://kairos.technorhetoric.net/21.2/praxis/devoss-et-al/index.html.

Kumari, Ashanka. "Yoü and I': Identity and the Performance of Self in Lady Gaga and Beyoncé.” The Journal of Popular Culture, vol. 49, no. 2, 2016, pp. 403-416.

Kumari, Ashanka. "Adding to Blake Set to Music: A Bibliography." Blake/An Illustrated Quarterly, vol. 49, no. 4, 2016, https://blakequarterly.org/index.php/blake/article/view/kumari494.

Kumari, Ashanka. Entry in "My Mundane Professional Life," special section of Composition Studies, v. 47, no. 1, 2019: Forthcoming.

Kumari, Ashanka. "On Class and Clothing: First-Generation PhD Viewpoints on Academic Culture." Dress Practices as Embodied Multimodal Rhetoric, special Issue of The Journal of Multimodal Rhetoric, edited by Katie Manthey, Fall 2019, Forthcoming.

\section{Book Chapters}

Parks, Steve, Bassam Alahmad, and Ashanka Kumari. "Syrians for Truth and Justice: Articulating Entanglements, Disrupting Disciplinarity." Making Future Matters, edited by Rick Wysocki and Mary P. Sheridan Computers and Composition Digital P/Utah State UP, 2018. http://ccdigitalpress.org/book/makingfuturematters/.

Kumari, Ashanka. "Desi Girl Gets a PhD: Brokering the American Education System with Cultural Expectations." Lingua Fracta: First Generation Scholars in Rhetoric, Composition, and Communication, edited by Letizia Guglielmo and Sergio Figueiredo. NCTE, Under Contract.

Kumari, Ashanka. "Mobility Through Everyday Things.” Mobility Work in Composition: Translation, Migration, Transformation, edited by Bruce Horner, Megan Faver Hartline, Ashanka Kumari, and Laura Sceniak Matravers. Utah State UP, Under Advanced Contract.

Kumari, Ashanka. "Start with What You Know." Explanation Points!: Publishing in Rhetoric and Composition, edited by John Gallagher and Dànielle Nicole DeVoss. University of Colorado/Utah State UP, Forthcoming.

Wysocki, Rick, Jon Udelson, Caitlin E. Ray, Jessica Newman, Laura Sceniak Matravers, Ashanka Kumari, Layne M.P. Gordon, Khirsten L. Echols, 
Michelle Day, Michael Baumann, Sara P. Alvarez, and Dànielle Nicole DeVoss."On Multimodality: A Multivocal Manifesto." Bridging the Gap: Multimodality in Theory and Practice. Ed. Santosh Khadka and Jennifer Lee. Utah State UP, Forthcoming.

\section{Articles Under Review}

Kumari, Ashanka and Brita M. Thielen. "Engaging Identities, Cultivating Compassion, Modeling Vulnerability: Practical Applications for Discussing Privilege in the Composition Classroom." Pedagogy: Critical Approaches to Teaching Literature, Language, Composition, and Culture.

\section{Digital Humanities Peer-Reviewed Publications}

Critical Encoding. Livingstone's Final Manuscripts (1865-1873)—Diaries, Journals, Notebooks, and Maps: A Critical Edition. Megan Ward and Adrian S. Wisnicki, dirs. Livingstone Online. First edition. College Park, MD: University of Maryland Libraries, 2018, http://livingstoneonline.org/his-own-words/livingstones-final-manuscripts1865-1873.

Junior Project Scholar and Critical Encoding/Editing Specialist. Livingstone's 1870 Field Diary and Select 1870-1871 Manuscripts: A Multispectral Critical Edition. Adrian S. Wisnicki and Megan Ward, co-directors. First edition. College Park, MD: University of Maryland Libraries, 2017. Located at http://www.livingstoneonline.org.

Kumari, Ashanka, Adrian S. Wisnicki, Keith Knox, and Megan Ward. "Prototyping Animated Spectral Images (ASIs)." In Livingstone's 1870 Field Diary. Adrian S. Wisnicki and Megan Ward, dirs. Livingstone Online. University of Maryland Libraries, 2016, http://livingstoneonline.org/spectralimaging/prototyping-animated-spectral-images-asis.

Aliff, Angela, Adrian S. Wisnicki, Megan Ward, Ashanka Kumari, and Erin Cheatham. "The Design of Livingstone Online." Livingstone Online. Adrian S. Wisnicki and Megan Ward, dirs. University of Maryland Libraries, 2016, http://livingstoneonline.org/about-this-site/the-design-livingstone-online.

Wisnicki, Adrian S., Megan Ward, and Ashanka Kumari. "Structuring the 1870 Field Diary." In Livingstone's 1870 Field Diary. Adrian S. Wisnicki and Megan Ward, dirs. Livingstone Online. University of Maryland Libraries, 2016, http://livingstoneonline.org/spectral-imaging/structuring-the-1870field-diary.

Wisnicki, Adrian S., Ashanka Kumari, Megan Ward, Roger Easton, and Keith Knox. "History \& Chronology of the 1870 Field Diary." In Livingstone's 1870 Field Diary. Adrian S. Wisnicki and Megan Ward, dirs. Livingstone Online. University of Maryland Libraries, 2016, 
http://livingstoneonline.org/spectral-imaging/history-chronology-the-1870field-diary.

Wisnicki, Adrian S., Megan Ward, Roger L. Easton Jr., Keith Knox, and Ashanka Kumari. "Notes on Processed Spectral Images." Livingstone Online. Adrian S. Wisnicki and Megan Ward, dirs. University of Maryland Libraries, 2016, http://livingstoneonline.org/spectral-imaging/notesprocessed-spectral-images.

Kumari, Ashanka, and Adrian S. Wisnicki. "A Brief History of Livingstone Online (2004-2013)." Livingstone Online. Adrian S. Wisnicki and Megan Ward, dirs. University of Maryland Libraries, 2015, http://livingstoneonline.org/about-this-site/brief-history-livingstone-online2004-2013.

\section{Conference Proceedings}

Baniya, Sweta, Les Hutchinson, Ashanka Kumari, Kyle Larson, and Chris Lindgren. "Representing Diversity in Digital Research: Digital Feminist Ethics and Resisting Dominant Normatives." Proceedings of the Annual Computers \& Writing Conference, 2018. Forthcoming.

\section{Scholarly Blog Posts}

Kumari, Ashanka. "A Reflection and Step-by-Step Process of Using OpenSource Software to Closed Caption Video." Sweetland Digital Rhetoric Collaborative, July 2016.

http://www.digitalrhetoriccollaborative.org/2016/07/29/a-reflection-and-stepby-step-process-of-using-open-source-software-to-closed-caption-video/.

\section{Conference Presentations}

Lyons, Kathleen, Kefaya Diab, Ashanka Kumari, and Lauren Brentnell. "Welcoming, Recognizing, and Unlimiting Identity in Mentoring gWPAs." To be presented at Council of Writing Program Administrators (CWPA) Conference. Baltimore, Maryland. July 2019.

Ulmer, Jessi, Bre Garrett, Melissa Nicholas, Mary De Nora, and Ashanka Kumari. "Rooting for Radical Inclusion in Writing Programs AND Writing Program Administration." To be presented at Council of Writing Program Administrators (CWPA) Conference. Baltimore, Maryland. July 2019.

Chen, Chen, Andrew Kulak, Ashanka Kumari, Vyshali Manivannan, Patti Poblete, and Lydia Wilkes. "(In)visible Labor: Radical Professional Participation in Fraught Digital Spaces." To be presented at Computers and Writing. East Lansing, Michigan. June 2019.

Olejnik, Mandy, Katelyn Lusher, Caitlin Martin, Martha Karnes, Adam Hubrig, Emily LaPadura, Kyllikki Rytov, Ashanka Kumari, Keshia Mcclantoc, and Cara Marta 
Messina. "Continuing the Conversation: Navigating Inclusivity and Vulnerability in Online Listservs and Digital Spaces." To be presented at Computers and Writing. East Lansing, Michigan. June 2019.

Bahl, Erin Kathleen, Chad Iwertz, Ashanka Kumari, Lourdes Fernandez, Sarah E. Austin, Noel Thistle Tague, Jens Lloyd, Paige Davis Arrington, Sherena Huntsman, Christa Teston, and Heather Falconer. "Spotlight Session: Methods for Emerging Researchers in Rhetoric and Composition." Concurrent Roundtable. Conference on College Composition and Communication. Pittsburgh, Pennsylvania. March 2019.

Kumari, Ashanka. "On Class and Clothing: First-Generation PhD Viewpoints on Graduate Culture.” Paper. Cultural Rhetorics 2018. East Lansing, Michigan. November 2018.

Parks, Steve and Ashanka Kumari. "Producing Truth, Congealing a New Reality: Syrians for Truth and Justice," Keynote Address. Thomas R. Watson Conference. Louisville, Kentucky. October 2018. Invited Keynote Address.

Kumari, Ashanka. "Identity Matters: Stories from the Future Wave of Rhetoric and Composition PhDs." Paper. Thomas R. Watson Conference. Louisville, Kentucky. October 2018.

Ellison, Kristie, Robin Garabedian, Gavin Johnson, Ashanka Kumari, Christina Rowell, and Allegra W. Smith. "Adventures in Phronetic Spaces: Graduate Students \& Inter-institutional Horizontal Mentoring via Social Media Groups." Roundtable. Computers and Writing. Fairfax, Virginia. May 2018.

Baniya, Sweta, Les Hutchinson, Ashanka Kumari, Kyle Larson, and Chris Lindgren. "Representing Diversity in Digital Research: Digital Feminist Ethics and Resisting Dominant Normatives." Roundtable. Computers and Writing. Fairfax, Virginia. May 2018.

Kumari, Ashanka. “'My Life is Just Like a List Now': PhD Student Perceptions on Navigating Graduate Lives." Paper. Conference on College Composition and Communication. Kansas City, Missouri. March 2018.

Kumari, Ashanka. "First-Generation Rhetoric and Composition PhD Student Perceptions on Navigating Graduate Study and Negotiating a Work-Life Balance." Paper. Graduate Student Regional Research Conference. Louisville, Kentucky. March 2018.

Kumari, Ashanka. "Feminist Pedagogy and a Case for Teaching Privilege in the Composition Classroom." Paper. Feminisms and Rhetorics. Dayton, Ohio. October 2017.

Bahl, Erin Kathleen and Ashanka Kumari. "'Not all those who wander are lost': Learning through Failure in Digital Composing." Paper. Computers and Writing. Findlay, Ohio: May 2017. 
DeVoss, Dànielle Nicole, Laura Sceniak Matravers, Layne M. P. Gordon, Ashanka Kumari, and Michael Baumann. "On Multimobile, Multimodal Composing." Panel. Thomas R. Watson Conference. Louisville, Kentucky. October 2016.

Olinger, Andrea R., Ashanka Kumari, Caitlin E. Ray, Jessica Newman, and Brittney Thompson. "Being a Girl in Louisville: Identity Constructions through the Digital Media Academy." Roundtable. Cultural Rhetorics. East Lansing, Michigan. September 2016.

Wisnicki, Adrian S. and Ashanka Kumari. "The Manuscripts of David Livingstone and New Frontiers for Spectral Imaging.” Paper. Digital Humanities 2016. Kraków, Poland. July 2016.

Wisnicki, Adrian S. and Ashanka Kumari. "Communities of Collaboration.” Digital Showcase. Keystone Digital Humanities Conference 2016. Pittsburgh, Pennsylvania. June 2016.

Kumari, Ashanka. “A Hashtag Away from Celebrity: Identity Control, Circulation, and Construction through Social Media Spaces." Paper. Southwest Popular/ American Culture Studies Conference. Albuquerque, New Mexico. February 2016.

Kumari, Ashanka. "Digital Literacy Pedagogy for Community Outreach Organizations: What is the Cost of Community Literacy?" Paper. Conference on College Composition and Communication. Tampa, Florida. March 2015.

Kumari, Ashanka. "Yoü and I': Identity and the Performance of Self in Lady Gaga and Beyoncé." Paper. Southwest Popular/American Culture Studies Conference. Albuquerque, New Mexico. February 2015.

Condello, Morgan, Ross Harrison, Jennifer Isasi, Alex Kinnaman, and Ashanka Kumari. "A Methodology for Character Networks at the Macroanalytical Level." Poster. Nodes \& Networks in the Humanities: Geometries, Relationships, and Processes - A Digital Humanities Forum. Lawrence, Kansas. September 2014.

Kumari, Ashanka, Courtney Lawton, Carmen McCue, Joseba Moreno, and Grace Thomas. "Detecting Linguistic Signal in Willa Cather's Early Journalism: Polishing the Bibliography." Poster. Digital Humanities 2014. Lausanne, Switzerland. July 2014.

\section{Nonrefereed Workshops and Presentations}

English, Edward, Ashanka Kumari, and Joseph Franklin. “Academic Workflows: Reference and Citation Management." University of Louisville English Department. January 2018.

Holst, Melissa, Ashanka Kumari, Ryan Luke, and Brandon McReynolds. "Balancing Roles as Students and GTAs." University of Louisville School of Interdisciplinary and Graduate Studies. August 2017. 
Baumann, Michael, Ashanka Kumari, Layne M. P. Gordon, Laura Tetreault, and Rick Wysocki. "Creating Online Teaching Portfolios.” University of Louisville Composition Program. April 2017.

Echols, Khirsten L., Sara P. Alvarez, Jelisa Clark, Ashanka Kumari, J'Amie Jennings, Detra Johnson, and Latonia Craig. "Women Faculty of Color." Panel sponsored by the University of Louisville School of Interdisciplinary and Graduate Studies. April 2017.

\section{Administrative and Research Experience}

Assistant Director, Thomas R. Watson Conference

- Organized, planned, and presented two three-day academic conferences (2016 \& 2018) including: organizing participant data, scheduling panels, and planning the conference program. Each conference featured 6-8 keynote speakers, 12-14 featured speakers, and $300+$ participants.

- Wrote and managed Watson Conference social media.

- Provided technological assistance throughout conference

- Coordinated logistical aspects of conference, including graduate student volunteers, book vendors, all meals, and reception.

- Invited to continue on as special assistant and consultant for the 2018 conference after completing official duties in July 2018.

Research Assistant, Critical Encoding/Editing Specialist, 2013-2017 and Publicity Lead, Livingstone Online Enrichment and Access Project

- Transcribed and XML encoded David Livingstone's writings

- Designed and implemented publicity plan including social media

- Developed aesthetics, design, and metadata

- Researched history of and literature about David Livingstone's writing to develop bibliography of materials using Zotero 
- Analyzed spectral images of David Livingstone's 1870 diary and transcribed and XML encoded these and other diaries and letters for NEH-grant funded project $(\$ 275,000)$ to develop Livingstone Online

- Developed aesthetics and design for website

- Wrote and managed Livingstone Online's social media outlets

Graduate Administrative Assistant, University of Nebraska-Lincoln Learning Communities

- Assisted with New Student Enrollment activities for the UNL First-Year Learning Communities Program

- Communicated with first-year undergraduate students and their parents during orientation sessions

- Assembled, organized, and proofread student enrollment data and program materials for New Student Enrollment days

Logistical Assistant, Nebraska Forum on Digital Humanities

- Organized the 2014 Nebraska Forum on Digital Humanities

- Wrote and disseminated publicity documents

- Coordinated logistical aspects of the forum including contacting presenters and volunteers, program events, and meals

Staff Reporter, The Crimson White, Tuscaloosa, AL

- Wrote and published dozens of news articles 2-3 times a week for duration of reporter term

- Investigated and evaluated sources relevant to news stories for credibility and accuracy

\section{Teaching Experience}

Graduate Teaching Assistant, University of Louisville

- Intermediate College Writing - English 102-DE (Distance Education, Online; theme: Popular Culture)

- Business Writing - English 306

- Scientific and Technical Writing - English 303

- Intermediate College Writing - English 102 (theme: Popular Culture)

- Introduction to College Writing - English 101 
Academy, University of Louisville

- Organized and facilitated, on a team of five University of Louisville graduate students led by Andrea R. Olinger, a two-week digital media camp for rising sixth grade girls from historically low-performing schools

- Led instruction on digital projects including video, photo editing

- Observed and interviewed girls about their experiences with technology to assess curriculum and how it might serve in future

Graduate Teaching Assistant, University of Nebraska-

Lincoln

- Writing, Rhetoric as Inquiry - English 150

Instructor, Writing Lincoln Initiative

- Taught $4^{\text {th }}$ and $5^{\text {th }}$ grade students at the Clyde Malone Center in an after-school writing workshop twice a week for one hour

- Worked with adult literacy learners at Matt Talbot Kitchen and Outreach

- Helped create weekly lesson plans and worked with writers on writing, vocabulary, and reading comprehension

\section{Editorial Experience}

Associate Editor, Kairos: A Journal of Rhetoric,

2018-Present Technology, and Pedagogy

Assistant Editor, Kairos: A Journal of Rhetoric, Technology, and Pedagogy

Editor, Cardinal Compositions, Louisville, KY 2016-2018

Editorial Assistant, Western American Literature, Lincoln, NE.

Editorial Assistant, Prairie Schooner, Lincoln, NE

2013-2014

Chief Copy Editor, The Crimson White, Tuscaloosa, AL

2012-2013

Assistant Editor, Chambered Nautilius, Tuscaloosa, AL

2011-2013

Writer and Editor, Le CITY deluxe international luxury

Summer 2012 magazine Barcelona, Spain

\section{Professional Development}

Participant. Delphi U: Online Pedagogy Institute. University of Louisville Delphi Center for Teaching and Learning, Spring 2018. 
Participant. Hacktheville 2017: Hackathon to Develop Web Materials for the Louisville refugee and immigrant populations. University of Louisville, March $31,2017$.

Participant. Digital Media and Composition Institute (DMAC). The Ohio State University. May 9-18, 2016.

Participant. Publishing Academy. School of Interdisciplinary and Graduate Studies. University of Louisville. February-April 2016.

Participant. PLAN Professional Development Workshop Series. School of Interdisciplinary and Graduate Studies. University of Louisville. 2015-2016. Participated in 10 workshops.

Participant. Digital Composition Colloquium. University of Louisville. August 18-19, 2015.

Participant. Games for Digital Humanists. Digital Humanities Summer Institute. University of Victoria in British Columbia. June 8-12, 2015.

Participant. Innovative Teaching Methods and Practices in Digital Humanities, Workshop at Digital Humanities 2014 led by Claire Clivaz, Walter Scholger, and Toma Tasovac. Lausanne, Switzerland. July 2014.

\section{Service}

\section{National}

Co-Writer. CCCC Task Force to Create a Position

2018-Present

Statement on Graduate Students

Member, Executive Council. NextGEN, International

Rhetoric and Writing Graduate Listserv

Executive Council Member. WPA-GO Graduate

Committee

Proposal Reviewer. Computers and Writing Conference

2018-Present

Proposal Reviewer. Digital Humanities Conference

2016-Present

\section{University}

Graduate Student Ambassador. University of Louisville 2017-Present

School of Interdisciplinary and Graduate Studies

Secretary. Multicultural/Minority Association of Graduate

2015-2017

Students, University of Louisville

Assessor. General Education Assessment of Written

Communication, University of Louisville

Spring 2017

\section{College}


Graduate Assistant. Discourse and Semiotics Workshop

Series, University of Louisville

\section{Department}

PhD Peer Mentor Coordinator University of Louisville

2017-2019

Rhetoric and Composition Program

PhD Peer Mentor. University of Louisville Rhetoric and

2016-2019 Composition Program

Leader. Working Group for Inclusive and Equitable

2016-2018 Graduate Student Sustainability, University of Louisville English Department

Co-President. English Graduate Organization, University of Louisville

Technical Assistant. 44 ${ }^{\text {th }}$ Annual Louisville Conference on Literature and Culture Since 1900

Co-Chair. Rhetoric Society of America, University of Nebraska-Lincoln Chapter

Graduate Student Representative. Composition and Rhetoric Hiring Committee, University of NebraskaLincoln

\section{Community}

Site Coordinator and Communication Director. Writing Lincoln Initiative

\section{Grants and Awards}

\section{Grants}

Graduate Network of Arts and Sciences Research Grant, University of Louisville

Graduate Student Council Research Grant, University of Louisville,

2018

Graduate Research Network Travel Award, Computers and 2018 Writing 2018 Conference

Graduate Student Council Travel Grant, University of Louisville 2016,2017 2018

2017 Feminisms and Rhetorics Conference Travel Grant

October 2017

Digital Humanities Summer Institute Tuition Scholarship

June 2015 
University of Nebraska-Lincoln Graduate Certificate in

March 2015

Digital Humanities Travel Award

Wilbur and Elizabeth Gaffney Travel Fellowship, University

February 2015

of Nebraska-Lincoln English Department

\section{Awards}

Diversity Fellowship, School of Interdisciplinary and

2015-16, 2018-

Graduate Studies, University of Louisville

19

Faculty Favorite, Delphi Center for Teaching and Learning,

2018

University of Louisville

Conference on College Composition and Communication

Scholars for the Dream Award, NCTE

2018

Barbara Plattus Award for Excellence in Graduate Teaching,

2018

University of Louisville English Department

Outstanding PhD Student Award, University of Louisville

2018

English Graduate Organization

Dr. M. Celeste Nichols Professional Development Award, University of Louisville Women's Center

Outstanding Graduate Student, University of Louisville Board of Trustees

Diana Cox Award for Images of Women, Paper award presented by the Southwest Popular/American Culture Association at the $36^{\text {th }}$ Annual SWPACA Conference in Albuquerque, New Mexico

\section{Languages}

Hindi (native speaker) Punjabi (native speaker)

\section{Professional Memberships}

Rhetoric Society of America

Popular Culture Association

Coalition of Women Scholars in the History of Rhetoric and Composition
National Council of Teachers of English

Alliance of Digital Humanities Organizations

Council of Writing Program Administrators

\section{References}


Dr. Andrea Olinger

Assistant Professor of English

University of Louisville

Dr. Bronwyn T. Williams

Professor of English

Director, University Writing Center

University of Louisville

Dr. Stephen J. Parks

Professor of Writing and Rhetoric

University of Virginia

Dr. Mary P. Sheridan

Professor of English

Director, 2018 Thomas R. Watson Conference

University of Louisville

Dr. Beth A. Boehm

University Provost, Professor of English

University of Louisville

Dr. LuMing Mao

Department Chair, Professor of English

University of Utah
(502) 852-3051

andrea.olinger@louisville.edu

(502) 852-2173

bronwyn.williams@louisville.

edu

(267) 258-9632

sjp3st@virginia.edu

(502) 852-1750

maryp.sheridan@louisville.ed

$\mathrm{u}$

(502) 852-3975

beth.boehm@louisville.edu

(801)-585-1608

luming.mao@utah.edu 